HELSINKI UNIVERSITY OF TECHNOLOGY

Faculty of Chemistry and Materials Sciences

Degree Programme of Forest Products Technology

Juuso Rantanen

\title{
CONSTRUCTION OF A SINGLE BAR REFINER
}

Master's Thesis for the degree of Master of Science in Technology submitted for inspection, Espoo, 22 December 2009.

Supervisor

Instructor
Professor Hannu Paulapuro

Eero Hiltunen, D.Sc. (Tech) 
Author

\section{Juuso Rantanen}

\section{Title of Thesis}

\section{Construction of a Single Bar Refiner}

\section{Abstract}

The target of this thesis work was to construct a laboratory scale low-consistency refiner by modifying an existing design to enable more realistic refining conditions. The aim of the modification was to be able to study refining energy and forces affecting fibres more closely, particularly enabling the determination of bar coverage and pulp consistency in the gap by image analysis. The designing and construction of a pulp flow system for the refiner unit was also an important part of the thesis. Setup and testing of a system for imaging fibres in the refining gap was realized.

The modification of the original design was made by designing a new stator bar with dimensions similar to the rotor bar. The purpose of this design was to create more realistic conditions during refining. This design was first tested with the original stator bar by machining it with a groove similar to the one in the rotor bar, and later constructing two additional bars to reach the desired smaller gap size. The pulp flow system was designed and constructed to enable even flow conditions for the refiner unit. The installing and setup of the laser illuminated imaging system was conducted to enable image capture of the refining phenomena.

Some problems were encountered during the course of this work. The errors in measuring the original gap size resulted in wrong dimensioning of the new stator parts. For this reason some modifications had to be made afterwards to reach the targeted gap sizes. The pulp flow system was constructed without any major issues, but problems with the refiner unit clogging when operating with pulp consistencies $>2 \%$ left some room for improvement. The imaging system installation and preliminary trials were successful, resulting in some good images from the gap between the rotor and stator bars. Images showed e.g. that bar coverage is clearly not $100 \%$ at $2 \%$ pulp consistency with $150 \mu \mathrm{m}$ gap size, and that there is potential in developing the image analysis method aiming to determine bar coverage and pulp consistency in the gap. The target of the thesis to construct a research tool for refining studies was achieved

\begin{tabular}{|l|l|}
\hline $\begin{array}{l}\text { Supervisor } \\
\text { Hannu Paulapuro }\end{array}$ & $\begin{array}{l}\text { Instructor } \\
\text { Eero Hiltunen, D.Sc. (Tech) }\end{array}$ \\
\hline $\begin{array}{l}\text { Chair } \\
\text { Paper Technology }\end{array}$ & $\begin{array}{l}\text { Chair code } \\
\text { Puu-21 }\end{array}$ \\
\hline $\begin{array}{l}\text { Pages } \\
70+9\end{array}$ & Language \\
English
\end{tabular}


TEKNILLINEN KORKEAKOULU

DIPLOMITYÖN TIIVISTELMÄ

Kemian ja materiaalitieteiden tiedekunta

Koulutus-/tutkinto-ohjelma: Puunjalostustekniikka

\begin{tabular}{|c|c|}
\hline \multicolumn{2}{|l|}{$\begin{array}{l}\text { Tekijä } \\
\text { Juuso Rantanen }\end{array}$} \\
\hline \multicolumn{2}{|l|}{$\begin{array}{l}\text { Diplomityön nimi } \\
\text { Yksiteräjauhimen rakentaminen }\end{array}$} \\
\hline \multicolumn{2}{|c|}{$\begin{array}{l}\text { Tämän diplomityön tavoitteena oli rakentaa laboratoriomittakaavan jauhin matalasakeusjauhatuk- } \\
\text { sen ilmiöiden tutkimista varten muokkaamalla jo olemassa olevan jauhimen terärakennetta vas- } \\
\text { taamaan todenmukaisemmin oikeita teräolosuhteita. Muokkauksen tavoite oli kyetä tutkimaan jau- } \\
\text { hatusenergiaa ja kuituihin vaikuttavia voimia. Erityisesti tavoitteena oli mahdollistaa parametrien, } \\
\text { kuten massan terävälisakeus ja terän peittävyys, määrittäminen kuva-analyysin avulla. Jauhimen } \\
\text { massakierron suunnittelu ja rakentaminen, sekä kuvauslaitteiston asennus ja testaus olivat myös } \\
\text { osa työtä. }\end{array}$} \\
\hline \multicolumn{2}{|c|}{$\begin{array}{l}\text { Alkuperäistä terärakennetta muokattiin siten, että staattoriterän dimensiot saatiin identtisiksi root- } \\
\text { toriterän kanssa. Tämän rakenteen tavoitteena oli saada jauhatusolosuhteet vastaamaan enemmän } \\
\text { todellisia jauhatusolosuhteita. Uutta rakennetta testattiin ensin koneistamalla vanha staattoriterä, ja } \\
\text { myöhemmin suunnittelemalla kaksi uutta terää, jotta teräväli saatiin pienemmäksi ja näin vastaa- } \\
\text { maan paremmin todellista jauhatustilannetta. Massakierron suunnittelun ja rakentamisen tavoittee- } \\
\text { na oli luoda jauhimelle tasaiset virtausolosuhteet, ja laservalaistun kuvauslaitteiston asennuksen } \\
\text { tarkoituksena oli mahdollistaa jauhatustapahtumien kuvaus terävälistä. }\end{array}$} \\
\hline \multicolumn{2}{|c|}{$\begin{array}{l}\text { Staattoriterien suunnittelussa ja valmistamisessa esiintyi joitakin ongelmia, erityisesti virhe alkupe- } \\
\text { räisen terävälin mittaamisessa johti siihen, että uusien terien mitoitukseen tuli virhe. Tämä onnis- } \\
\text { tuttiin kuitenkin korjaamaan pienillä muutoksilla terien rakenteeseen. Massakierron rakentamisessa } \\
\text { ei esiintynyt suuria ongelmia, mutta sakeuden nostaminen yli } 2 \% \text { :iin johti usein jauhimen tukkeu- } \\
\text { tumiseen, joten sitä korkeampiin sakeuksiin ei toistaiseksi päästy. Kuvauslaitteiston asentaminen ja } \\
\text { alustavat kokeet olivat menestyksekkäitä, ja tuloksena oli hyvälaatuisia kuvia terävälistä. Kuvista } \\
\text { voitiin mm. päätellä, että terä ei peity kokonaisuudessaan massalla } 2 \% \text { sakeudessa } 150 \text { mm terävä- } \\
\text { lillä. Alustavien kokeiden perusteella kuva-analyysin kehittäminen massan sakeuden ja terän peit- } \\
\text { tävyyden määrittämiseksi on mahdollista. Diplomityön tavoite toimivan jauhatustutkimuslaitteen } \\
\text { rakentamiseksi saavutettiin. }\end{array}$} \\
\hline $\begin{array}{l}\text { Työn valvoja } \\
\text { Hannu Paulapuro }\end{array}$ & $\begin{array}{l}\text { Työn ohjaaja } \\
\text { Eero Hiltunen, D.Sc. (Tech) }\end{array}$ \\
\hline $\begin{array}{l}\text { Professuuri } \\
\text { Paperitekniikka }\end{array}$ & $\begin{array}{l}\text { Koodi } \\
\text { Puu-21 }\end{array}$ \\
\hline $\begin{array}{l}\text { Sivumäärä } \\
70+9\end{array}$ & $\begin{array}{l}\text { Kieli } \\
\text { englanti }\end{array}$ \\
\hline $\begin{array}{l}\text { Avainsanat } \\
\text { Jauhin, rakentaminen, kuva-analyysi, kuidut }\end{array}$ & $\begin{array}{l}\text { Päiväys } \\
22.12 .2009\end{array}$ \\
\hline
\end{tabular}




\section{ACKNOWLEDGEMENTS}

This thesis was done at TKK Paper and Printing Technology Group with the invaluable help of the staff. I am especially grateful to Timo Ylönen and everyone at the workshop for their assistance.

I would also like to thank my instructor Eero Hiltunen for his professional guidance and help throughout the course of this thesis work. My thanks to Professor Hannu Paulapuro for giving me the opportunity to conduct my thesis in his research group, and to Professor Emeritus Richard Kerekes from the University of British Columbia for his expertise and ideas regarding this project. Special thanks to researcher Kaarlo Nieminen for the image analysis.

I am in greatest gratitude to my family and friends for all these years. Especially I would like to thank my parents Jukka and Anne for giving me support both mentally and financially during my student years. Finally I want to express my thanks to my dear girlfriend Sara.

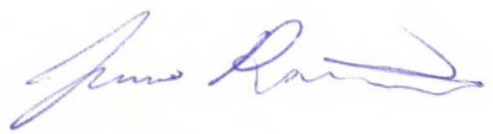

Juuso Rantanen, Espoo, 22 December 2009. 


\section{TABLE OF CONTENTS}

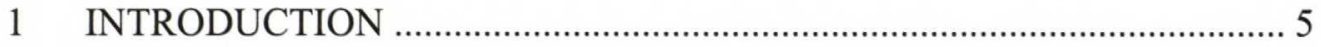

2 HISTORY OF REFINING.................................................................. 6

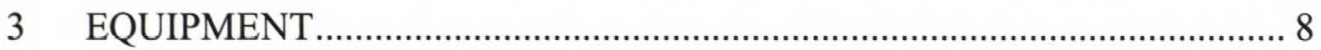

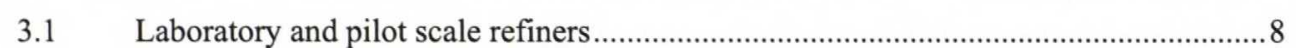

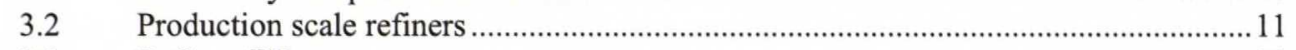

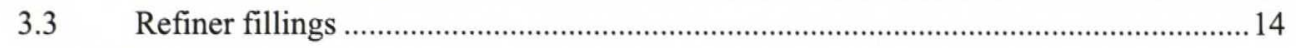

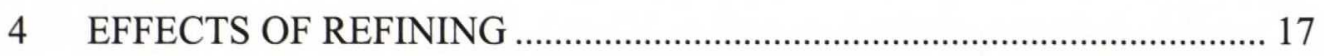

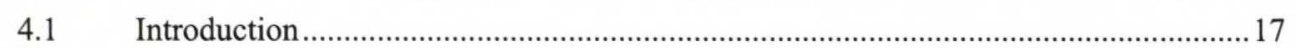

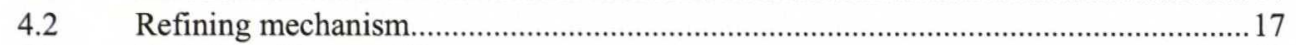

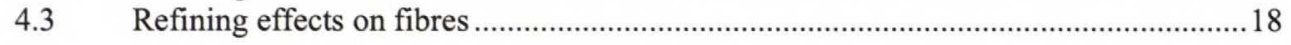

5 THEORIES OF REFINING .............................................................. 21

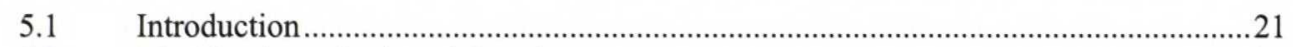

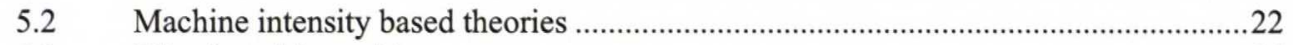

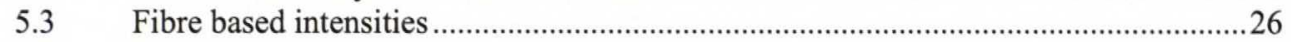

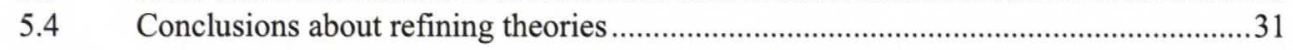

6 REFINING ENERGY AND FORCES ………………………………..... 32

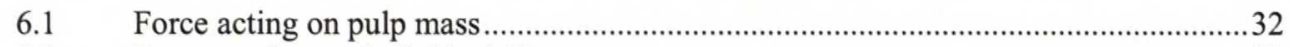

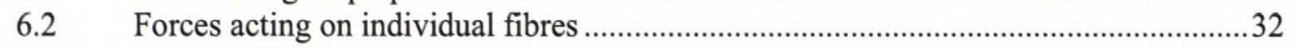

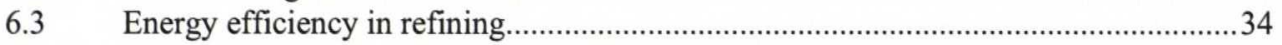

7 CONCLUSIONS OF THE LITERATURE REVIEW …………………….... 36

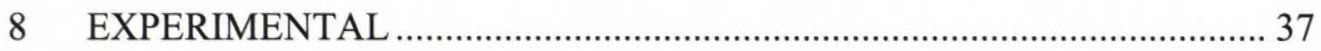

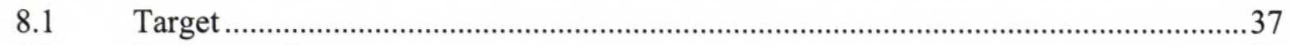

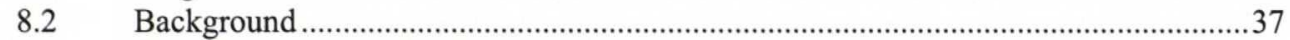

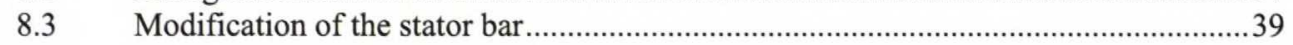

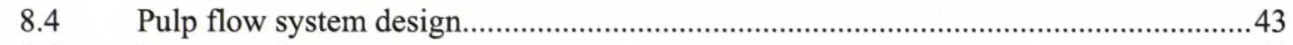

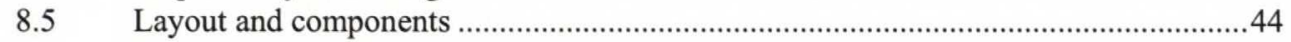

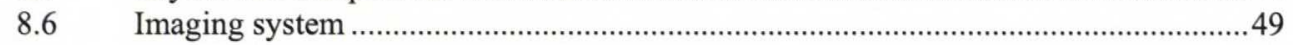

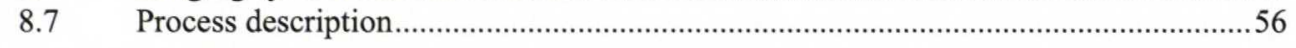

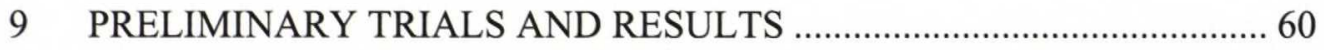

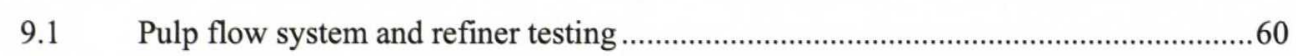

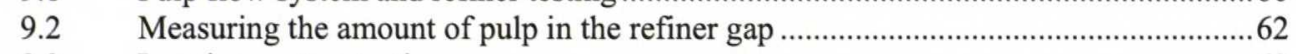

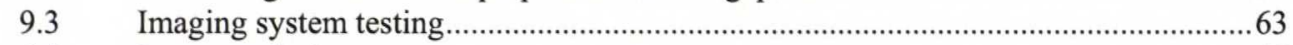

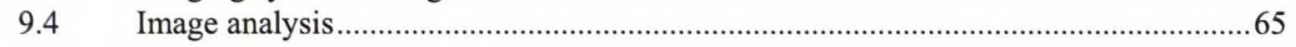

10 RECOMMENDED NEXT STEPS …………………………………...... 68

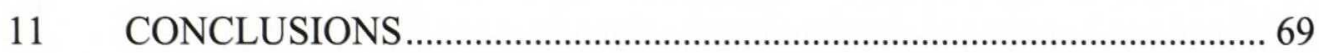

LIST OF REFERENCES

APPENDICES 


\section{INTRODUCTION}

Beating or refining of chemical pulp has been used by papermakers to introduce better papermaking quality for the final product. Untreated chemical pulp fibers have low tendency of bonding and flexibility which may result in low paper strength properties. Also the formation of sheets can be uneven due to high flocculation of pulp fibres $/ 1 /$.

Refining of chemical pulp is one of the most researched areas in papermaking and much progress has been already made. Despite this fact there still remain some areas and phenomena that are not fully understood. Earlier studies have been focusing mostly on changes produced in pulp and their effect on paper quality, for example internal and external fibrillation, fibre shortening and secondary fines production /2, 3/. Refining energy and especially forces that eventually create these changes have not been studied as thoroughly, hence the need for this project.

The target of this thesis was to construct a laboratory scale refiner for chemical pulp (Single Bar Refiner, SBR) to study the refining forces and phenomena itself more closely. The specific objective was to enable determination of fractional bar coverage and pulp consistency in the gap. A first version of SBR was already built as part of an earlier project in which TKK Paper and Printing technology group had a significant contribution $/ 4 /$. However, some changes on the design of the SBR were proposed to get a better and more realistic understanding of the mechanics of chemical pulp refining.

The literature part of this thesis consists of two parts. The first part is a basic introduction on low-consistency refining of chemical pulp; history, equipment, effects on fibres etc. The second part gives an understanding about the mechanics and forces that take place between the refiner bars and within fibres. Different theories of these phenomena will also be introduced in this part. The practical part will include the design, construction and some preliminary trials with the Single Bar Refiner. 


\section{HISTORY OF REFINING}

The term "beating" originates from early papermaking history when wet rag fibres were manually beaten to disintegrate them and create bonding surfaces. Nowadays papermakers still widely talk about beating instead of refining of chemical pulp and the term is also found in modern literature. The first mechanical refining devices were introduced during the $13^{\text {th }}$ century in Italy where the stamping or hammer mills were invented (Figure 1). A battery of heavy pestles fitted with metallic surfaces was operated by a shaft that took its energy usually from a waterwheel. Rags were disintegrated to shorter fibres to better suite papermaking demands.

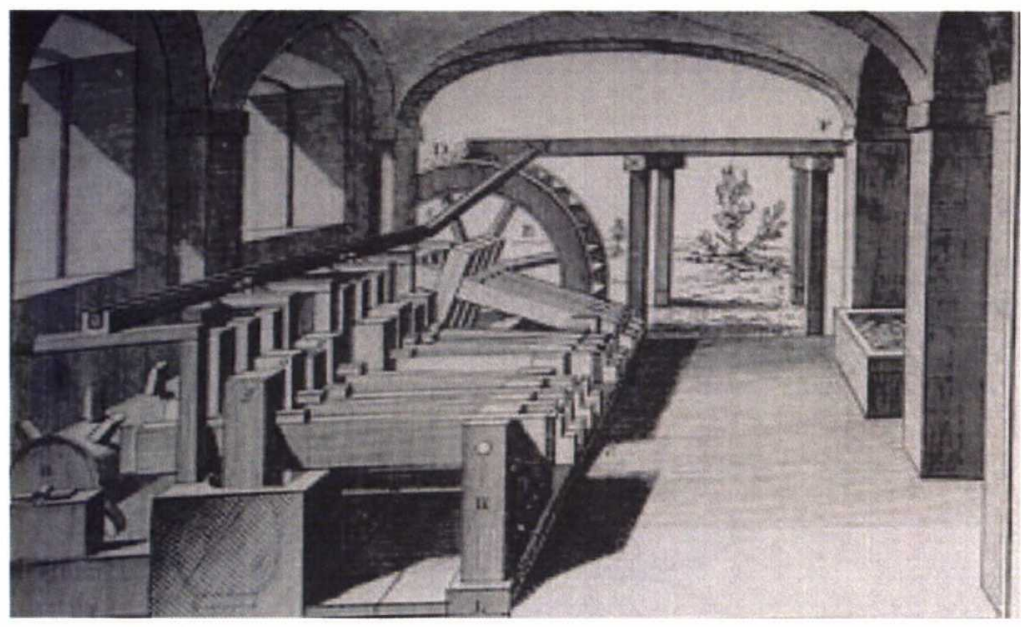

Figure 1. Hammer mills used to prepare fibres for papermaking $/ 1 /$.

Later after the invention of Hollander beaters the refining process became more and more mechanized. Better formation and surface properties for end product could not be reached if the fibres from chemical pulp or cotton rags retained their original length. In Hollander beater (Figure 2) the fibres passed between rotating (rotor) and static (stator) bars that enabled fibre length reduction and other refining effects. Most of the modern day refiners are using the same principle. /5, 1/ 

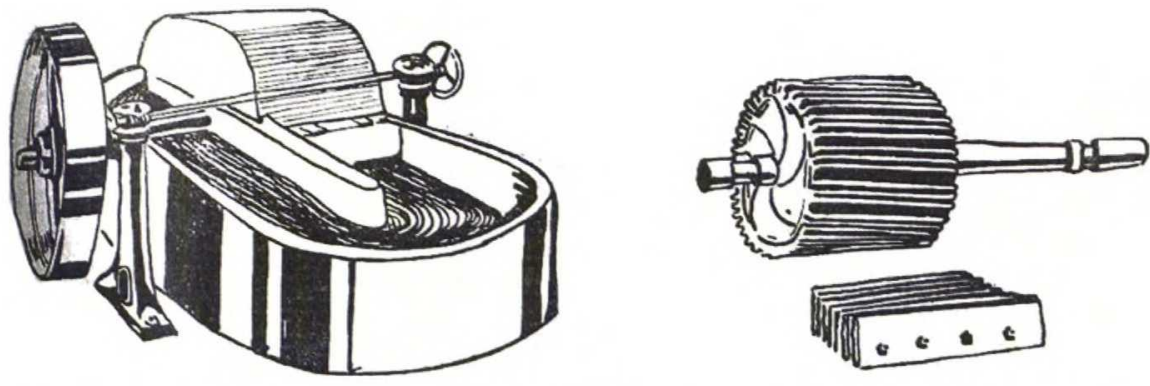

Figure 2. An early 20th century Hollander (left) with its rotor and stator bars (right) /6/. 


\section{EQUIPMENT}

\subsection{Laboratory and pilot scale refiners}

\subsubsection{Valley beater}

Many of the laboratory scale refiners are based on similar construction as the historical Hollander beater. This is due to its simple and cost-effective design, adequate capacity for laboratory work and reliability. Perhaps the most commonly used laboratory refiner in studying basic refining phenomena is the Valley beater, also known as the Hollander beater illustrated in Figure 3. It has a rotating cylinder (rotor) with bars and 2-3 bar equipped counter bed plates as a stator. Hollander beaters are batch refiners. They are quite energy intensive but they produce a gentle and homogeneous refining result. The fact that both refining energy and refining intensity can be independently controlled is also an advantage.
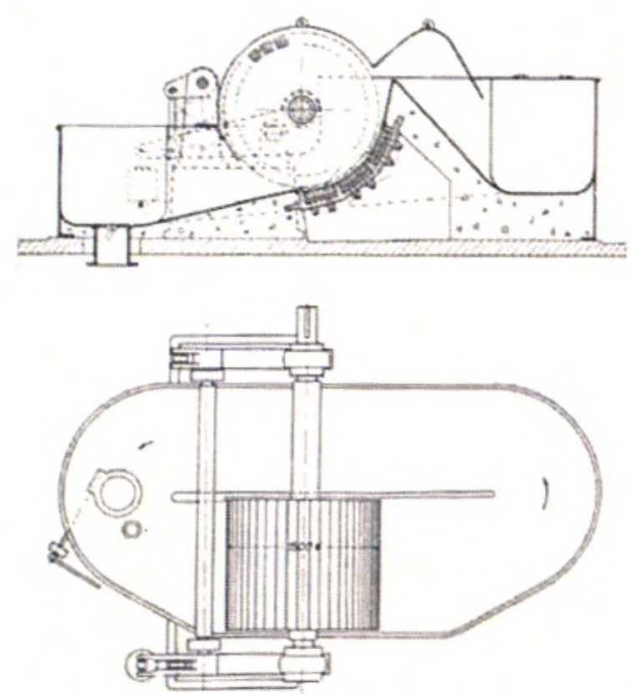

Figure 3. A schematic illustration of a Hollander beater $/ 7 /$.

\subsubsection{PFI-mill}

The PFI-mill has become a popular laboratory refiner due to the small pulp volumes that can be used. Also the versatility of rotational direction and shear rate 
are advantages. It operates in high energy and low intensity mode due to the high consistency of pulp, high shear ratio and compression forces. The refining action is created by a rotor revolving against the chamber walls. This mechanism inflicts compression and shear forces on the fibres. The working principle of the PFI-mill generates continuous fibre network redistribution which together with high pulp consistency gives a high specific energy. /8/

\subsubsection{Escher-Wyss conical laboratory refiner}

One of the first conical refiners that enabled laboratory refining under controlled conditions was the Escher-Wyss conical laboratory refiner, shown in Figure 4. It was developed in the 1950's specifically for laboratory purposes and later modifications have been introduced to improve the process control.

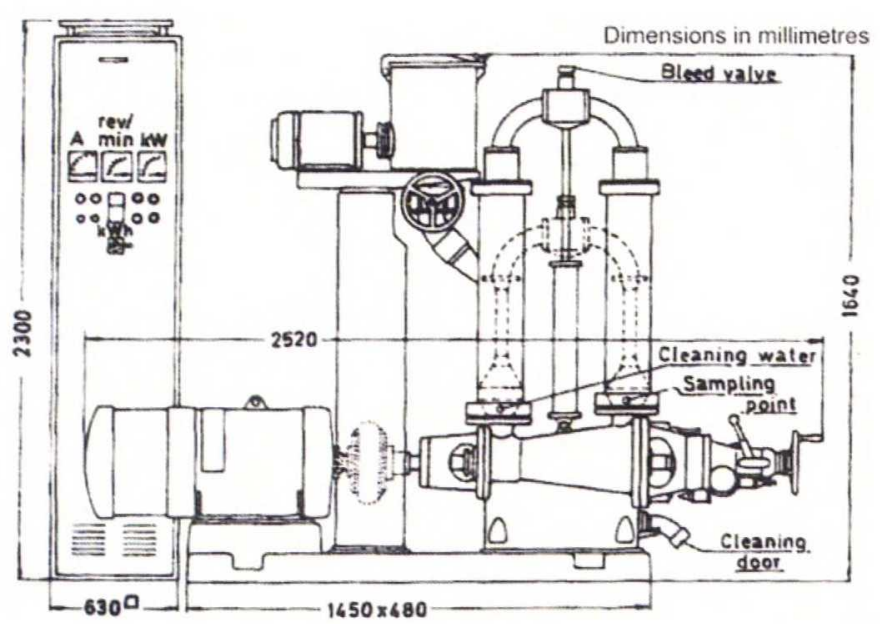

Figure 4. The Escher-Wyss conical laboratory refiner /1/.

Recent versions of the refiner can measure the refining intensity as well as calculate the specific energy based on pulp flow and power consumption. Pulp flow is controlled both by impellers at the inlet and outlet of the refiner as well as by pumping action of the fillings. Sampling is made through a specific valve that was designed to prevent settling of the pulp fibres. With conditioned fillings, the refining results are highly reproducible for a certain pulp type. 


\subsubsection{Voith LR 40 laboratory refiner}

The LR 40 laboratory refiner by Voith has been designed to imitate production scale refining treatment as closely as possible. This means that filling design similar to that of a mill-scale refiner can be installed. The only significant difference is that the pulp passes the refining zone multiple times which may have an influence on the result. After its commissioning in 2002 a study has been made by Koskenhely $/ 9 /$ concerning its reproducibility and controllability. His results indicate that with adequate warm-up time and regular checking of no-load power, measurements are reliable. Basic instrumentation and components of the LR 40 laboratory refiner are shown in Figure 5.

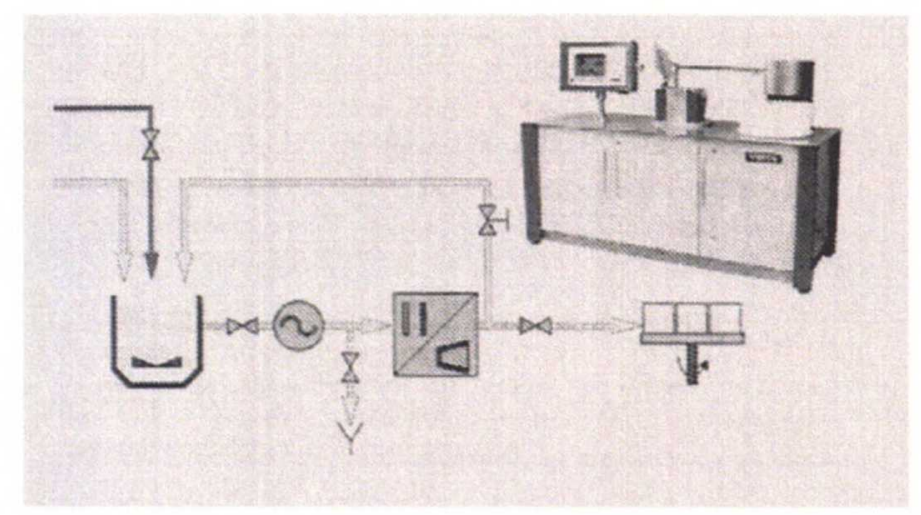

Figure 5. Basic instrumentation and mechanical parts of the laboratory refiner LR $40 / 9 /$.

\subsubsection{ProLab laboratory refiner}

One of the latest inventions in laboratory refining equipment is the ProLab refining station built by Metso Paper (Figure 6). The fully automated refiner unit consists of a pulper, mixing chest, Mohno-pump, refiner housing with main motor, sampling device and appropriate piping. The refiner can be used in both disc and conical mode, and sampling is delivered automatically at predefined levels of specific energy. The ProLab refiner station is a compact solution for research and quality control purposes. Table 1 shows the technical specifications of the refiner. 


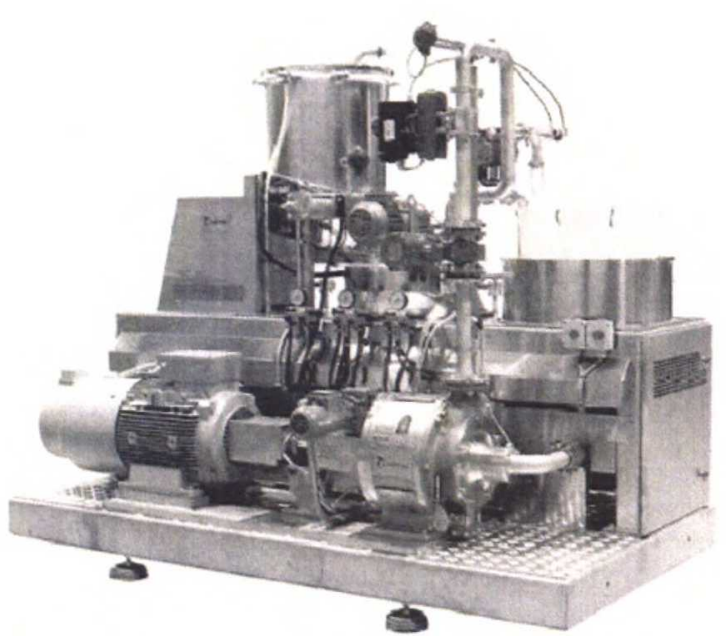

Figure 6. The ProLab laboratory refining station /1/.

Table 1. Technical specifications of the ProLab laboratory refiner $/ 10 /$.

\begin{tabular}{lr} 
Power, kW & 30 \\
\hline Rotor diameter, mm & 58 \\
Minimum & 130 \\
Maximum & $2-7$ \\
\hline Pulp consistency, \% & $50-120$ \\
\hline Pulp flow, L/min & $0.5-6.0$ \\
\hline Pulp feeding pressure, bar & \\
\hline Rotational speed, rpm & $600-4500$ \\
\hline Peripheral speed, m/s & $5-14$ \\
Minimum & $10-27$ \\
\hline Maximum & $10-45^{*}$ \\
\hline SRE/batch, kW.h/ton & $0.1-6.0^{*}$ \\
\hline SEL, $\mathrm{J} / \mathrm{m}$ & $115-1500^{*}$ \\
\hline $\mathrm{SSL}, \mathrm{J} / \mathrm{m}^{2}$ & \\
\hline *Depending on type of fillings and pulp.
\end{tabular}

\subsection{Production scale refiners}

\subsubsection{Introduction}

Conical and disc refiners are most commonly used in mill-scale refining of chemical pulp. In both configurations pulp is fed via inlet through the refining zone and to the outlet. Refiners can have either one or two refiner zones depending on whether there are multiple stator elements. Both of these types are believed to 
generate similar refining effects and they are usually controlled by the same methods. $/ 9 /$

\subsubsection{Jordan refiner}

The first production scale conical refiner was patented by Joseph Jordan and Thomas Easton in 1858 . The angle of the rotor was approximately $11-16^{\circ}$ and the pulp consistency was around 3-4 \%. Cross-section of a typical Jordan-type conical refiner is shown in Figure 7.

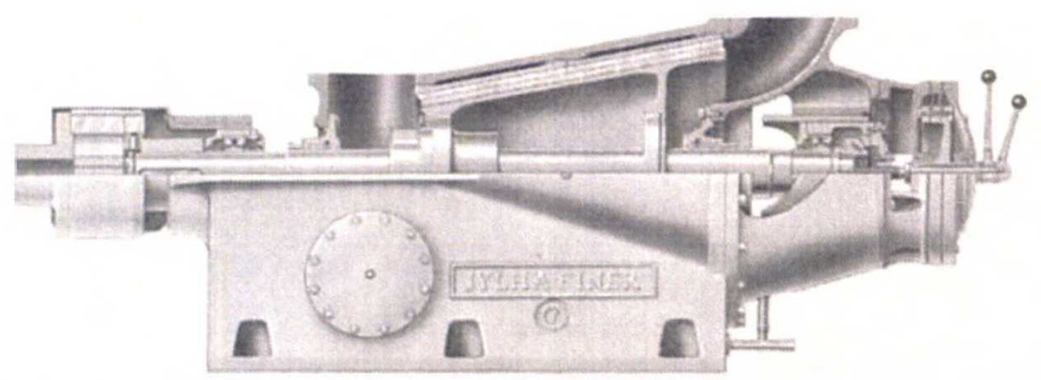

Figure 7. Cross-section of a Jordan-type refiner $/ 7 /$.

The refining result was mostly fibre cutting with the traditional coarse type fillings, but when fine bars were used, the resulting fibre treatment was excellent. For this reason Jordan refiners could be used for all kinds of fibre types. However due to the size, service time requirements and low capacity, the number of these refiners has decreased. /7, 1/

\subsubsection{Claflin refiner}

Claflin-type conical refiner was introduced around 1920. Its construction is close to that of Jordan refiner with the differences being a wider rotor angle of about $30^{\circ}$ and a higher peripheral speed $/ 1 /$. Higher speed was probably causing less fibre shortening than with Jordan refiners. Figure 8 shows a typical Claflin-type refiner. 

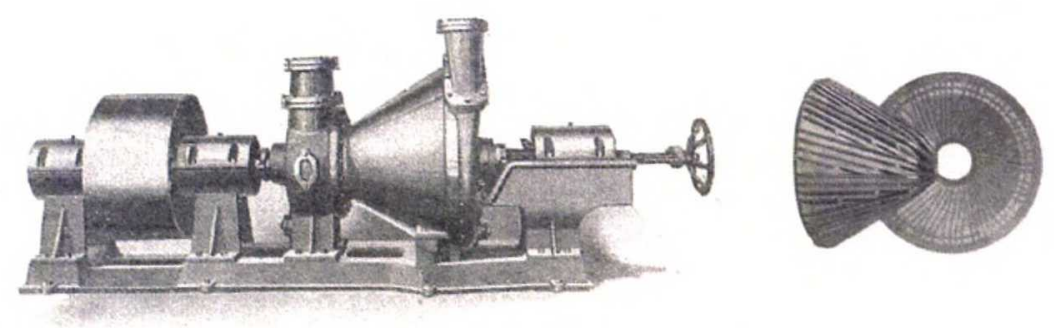

Figure 8. A Claflin refiner (left) and its typical fillings (right) /1/.

\subsubsection{Modern conical refiners}

Nowadays there are several suppliers for conical refiners. A common cone angle of around $20^{\circ}$ is widely used, and other typical features like energy efficiency and high production capacity are obvious features to meet the requirements of modern papermaking. Some double- and triple-conical refiner designs are also available.

\subsubsection{Disc refiners}

Disc refiners can be divided into groups depending on the number of discs that are used. Single-disc refiners are used commonly in high-consistency refining because their capacity in low-consistency refining does not meet the requirements of papermaking today. Also the feeding of low-consistency pulp into a single disc refiner is difficult. J. and R. Kingsland introduced the first known disc refiner in $1856 / 1 /$. It had one disc rotating and the other one stationary. The popularity of disc refiners started to increase when D. M. Sutherland produced the Sutherland disc refiner illustrated in Figure 9.

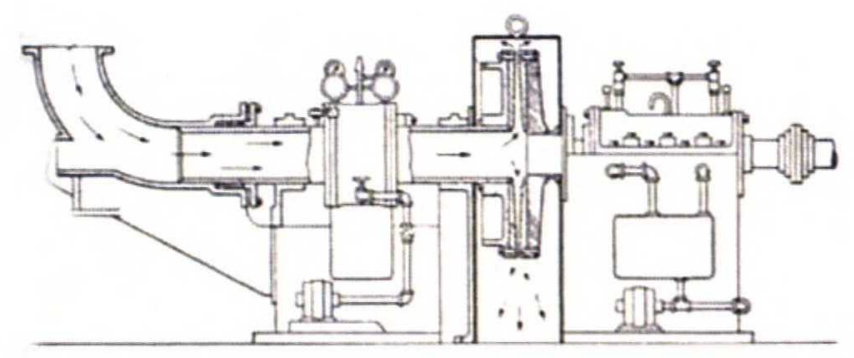

Figure 9. The design of a Sutherland disc refiner $/ 11 /$. 
Later, several double-disc designs based on this original refiner have been developed. In this type of design the pulp flow is divided through two refining zones formed on both sides of the rotator disc. Problem with this type of design is that the pulp flow is often split unevenly between the refining zones, which can lead to a less homogenous refining result. An example of a modern double disc refiner for low-consistency refining is shown in Figure 10.

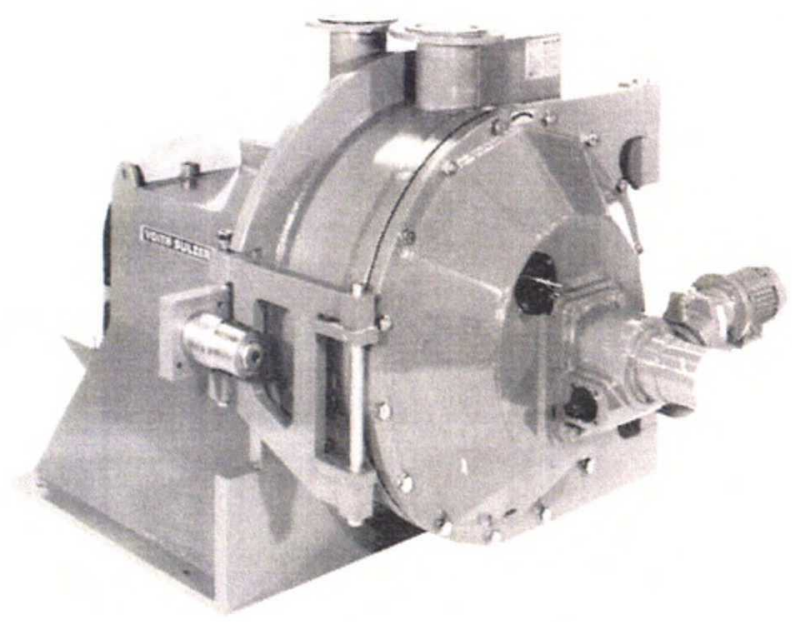

Figure 10. AVoith Sulzer Double-Disc refiner /7/.

\subsection{Refiner fillings}

There are several materials and material composites available for producing refiner fillings. The manufacturing process can be casting, welding, and machining or laser technology which can produce very narrow grooves and bars on the fillings. Decreasing groove and bar width has been the trend in recent decades to allow the refiner to operate with a lower calculated intensity, $S E L$ and will result in having a higher cutting edge length in the refiner due to the increase in the number of bars per refiner area. /11/

Studies show that a high bar angle is more likely to promote fibrillation and a low bar angle can cause fibre cutting. This is due to the fact that fibres subjected to parallel bar edges are more likely to experience cutting effect than fibrillation. Also when refining shorter fibres a lower bar angle of about $20^{\circ}$ is used com- 
pared to a bar angle of about $35^{\circ}$ when refining longer fibres. These angles allow the refiner to rotate in both pumping direction and non-pumping direction. $/ 12,11$ /

Sharpness of the bar edge and edges containing small-scale flaws are shown to cause severe fibre shortening. Thus the material and wear properties of the leading bar edges are also very important parameters /9/. Figure 11 shows a magnification of a low-consistency refiner bar edge.

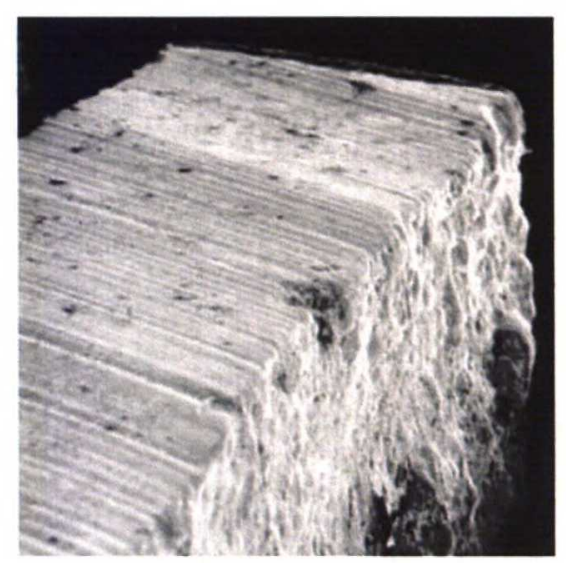

Figure 11. A magnification of a low consistency refiner bar edge /13/.

In his thesis, Koskenhely /9/ has studied the refiner gap behavior using different softwood fibre fractions (Figure 12). He concluded that at a given refining intensity, the gap of short fibre fraction (SF) was clearly narrower than that of long fibre fraction (LF). When refining unfractioned softwood kraft pulp (SWK), the gap position was usually at a value between these two fractions. These results are assumed to be because of the larger fibre flocs in longer fibre fraction. 


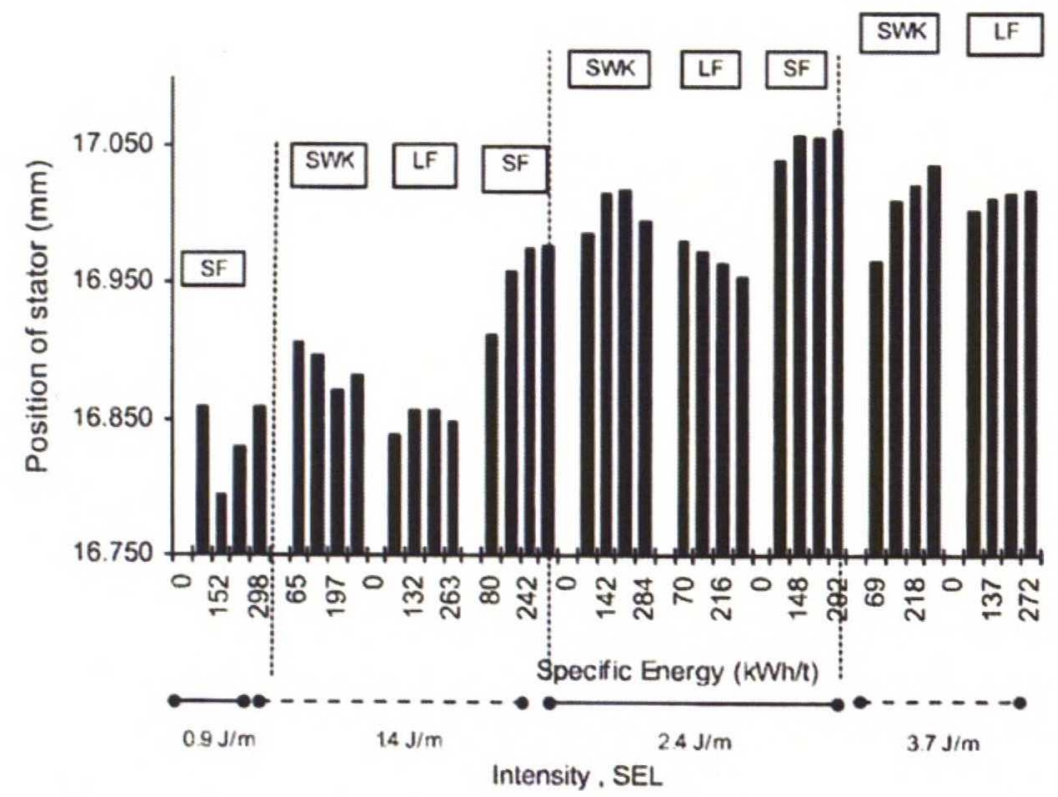

Figure 12. Changes in gap size (position of stator) for pressure-screen fractions refined under varying intensity and specific energy. Higher value of the stator position means narrower gap $19 /$. 


\section{EFFECTS OF REFINING}

\subsection{Introduction}

If paper is made entirely from unrefined chemical pulp, it will have poor strength properties and formation because of very low fibre-bonding potential. In chemical pulp refining, fibre properties are modified by mechanical treatment in such way that fibre bonding is improved and good formation is achieved for the end product. Refining is sometimes used also to develop other paper properties such as optical properties and porosity.

\subsection{Refining mechanism}

One view of basic refining mechanism is shown in Figure 13. Fibres are treated with metallic bars while mixed with water to $2-6 \%$ consistency. In the first stage of refining, fibre flocs are collected by the leading edges of the bars. Fibre floc receives a strong pressure peak at the stage when edge-to-edge contact occurs which leads to most of the water being compressed out of the floc. At this point only those fibres that remain in the floc receive the refining treatment. When edge-to-surface stage begins, the leading edges compress the fiber floc against the bar surface and most of the refining is performed. At this point the average gap width is around $100 \mu \mathrm{m}$ which corresponds to the thickness of 2-20 fibres depending on if they are collapsed or not. The fibre floc remains compressed until the bars have crossed each other. The length of the refining impact depends on the sharpness, width and angle of the intersecting bars. 


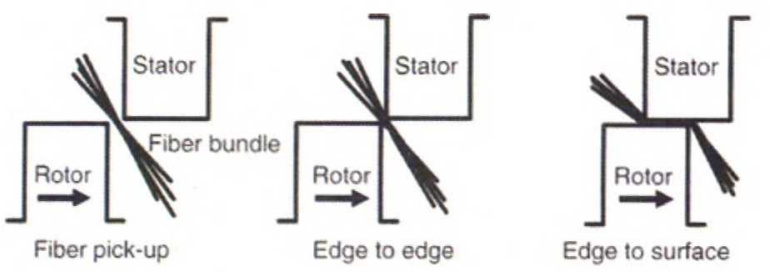

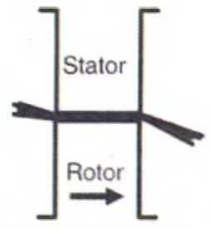

Surface to surface

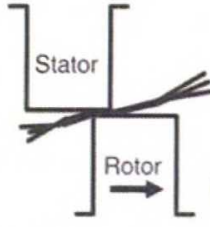

Surface to surface

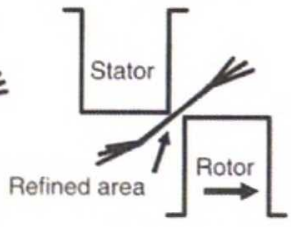

End of refining

Figure 13. One view of refining mechanism of chemical pulp fibres $/ 7 /$.

Page /14/ has proposed a mechanism for a single floc behavior in a refiner gap (Figure 14). Here most of the fibres are not in contact with the refiner bars, but with each other which results in friction between fibres creating shear forces. All fibres in the floc are subjected to shear forces depending on the coefficient of friction between fibre and metal or fibre and fibre.

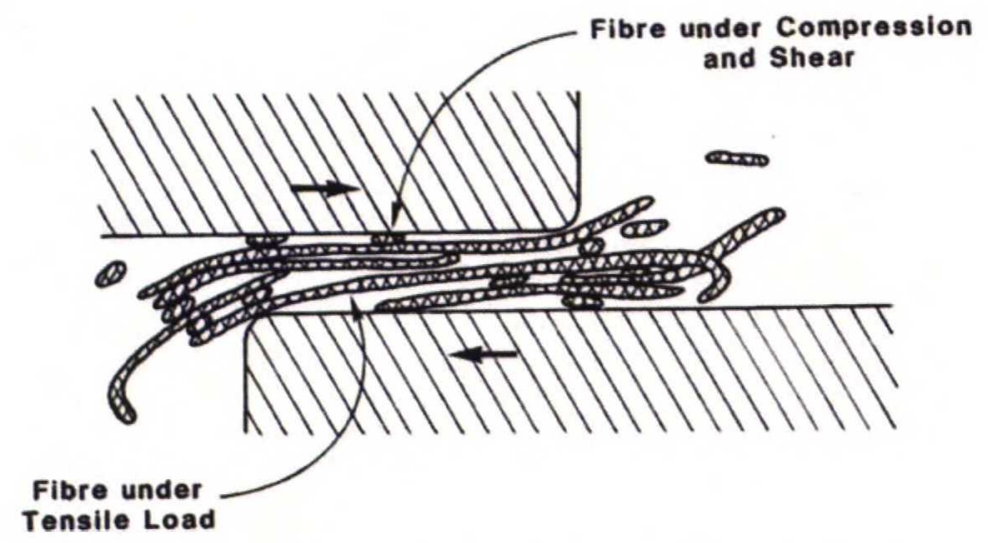

Figure 14. Impression of fibres trapped between the passing stator and rotor bars $/ 14 /$.

\subsection{Refining effects on fibres}

\subsubsection{Internal fibrillation}

Fibres receive treatment during refining which forces them to compress and relax rapidly. This induces changes in the cell wall structure of the fibres. As a result 
water is able to penetrate the cell wall structure and replace the internal bonds causing swelling of the celluloses and hemicelluloses. As a consequence, swelling degree, flexibility and conformability of fibres increase which leads to improved inter-fibre bonding and strength properties of paper $/ 15,14 /$.

\subsubsection{External fibrillation}

The most visible refining effect is the external fibrillation of fibres. This can be seen as fibrils and parts of cell wall on the surface of the fibre under microscope, as illustrated in Figure 15. External fibrillation improves the consolidation of the sheet and bonding between fibres due to the swollen celluloses and hemicelluloses that are covering the bundles of microfibrils $/ 15 /$.

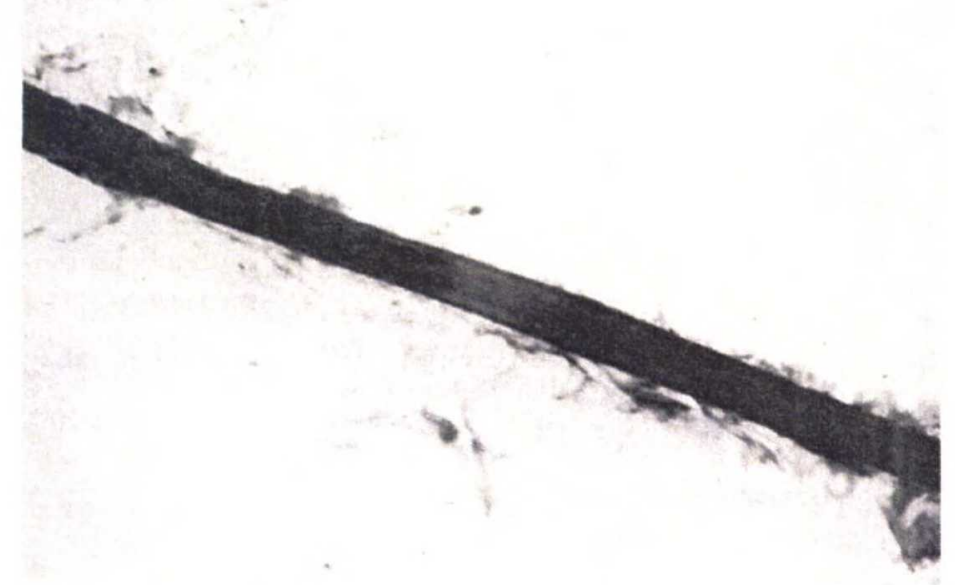

Figure 15. Lightly refined summerwood fibre showing sheaths and fibrils on surface. Magnification $100 \times$ / $/ 16 /$.

\subsubsection{Production of fines}

By definition, fines fraction is the part of the pulp that passes through the 200 mesh wire of a Bauer-McNett fractionator. Fines of the chemical pulp can be divided into primary and secondary fines. Primary fines are produced during pulp cooking and they consist of ray cells, parenchyma cells, bark residues and fibre fragments. The secondary fines form during the refining stage due to abrasion of fibre against each others or against refiner bars. They consist of primary wall frag- 
ments, fibrils and microfibrils $/ 17 /$. The primary fines content is usually below 2 $\%$, but after heavy refining the secondary fines content can be much higher.

\subsubsection{Fibre cutting and shortening}

Fibre cutting and shortening are caused by the breaking of covalent bonds of the fibres. When refiner bars pass each other, the mechanical shear results to cutting and shortening of the fibres. This cutting effect is more likely to happen during early stages of the refining process when the fibres have not yet developed flexibility and increased capacity to distribute the energy /12/. Studies have also shown that lower refiner peripheral speed is likely to increase fibre shortening $/ 1$.

\subsubsection{Fibre straightening}

Recent studies have indicated that the straightening of the fibres should be also considered as a main effect of chemical pulp refining. Especially in the beginning of low-intensity refining the average fibre length appears to increase because of fibre straightening $/ 18,2 /$. 


\section{THEORIES OF REFINING}

\subsection{Introduction}

Many theories of the chemical pulp refining have been developed to determine the most suitable refining strategy. Jagenberg was the first scientist back in as early as 1887 to introduce such terms as "edge length per second" and "beating area" /19/. These are still used as a basis for further research. After that a number of more or less scientific theories have been developed. This part of the study will introduce most commonly accepted and some further developed theories.

The common feature for all low-consistency refining theories is that total applied refiner power is divided into net power and no-load power. No-load power should be measured by backing off refiner plates with pulp suspension flowing through the refiner. Table 2 shows the no-load power for two medium angle conical and for two double-disc refiners. Net power is the component that is affecting the fibres, and it can be calculated by deducting no-load power from total refiner power. $/ 7 /$.

Table 2. No-load power of various types of refiners $/ 7 /$.

\begin{tabular}{|c|c|c|c|c|c|}
\hline \multicolumn{3}{|c|}{ Smaller refiners JC-01 and DD 20 in. } & \multicolumn{3}{|c|}{ Bigger refiners JC-04 and DD 42 in. } \\
\hline \multirow{2}{*}{$\begin{array}{l}\text { Speed } \\
\text { rpm }\end{array}$} & \multicolumn{2}{|c|}{ No load power, kW } & \multirow{2}{*}{$\begin{array}{l}\text { Speed } \\
\text { rpm }\end{array}$} & \multicolumn{2}{|c|}{ No load power, kW } \\
\hline & JC-01 & DD 20 in. & & JC-04 & DD 42 in. \\
\hline 1500 & 150 & - & 750 & 610 & - \\
\hline 1200 & 82 & 130 & 720 & 550 & - \\
\hline 1000 & 50 & 73 & 600 & 340 & 390 \\
\hline 900 & 40 & 50 & 514 & 220 & 250 \\
\hline 750 & 27 & 35 & 500 & 200 & 230 \\
\hline 720 & 24 & 32 & 400 & 115 & 120 \\
\hline
\end{tabular}




\subsection{Machine intensity based theories}

\subsubsection{Introduction}

Machine intensity based theories take only machine parameters into account. This means that any fibre or pulp related properties are ignored.

\subsubsection{Specific edge load}

Brecht /20/ has formulated today's concept of specific refining energy in lowconsistency refining as follows:

$$
S R E=\frac{\left(P_{t o t}-P_{0}\right)}{c_{F} \cdot \dot{V}}
$$

This can also be converted to total refining energy:

$$
\operatorname{TRE}=\frac{P_{t o t}}{c_{F} \cdot \dot{V}},
$$

where

$\begin{array}{ll}P_{t o t} \text { is } & \text { total refining power } \\ P_{0} & \text { no-load power } \\ c_{f} & \text { pulp consistency } \\ \dot{V} & \text { volume flow. }\end{array}$

Wultsch and Flucher $/ 21 /$ introduced their refining theory in 1958. They used the number of rotor and stator bars and net refining power per crossing speed to calculate bar treatment intensity. Brecht and Siewert /22/ further developed this theory by demonstrating the dominant impact of the bar edge. This led to the currently used formula of specific edge load: 


$$
S E L=\frac{P_{t o t}-P_{0}}{n \cdot z_{r} \cdot z_{s} \cdot \bar{l}}(\mathrm{~J} / \mathrm{m})
$$

$$
\begin{array}{ll}
\text { where } & \\
n \text { is } & \text { rotational speed of rotor } \\
z_{r} & \text { number of rotor bars } \\
z_{s} & \text { number of stator bars } \\
\bar{l} &
\end{array}
$$

Because the specific edge load theory does not take into account the net energy received by fibres, it has its limitations. However it is widely used because of its simplicity.

\subsubsection{Modified edge load}

Meltzer $/ 23$ / has recently modified the specific edge load theory by taking also the width of the bar and groove along with the average intersecting angle into account:

$$
M E L=S E L \cdot \frac{1}{2 \cdot \tan \alpha} \cdot \frac{w_{b}+w_{g}}{w_{b}},
$$

$\begin{array}{ll}\text { where } & \\ w_{b} \text { is } & \text { width of the bar } \\ w_{g} & \text { width of the groove } \\ \alpha & \text { bar angle. }\end{array}$

\subsubsection{Reference specific edge load}

Roux /24/ has proposed a new formula for calculating specific edge load because it was seen empirically that original theory does not take into account fillings' geometrical parameter effects on fibre shortening. His version of SEL accounts for the geometrical parameters such as sum of grinding angles, sector angle and configuration of bars. Reference specific edge load is calculated: 


$$
C_{S}^{0}=\frac{3\left(w_{b, s}+w_{g, s}\right)\left(w_{b, r}+w_{g, r}\right)}{2 \pi \omega\left(1-k^{3}\right)} \cdot \frac{P_{n e t}}{r_{2}^{2}}
$$

$\begin{array}{ll}\text { where } & \\ w_{b, s} \text { is } & \text { width of stator bar } \\ w_{g, s} & \text { width of stator groove } \\ w_{b, r} & \text { width of rotor bar } \\ w_{g, r} & \text { width of rotor groove } \\ \omega & \text { bar peripheral speed } \\ r_{2} & \text { external rotor radius } \\ k & \text { ratio of internal and external rotor radius }\left(\mathrm{r}_{1} / \mathrm{r}_{2}\right)\end{array}$

An expression for the normal compressive force $F_{n}$ subjected onto the fibres between passing bars is formulated:

$$
\frac{F_{n}}{\bar{n}}=\frac{C_{S}^{0}}{f \sin (\alpha+\beta+\theta)}
$$

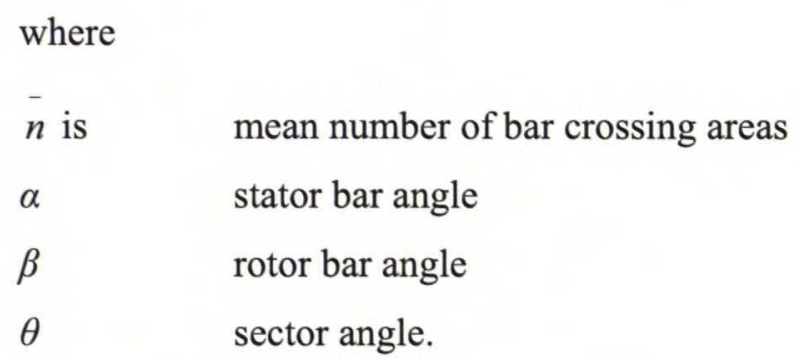

\subsubsection{Specific surface load}

Specific surface load theory (SSL) was introduced by Lumiainen in $1990 / 25 /$. He assumed that the energy is transferred to the fibre bundles also in edge-to-surface contact as well as in edge-to-edge contact. The SSL accounts for energy expenditure over bar width and is in fact an extension of the SEL theory with the value of the bar width included. 
According to his concept, the refining action is described by the number, intensity and duration of the refining impacts. Specific surface load theory assumes that specific refining energy is a product of impact number and impact energy:

$S R E=I N \cdot I E(\mathrm{kWh} / \mathrm{t})$.

Impact energy further is a product of specific surface load and impact length which is explained in Figure 16.

$I E=S S L \cdot I L(\mathrm{~J} / \mathrm{m})$

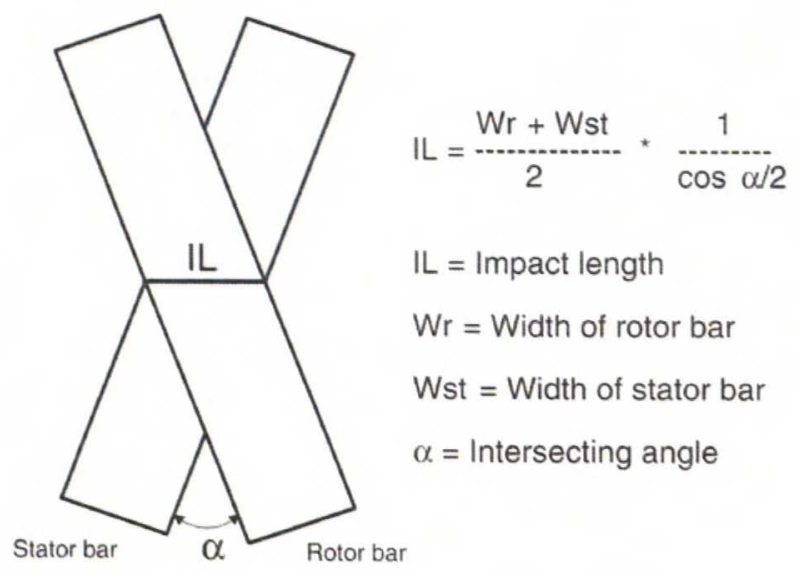

Figure 16. Definition of the impact length $/ 7 /$.

Specific surface load can be now calculated:

$$
S S L=\frac{P_{t o t}-P_{0}}{n \cdot z_{r} \cdot z_{s} \cdot \bar{l} \cdot\left(\frac{w_{r}+w_{s}}{2 \cos \left(\frac{\alpha}{2}\right)}\right)}(\mathrm{N} / \mathrm{m}) .
$$

The specific surface load theory has partly replaced the specific edge load theory. The SSL theory seems to work well when refiner bars are so narrow that fiber 
flocs cover the whole width of bar surface when receiving refining impact. On the other hand the specific edge load theory introduced earlier works better with coarse fillings when bars are wider than fibre flocs. Both of the theories have their limitations but they offer practical tools for selecting fillings and adjusting refining parameters. /7/

\subsubsection{Modified specific surface load}

The modified specific surface load theory (MSSL) was introduced by Musselman et al. $/ 26 /$ in 1997 . His theory is derived from modified specific edge load theory assuming that the stator bar width $w_{b, s}$ does not have as significant contribution on the intensity of refining as the rotor bar width $w_{b, r}$. This is due to the fact that the rotor was assumed to account for the transportation of fibres onto the stator bars. MSSL is calculated:

$$
M S S L=\frac{P_{t o t}-P_{0}}{n \cdot z_{r} \cdot z_{s} \cdot \bar{l}\left[\frac{w_{b, r}}{\cos \left(\frac{\alpha}{2}\right)}\right]_{\left(\mathrm{J} / \mathrm{m}^{2}\right) .}}
$$

\subsection{Fibre based intensities}

\subsubsection{Introduction}

In addition to the machine parameters, fibre based intensities include also more or less fibre and pulp properties. This leads to a more accurate but also more complex theories of the refining phenomenon.

\subsubsection{Floc hypothesis}

In 1990, Hietanen and Ebeling /27/ proposed a new theory for the mechanics of chemical pulp refining. The role of fibre flocs in refining has been under discussion since 1920 's and after that various authors have dealt with this phenomenon. 
Floc hypothesis theory is based on the assumption that in low consistency refining (2-6\%), fibres are refined as flocs instead of independently receiving treatment. Flocs are continuously formed and broken up under the shear forces in the refining zone and grooves. Excessive refiner energy is consumed in maintaining turbulent conditions when flocs are transported through the refining zones without undergoing any refining treatment.

The thickness of individual flocs in low consistency refining is normally $1-5 \mathrm{~mm}$. They are relatively large compared to the size of the refiner gap, which is usually $50-150 \mu \mathrm{m}$. For this obvious reason the probability that flocs will be driven into the gap is low resulting in much larger volume of pulp flow being driven through rotor and stator grooves than through the gap. This gives a heterogeneous refining result where some fibres have lost their shape completely because of the harsh treatment while some fibres do not show any structural changes at all.

Floc hypothesis theory introduces a modern approach for increasing refining efficiency and homogeneity. Designing the refiner zone so that all or most of the fibres entering it undergo treatment would enable more homogeneous refining result. The volume of the refining zone should also be minimized to enable the refining work to be concentrated on a small fluid volume. This gives the fibres a possibility to receive a more energy efficient and homogeneous treatment.

Laboratory scale tests have been made with a small disc refiner that was built based on the concept of floc hypothesis theory, and the results are promising. However at this time no production scale refiner has been developed based on this theory.

\subsubsection{Frequency and intensity}

Lewis and Danforth /28/ attempted to describe the refining process with two independent expressions. The number of impacts describes the amount of treatment received by fibres and the severity of impacts described the type of treatment. 
Also the pulp properties were included in the calculations through pulp consistency. Figure 17 shows an illustration of this theory.

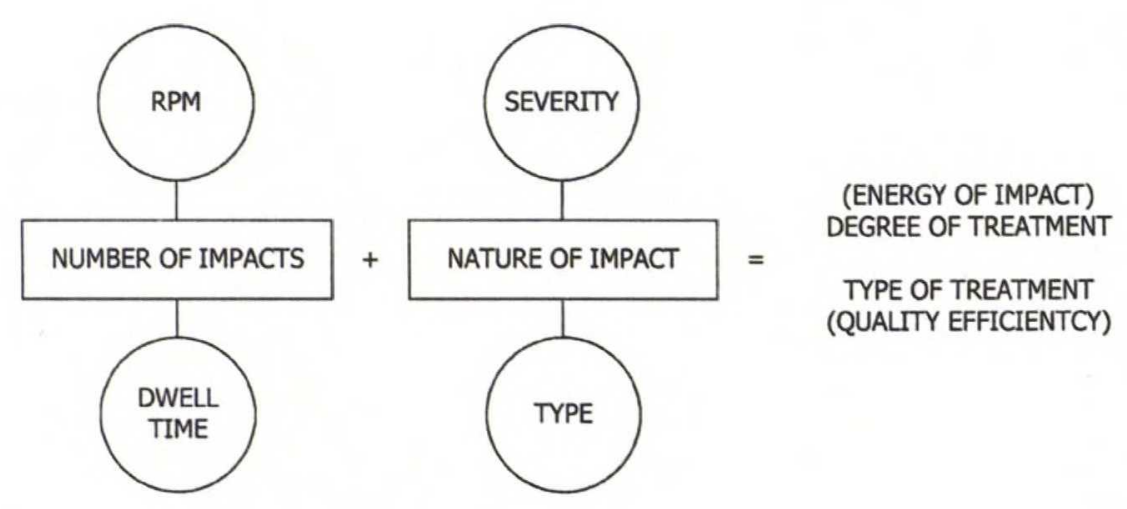

Figure 17. Effect of number and nature of impacts on type and degree of refining treatment /28/.

Danforth later developed this theory into two equations. The equation for severity of impacts is:

$$
S=\frac{\left(P_{t o t}-P_{0}\right) \cdot A_{t}}{D \cdot(R P M) \cdot L_{r} \cdot L_{s} \cdot c} \cdot K_{2}
$$

and for number of impacts:

$$
N=\frac{L_{r} \cdot L_{s} \cdot(R P M) \cdot c}{X \cdot R} \cdot K_{1},
$$

where

$\begin{array}{ll}A_{t} \text { is } & \text { total area of refining zone } \\ D & \text { effective diameter } \\ R P M & \text { rotor revolutions per minute } \\ L_{r} & \text { total length of rotor edges } \\ L_{s} & \text { total length of stator edges } \\ c & \text { stock consistency }\end{array}$


$X \quad$ average bar contact length

$R \quad$ throughput rate

$\mathrm{K}_{1}, \mathrm{~K}_{2} \quad$ constants.

Most of the factors affecting refining result are included in this theory. However because its complexity and constants that are not easily available, it is not so commonly used.

\subsubsection{C-factor}

Kerekes /29/ introduced a more comprehensive approach on refining effects in 1990. Using the same approach as Lewis and Danforth, he derived net refining energy as a product of number and intensity of the impacts:

$E=N \cdot I$

Figure 18 shows the different effects of refining intensity and frequency on the refining result with similar energy consumption.

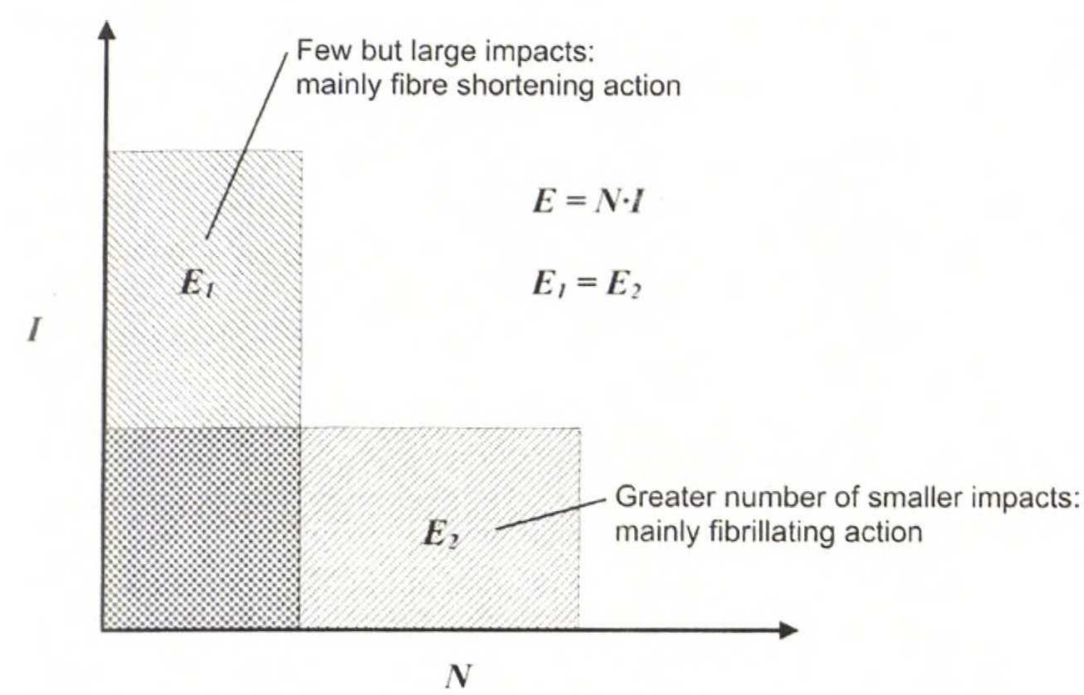

Figure 18. The two combinations of refining intensity and frequency effects on the refining result $/ 29 /$. 
C-factor represents the capacity of a refiner to inflict impacts on pulp fibres. Kerekes has approached the refining process also from the pulp properties point of view instead of concentrating only on machine parameters and process variables. The C-factor connects the net power input $P_{n e t}$ and pulp mass flow rate $F$, to the average number $N$ and intensity of impacts $I$ by the following equations $/ 7 /$ :

$N=\frac{C-\text { factor }}{F}$

$I=\frac{P_{n e t}}{C-\text { factor }}$

The C-factor is a function of refiner filling geometry, rotation speed, pulp consistency, fiber length and coarseness.

For a disc refiner in simplified conditions where the gap size is small and the bar pattern is similar on both rotor and stator, the $\mathrm{C}$-factor is given by the following equation:

$C=8 \cdot \pi^{2} \cdot G \cdot D \cdot \rho \cdot C_{F} \cdot l \cdot n^{3} \cdot \omega \cdot(1+2 \tan \phi)$.

$\left(R_{2}^{3}-R_{1}^{3}\right) / 3 \cdot w \cdot(l+D)$

and for a conical refiner in simplified conditions:

$C=8 \cdot \pi^{2} \cdot G \cdot D \cdot \rho \cdot C_{F} \cdot l \cdot n^{3} \cdot \omega \cdot(1+2 \tan \phi)$.
$\left[R_{1}^{2} \cdot L+L^{2} \cdot R_{1} \sin \theta+\left(L^{3} / 3\right) \sin ^{2} \theta\right] / w \cdot(l+D)$

where

$G$ is $\quad$ width of grooves

$D \quad$ depth of grooves

$\rho \quad$ density of water

$C_{F} \quad$ pulp consistency 


$\begin{array}{ll}l & \text { length of fiber } \\ n & \text { number of bars per unit arc length of rotor/stator } \\ \omega & \text { rotational velocity of refiner } \\ \phi & \text { bar angle on rotor/stator } \\ R_{1} & \text { inner radius of disc refiner plate } \\ R_{2} & \text { outer radius of disc refiner plate } \\ w & \text { coarseness of fibre } \\ L & \text { length of refining zone } \\ \theta & \text { angle of conical refiner. }\end{array}$

$\mathrm{C}$-factor analysis is probably the most comprehensive refining theory developed so far. It also builds on other widely used and well known theories such as specific edge load and specific surface load. However for example fillings wear can have an effect on $\mathrm{C}$-factor. Because these factors can be difficult to determine and calculations are sometimes very complex, this theory is not widely used among papermakers $/ 7 /$.

\subsection{Conclusions about refining theories}

If full understanding and control is targeted, theories including fibre and pulp properties seem logical. There are some results which imply that the refining effect on fibres is described well by the C-factor theory. Similar unpublished results have been received in studies conducted in Finland /30/. Theories based simply on machine parameters and data have practical use. As there does not seem to be clear advantages in any specific one, for papermakers it has been reasonable to use the simplest one: The specific edge load theory (SEL). 


\section{REFINING ENERGY AND FORCES}

\subsection{Force acting on pulp mass}

Shear stress acting on pulp mass is dependent on specific edge load, sliding distance, partial bar and partial fibre coverage by equation:

$\sigma_{F}=\frac{S E L}{b \cdot z \cdot s}$

where

SEL is specific edge load

$b \quad$ length over bar width covered

$z \quad$ fractional bar coverage

$s \quad$ sliding distance.

\subsection{Forces acting on individual fibres}

Quantifying forces acting on individual fibres can be difficult because of the large distribution of forces within fibre networks. Kerekes and Senger /31/ have estimated the average normal force acting on a fibre by the equation:

$f_{N}=\frac{\sqrt{\pi} \cdot d_{0} \cdot l^{\frac{3}{2}} \cdot C_{s} \cdot \sqrt{k G}}{4 \cdot a \cdot T} \cdot\left(\frac{S E L}{\pi \cdot S \cdot b \cdot z}\right)^{0,7}$,

where

$d_{0}$ is uncompressed fibre diameter

$l \quad$ fibre length

$C_{s} \quad$ consistency of the floc before compression

$k \quad$ fractional proportion of the groove from which fibres are captured

$G \quad$ groove width

$T \quad$ gap size

SEL specific edge load 
S

$z$

$a, b$

sliding distance

fractional distance along unit bar length covered with fibre constants.

Values of some of the constants in this equation are not known at the present time $132 /$. One target of this thesis is to be able to measure fractional distance along unit bar length covered with fibre $z$, and possibly consistency of the floc before compression $C_{s}$.

Figure 19 shows a simple example of the effect of the bar coverage on forces acting on fibres. With smaller bar coverage, the normal force on a single fibre is increasing linearly due to the distribution of the force on a smaller area.

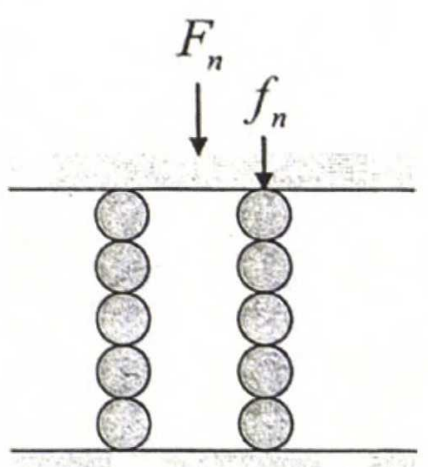

$$
f_{n}=\frac{F_{n}}{2}
$$

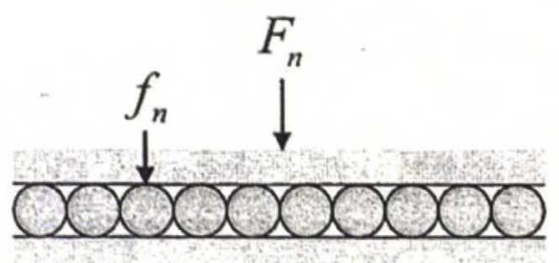

$$
f_{n}=\frac{F_{n}}{10}
$$

Figure 19. Simplified example of how smaller fractional bar coverage gives a larger force on fibres $f_{n}$ than do more evenly distributed fibres for the same bar normal force $F_{n} / 32 /$.

The shear force on a fibre can be calculated from the normal force by an effective coefficient of friction

$$
f_{S}=\mu_{E} \cdot f_{N}
$$

Martinez and Kerekes $/ 33 /$ measured a typical shear force distribution along the width of the bar surface of a single-bar laboratory refiner they constructed. Figure 
20 shows that the force peaks to a maximum at a time of $0.35 \mathrm{~s}$ which corresponded to a distance of around 3-5 $\mathrm{mm}$ (total bar width was $10 \mathrm{~mm}$ ) from the leading edge. Several studies conducted afterwards confirm this type of distribution also for normal force $/ 34,35,36$ / except for the magnitude which is usually 10 times higher than with shear force.

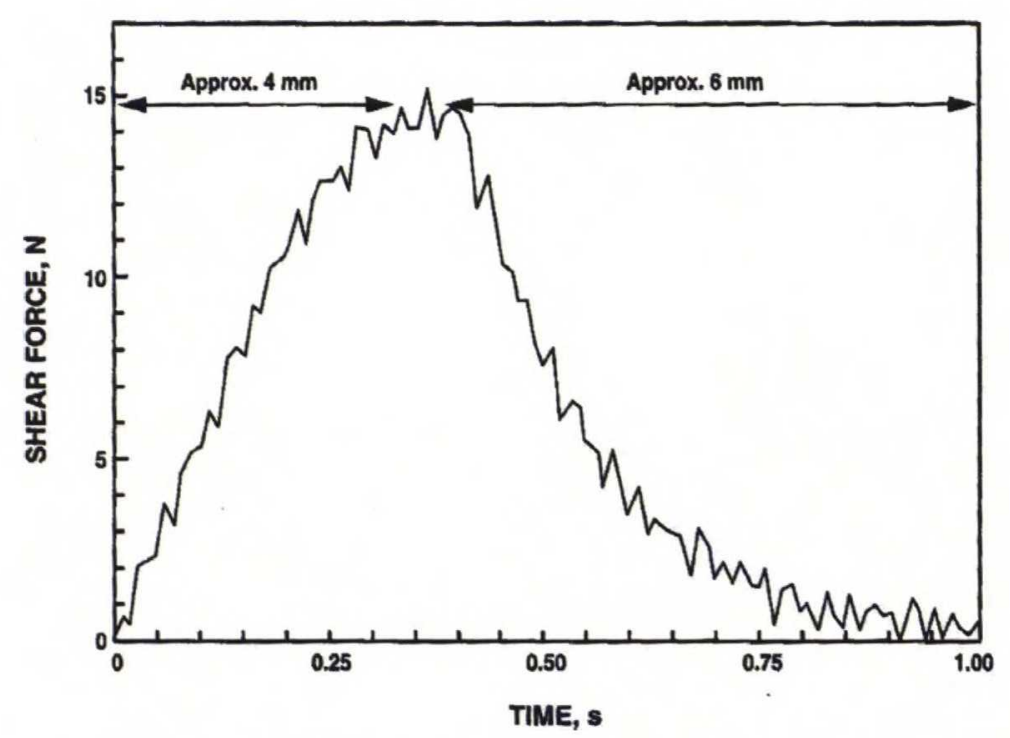

Figure 20. A typical shear force distribution along the width of the bar surface $/ 33 /$.

\subsection{Energy efficiency in refining}

Refining effects are produced by breaking of molecular bonds caused by forces which create strains in fibres. According to Kerekes, force balances link bar action to fibre deformation, which permits comparison between energy expended and energy transferred. This theoretical efficiency is very low varying according to different studies from $0.2 \%$ to $15 \%$. Bar energy is also transferred to fibres as external fibrillation and surface fines production as they depend on both force and sliding distance. However the true energy efficiency is not known because of the process constrains set by quality considerations. $/ 32 /$

As mentioned earlier, refining can be divided into three phases which are:

- Edge-to-edge 
- Edge-to-surface

- Surface-to surface.

All of these phases consume energy and the effective part of it is transferred to the fibres. The no-load power remains as constant during the refining impact. Total refining energy is split between the phases as shown in Figure 21.

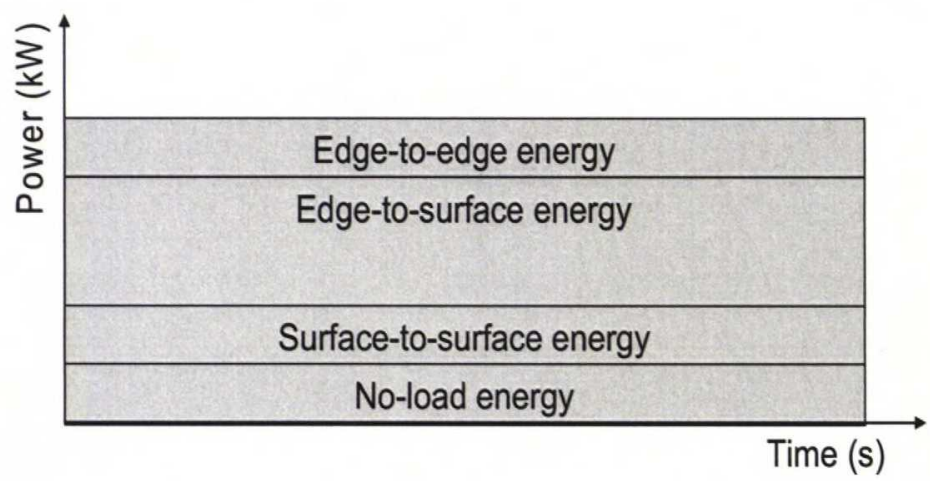

Figure 21. Total refining energy split as presented by Lumiainen /37/.

When the leading edges approach each others the power quickly reaches its maximum value. After this phase it decreases to the no-load energy level as illustrated in Figure 22. However since all phases occur simultaneously, the total power consumption remains at a constant level.

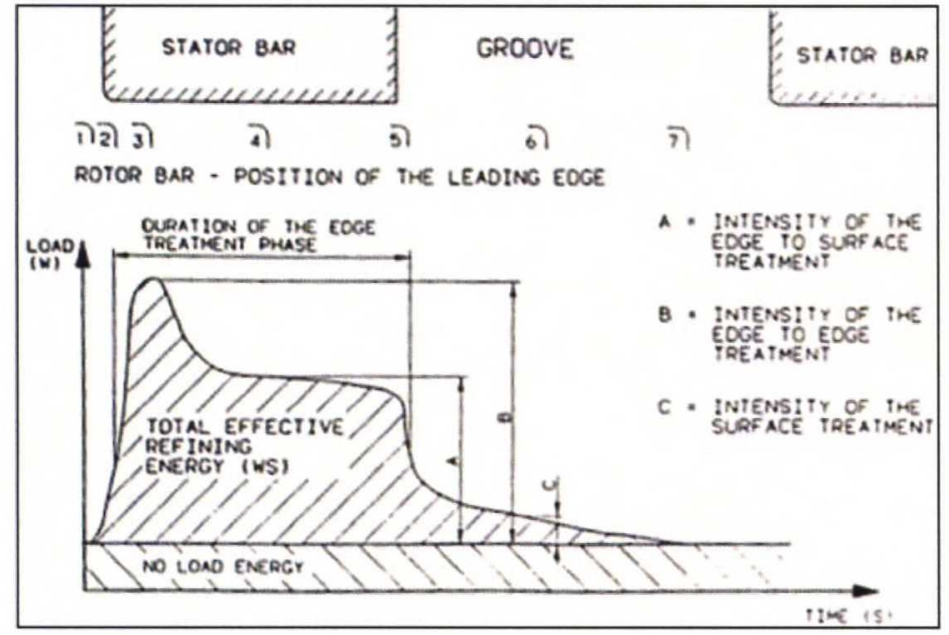

Figure 22. Intensity and duration of the refining impact. 


\section{CONCLUSIONS OF THE LITERATURE REVIEW}

There are many different theories developed concerning low-consistency refining and its effect on pulp and fibres. Despite the fact that it is one of the most researched areas of papermaking, many unknown issues still remain. These include parameters such as bar coverage and pulp consistency in the refining gap. Many of the studies conducted in the earlier days concentrate mostly on the machine parameters rather than pulp or fibre related parameters. This has lead to the use of the simplest theories, such as specific edge load (SEL) theory when controlling the refining process. Understanding of the forces acting on pulp and even individual fibres during refining is still very much an unknown issue. There are some studies that have concentrated on measurement of normal and shear forces on fibres during refining in the past decades, but more research in this area is definitely required. 


\section{EXPERIMENTAL}

\subsection{Target}

Target of the thesis work was to construct a Single Bar Refiner station in order to enable measurement of fractional bar coverage and pulp consistency in the gap between rotor and stator bars by image analysis. Improved knowledge of the low consistency refining phenomenon is expected to provide potential for energy savings in low-consistency refining of chemical pulp and possibly also in thermomechanical pulp refining (TMP). Also improving quality control by for example introducing novel refiner constructions and tailor-made refining for different end uses could be some of the future innovations.

The experimental section of this thesis describes the designing and construction process of the Single Bar Refiner station in detail. There were also some preliminary trials that were conducted with the refiner, which included the imaging system testing. Results from those trials are also included in this section. The SBR station was placed to the machine hall of TKK Forest Product Department and will be mainly operated by Paper and Printing technology group.

\subsection{Background}

Starting point of this thesis was linked to an earlier project where first version of the Single Bar Refiner, later referred as SBR, was constructed by modifying the chamber of a pump. The rotor shaft of the pump was fitted with a cylinder equipped with two bars to create a refining effect on the fibres passing between the stator and rotor bars (Figure 23). 


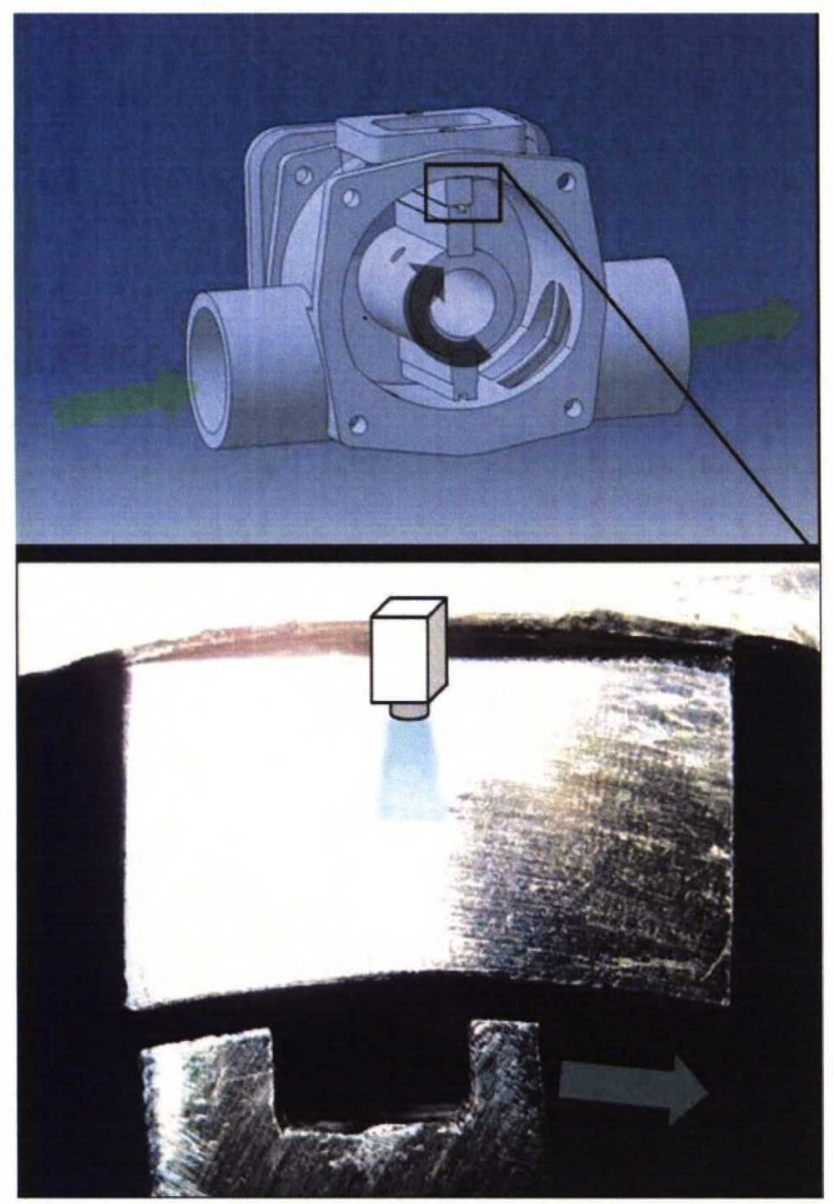

Figure 23. The refining gap on the first version of the Single Bar Refiner unit $/ 4 /$.

The stator bar was installed on the upper side inside the chamber. In the first version of the refiner, the rotor bar was grooved and the stator bar was flat. The imaging could be conducted from the above through an acrylic window which was also part of the stator bar, or from the front side through an acrylic plate (Figure 24).

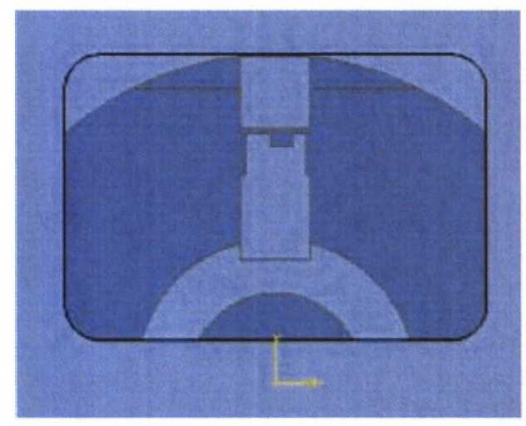

Figure 24. The front window of the refiner unit $/ 4 /$. 
The first version was tested only shortly due to the ENGINE project closure, but the results were promising. Some good images and video material was shot and also a technique for image analysis was developed $/ 4 /$. After the construction of the refiner some modifications were suggested to create more realistic refining conditions in the gap between the bars. Because of the stator design (no groove), the fibre capture was not realistic enough because the fibres were captured in the refining zone from a much larger volume than in real situation. Grooving the stator bar would create a finite volume for the pulp suspension and was expected to have an effect on the fibre behavior in the gap. Also the size of the refining gap between stator and rotor bars was unrealistically large.

\subsection{Modification of the stator bar}

\subsubsection{Introduction}

One of the main targets of the SBR construction was to design a stator with two bars with a groove between them instead of only one wide bar, as was the case in the first version. Second important modification was to decrease the gap between stator and rotor bars to a more realistic value of $150 \mu \mathrm{m}-300 \mu \mathrm{m}$ from the original gap size which was estimated to be $\sim 500 \mu \mathrm{m}$.

\subsubsection{Grooving the original stator bar}

The modification of the SBR stator bar was started by designing a groove on the stator bar used in the original setup. The groove dimensions were similar to the ones used in the rotor bar (Figure 25).

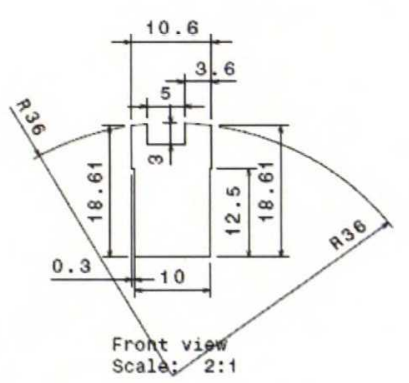

Figure 25. Dimensions of the rotor bar $/ 4 /$. 
The stator bar consisted of a stainless steel and acrylic parts that were connected to each others. The acrylic part was installed outside the refiner casing between a metal frame and the stainless steel part. Two M6 bolts were used to keep the parts together and attached to the casing. The groove was machined on both parts $5 \mathrm{~mm}$ wide from the center to a depth of $3 \mathrm{~mm}$. Figure 26 and Figure 27 describe the structure of the grooved acrylic and stainless steel parts.

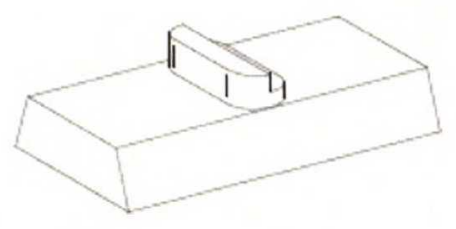

Figure 26. Structure of the acrylic part of the SBR stator bar.

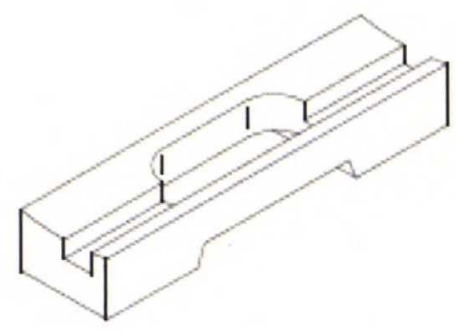

Figure 27. Structure of the stainless steel part of the SBR stator bar.

With this modification the designed structure could be tested with the original gap size to see the behavior of the refiner. The results of these trial runs are discussed later.

\subsubsection{Reducing the gap size between refiner bars}

\section{Introduction}

Two different methods were considered to reduce the gap between the rotor and stator bars to the wanted level of $150 \mu \mathrm{m}-300 \mu \mathrm{m}$. First method under discussion was to use some type of shims at certain points of the stator structure to adjust the gap. Another option was to design new acrylic and stainless steel parts for each gap size desired. Because of the difficult design of the stator bar, using new parts 
was considered as more useful approach than adjusting the gap size with shims. The starting point was to design two sets of parts, first set for the gap size of 150 $\mu \mathrm{m}$ and the second one for the gap size of $300 \mu \mathrm{m}$.

\section{Measuring the original gap}

First problem was to measure the gap size from the original refiner structure to be able to define exact dimensions for the new parts. This was accomplished by first taking a photograph from the side of the refiner unit at the point where the rotor and stator bars are parallel to each other (Figure 28).

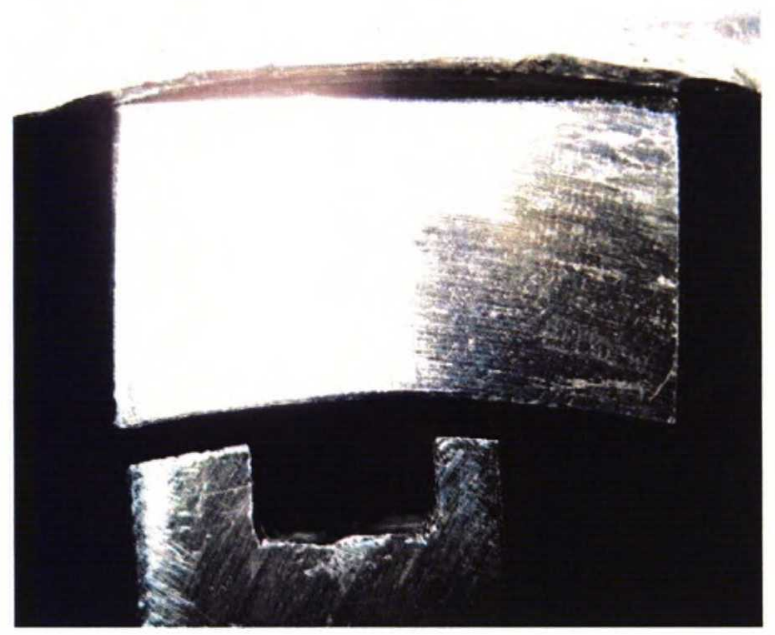

Figure 28. Picture of the rotor bar and the original stator bar (without groove).

From this photograph it was possible to determine the relation of the gap clearance to a known dimension (in this case bar height) and then calculate the gap size:

$g=\frac{P_{g}}{P_{b}} \cdot b$,

where

$\begin{array}{ll}P_{g} \text { is } & \text { gap size [pixels] } \\ P_{b} & \text { bar height [pixels] } \\ b & \text { bar height [mm]. }\end{array}$


The measured bar height was $9,1 \mathrm{~mm} / 740$ pixels and gap size 83 pixels. We can now calculate the gap size of the original setup using equation 20 :

$g=\frac{P_{g}}{P_{b}} \cdot b=\frac{83 p i x}{740 \text { pix }} \cdot 9,1 \mathrm{~mm}=1,0 \mathrm{~mm}$.

\section{Designing the new stator bars}

The dimensions for the new acrylic and stainless steel parts could now be calculated from the original gap size. For example bar height for new stainless steel part:

$b_{x}=b+\left(1,0 m m-g_{x}\right)$,

where

$g_{x}$ is desired gap size.

For a desired gap size of $300 \mu \mathrm{m}$ we get a bar height of:

$b_{300}=9,1 \mathrm{~mm}+(1,0 \mathrm{~mm}-0,3 \mathrm{~mm})=9,8 \mathrm{~mm}$.

By measuring the dimensions of the original acrylic and stainless steel parts and using this information, drawings for all new stator components could be designed using Solid Edge CAD software. Drawings with all the dimensions are included as appendices 1-4.

\section{Fitting the new stator bars}

When the new stator bar parts designed for the gap size of $150 \mu \mathrm{m}$ were installed, the rotor was not able to rotate because the bar seemed to be too high. With the parts designed for the gap size of $300 \mu \mathrm{m}$, the rotor could barely slide past the stator bar. This problem occurred probably because of the errors in measuring the 
original gap size. Because the measurement was made only from one side of the stator - rotor contact, irregularities along the length of the stator bar were not visible and therefore could not be taken into consideration.

The solution to this problem was to assume that the new stator parts were $300 \mu \mathrm{m}$ too high. This in fact was the case because the gap size was actually 0 when a gap size of $300 \mu \mathrm{m}$ was wanted. This is due to the fact that the rotor was touching the stator while still able to slide past it. This lead to a conclusion that the original gap size was actually $700 \mu \mathrm{m}$ instead of the $1000 \mu \mathrm{m}$ calculated earlier. As a result, a $300 \mu \mathrm{m}$ chip was taken off from both of the stainless steel parts and $300 \mu \mathrm{m}$ shims were used under the acrylic parts to keep the refiner casing sealed.

\subsection{Pulp flow system design}

To enable even pulp flow through the refiner, a flow system with recirculation was designed (Figure 29). A steel reinforced clear PVC hose with an inner diameter of $32 \mathrm{~mm}$ was chosen for fluid transportation because of its flexibility, durability and relatively low price. Manually operated globe valves were chosen for process points where control of the flow was considered necessary. These points are:

- After the pulp disintegrator to drain the suspension to the storage tank

- After the storage tank to open/close access to the flow system

- Two points after the pump to control flow direction and speed to the refiner and back to the storage tank (recirculation). 


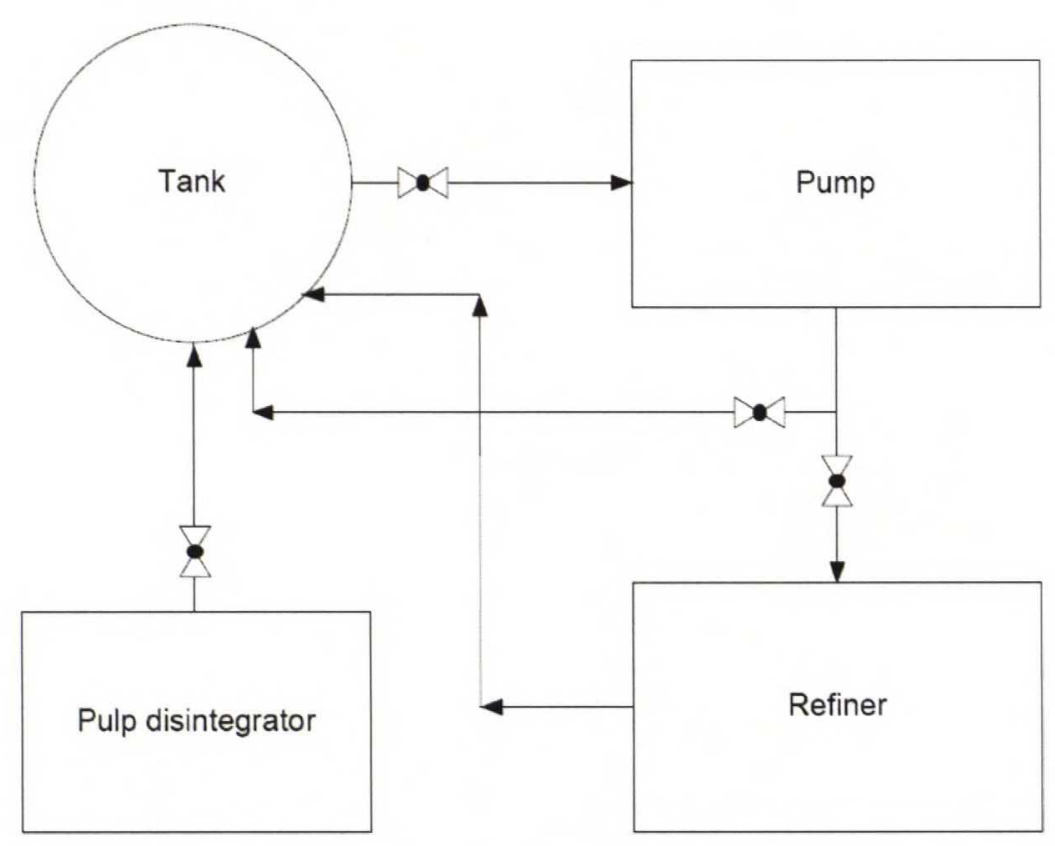

Figure 29. Pulp flow chart and position of the globe valves.

\subsection{Layout and components}

\subsubsection{Layout design}

The refining station includes following components:

- Pulp disintegrator

- Tank

- Pump

- Refiner unit

- Imaging system

The imaging system includes a camera, laser unit equipped with fiber optics for illumination, control unit and a laptop computer. These were mounted on two separate tables to ensure dry operation conditions for the computer and control unit. 
Figure 30 describes the layout design and location of the components. The most challenging part of the layout design was the limited space allocated for the refiner station. The dimensions were limited by three walls and a large electric motor used for other applications in the machine hall. The refiner station was installed in the base floor of machine hall (PUU 1) next to the large pulp disintegrator.

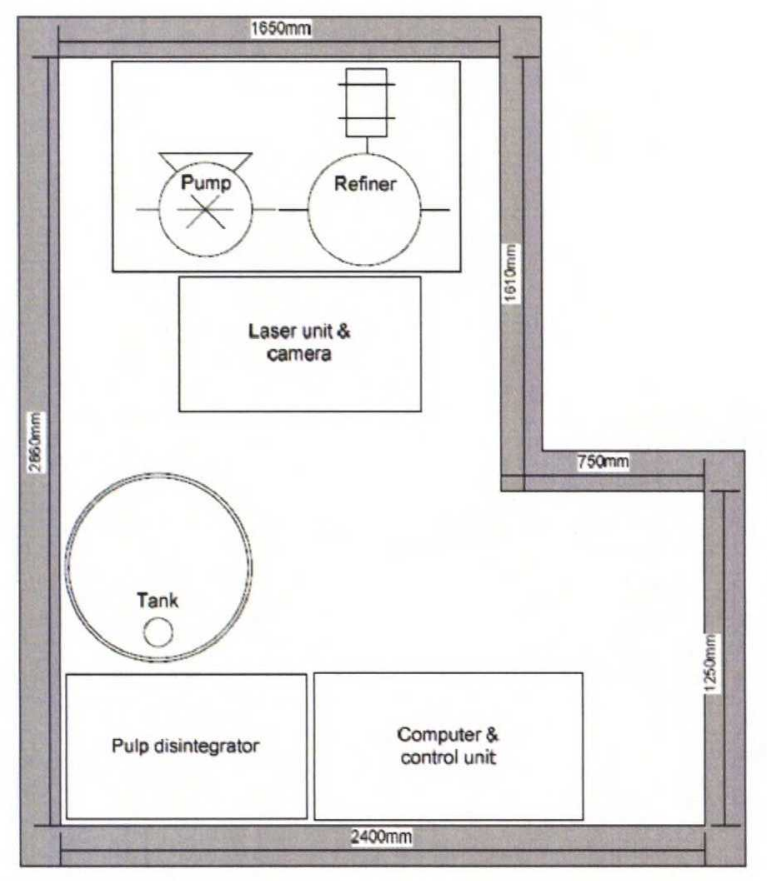

Figure 30. Single Bar Refiner Station dimensions, layout and components.

\subsubsection{Components of the refiner station}

\section{Pulp disintegrator}

Before operating the Single Bar Refiner, pulp has to be disintegrated. A laboratory scale vertical pulp disintegrator was installed for this purpose (Figure 31 ). With a capacity of $43 \mathrm{dm}^{3}$ it was suitable for this application. It is equipped with a $3 \mathrm{~kW}$ electric motor which runs at $2800 \mathrm{rpm}$ when empty. The disintegrated pulp suspension can be drained after operation via a globe valve located in the bottom. 


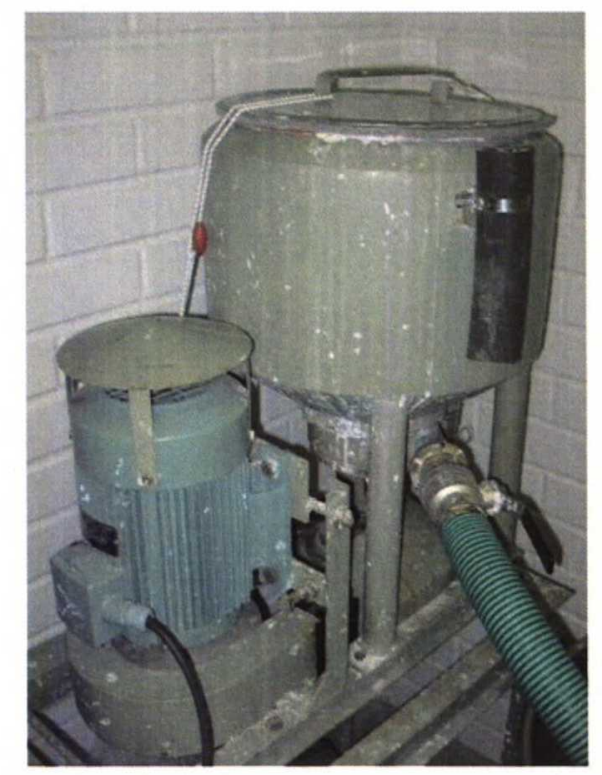

Figure 31. A laboratory scale pulp disintegrator used for slushing the dry pulp.

\section{Storage tank}

The amount of pulp in the flow system was calculated in order to estimate the minimum size of the pulp storage tank needed. This was then multiplied by three to ensure good flow conditions:

$V_{\min }=3 l \pi r^{2}$,

where

$l$ is $\quad$ total length of the flow circulation [m]

$r \quad$ radius of the hose [m].

In this case the total length of the circulation is $10 \mathrm{~m}$ and the radius of the hose is $16 \mathrm{~mm}$ so using equation 22 the minimum volume can be calculated:

$V_{\min }=3 l \pi r^{2}=3 \cdot 10 m \cdot \pi \cdot(0,016 m)^{2}=0,024 m^{3}=24 d m^{3}$.

A steel tank with a volume of $142 \mathrm{dm}^{3}$ was installed to store the pulp suspension during operation of the refiner (Figure 32). There were also some other second- 
hand storage tanks available in the machine hall but this one was the best option because of its compact size and high capacity. In this perspective the capacity of the tank is high enough for this application and also for possible future modifications to the pulp flow system. It is also practical to conduct consecutive tests with different pulp consistencies because of the extra capacity for dilution water.

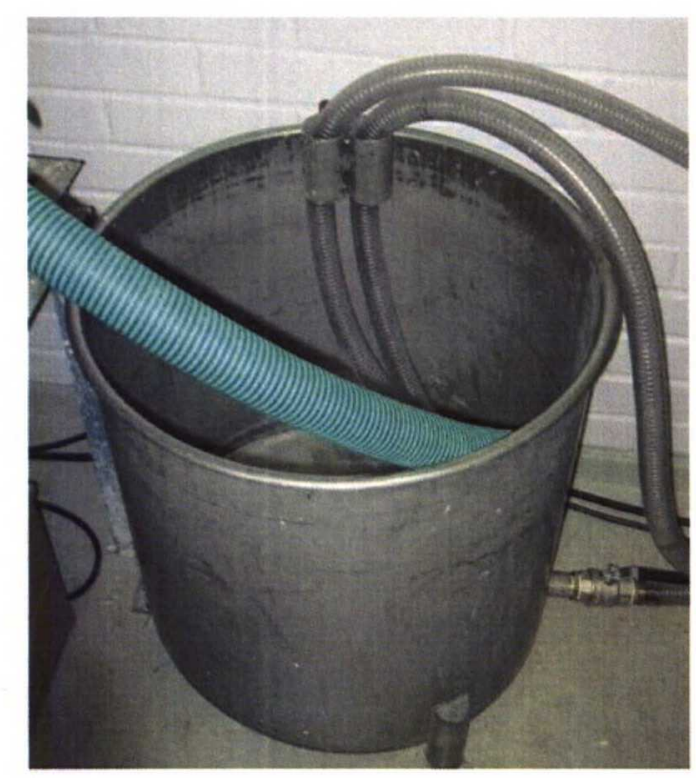

Figure 32. The tank used for storing the pulp suspension.

\section{Pump}

To create flow conditions for the refiner unit, a gear pump (Figure 33) was installed after the storage tank. It had been used earlier for transportation of pulp suspensions in the machine hall and was available, which made it optimal for this use. The pump is also powerful enough to mix the pulp suspension in the storage tank when recirculation valve is open which makes an additional mixer unnecessary. 


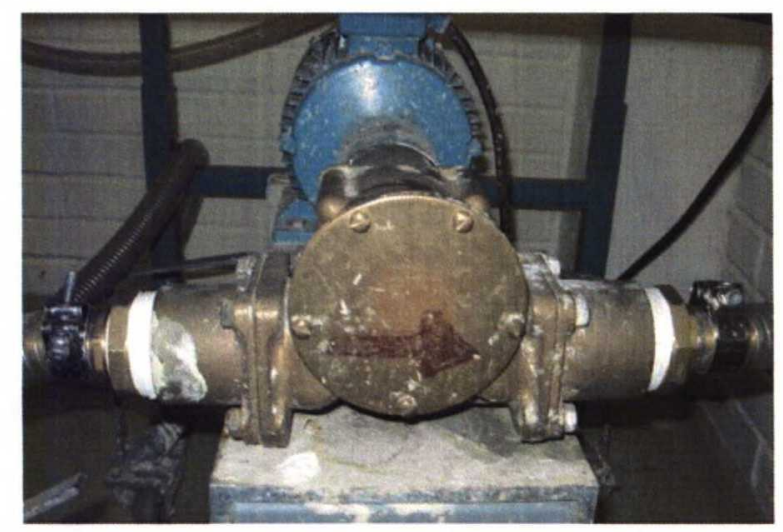

Figure 33. The pump used in the pulp flow system.

\section{Refiner unit}

The refiner unit was constructed by modifying the chamber of a pump. This was done by replacing the pump rotor with a part that acts as a refiner rotor. The rotor has two metal bars located symmetrically around the rotor cylinder. This creates two contacts of the stator and rotor bar per one revolution of the drive shaft. Both bars were grooved with a width of $5 \mathrm{~mm}$ and a depth of $3 \mathrm{~mm}$ which corresponds to the dimensions of the grooves used in the Voith LR 40 laboratory refiner at TKK and were therefore chosen here. A metal bar fitted with an acrylic imaging window was attached on top of the pump casing which enabled image capture of the events that take place in the refining gap. The power of the refiner motor can be adjusted within a scale of $0,15 \mathrm{~kW}-0,75 \mathrm{~kW}$.

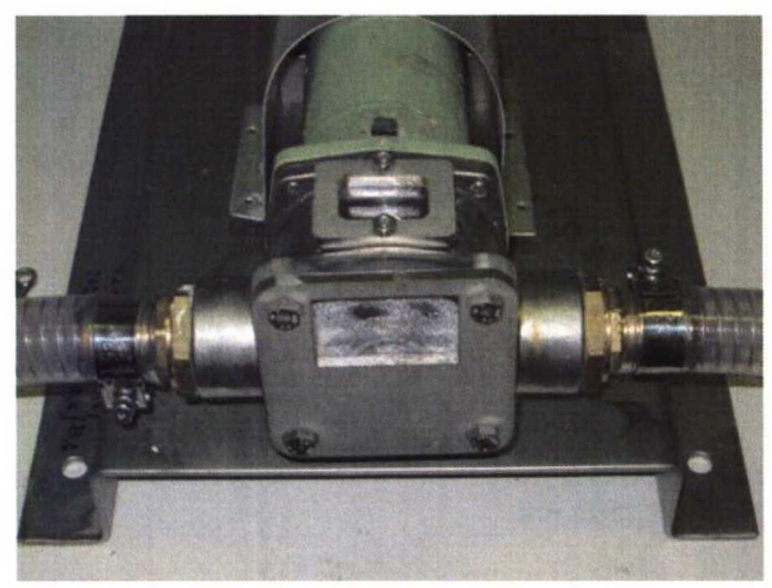

Figure 34. The Single Bar Refiner unit. Flow direction is from left to right. 
As mentioned earlier the refiner unit and rotor were designed and constructed as a part of ENGINE - project discussed in the introduction of the experimental section. Only the design and modifications on the stator bar and the motor on the refiner were changed as part of this thesis.

The imaging is conducted from above the refiner through the acrylic part of stator bar. The position of the bars and illustrative description of the imaging is shown in Figure 35.

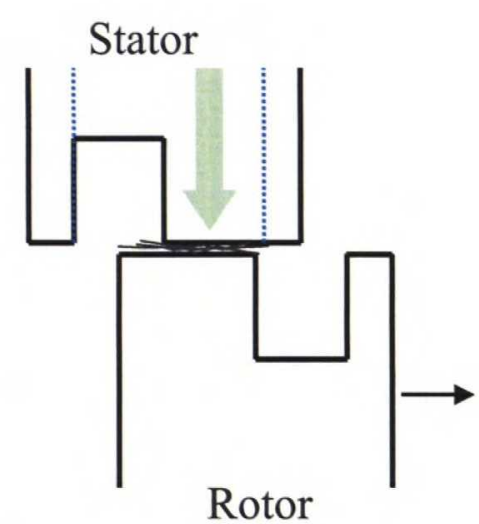

Figure 35. An illustrative description of the imaging process.

\subsection{Imaging system}

\subsubsection{Introduction}

The imaging system for capturing images inside the gap between the rotor and stator bars was designed to enable image analysis of the fibre behavior during the refining phenomenon. Some similar methods to capture fibres during refining using photography has been used by various researchers in the past decades $/ 38,39$, 40/. However these studies have concentrated mostly on thermomechanical pulp refining, so imaging method for low-consistency refining of chemical pulp with this type of laser imaging system has not been published. The main target of the 
image analysis was to study the possibility to measure pulp consistency and fractional bar coverage in the gap between the stator and rotor bars.

All components of the imaging system were supplied by Cavitar Oy, a company which is specialized in projects that require laser illuminated imaging. The laser illumination was needed to capture sharp high resolution images from fibres and fibre flocs captured between the bars during refining. The system with its components and connections are described in Figure 36.

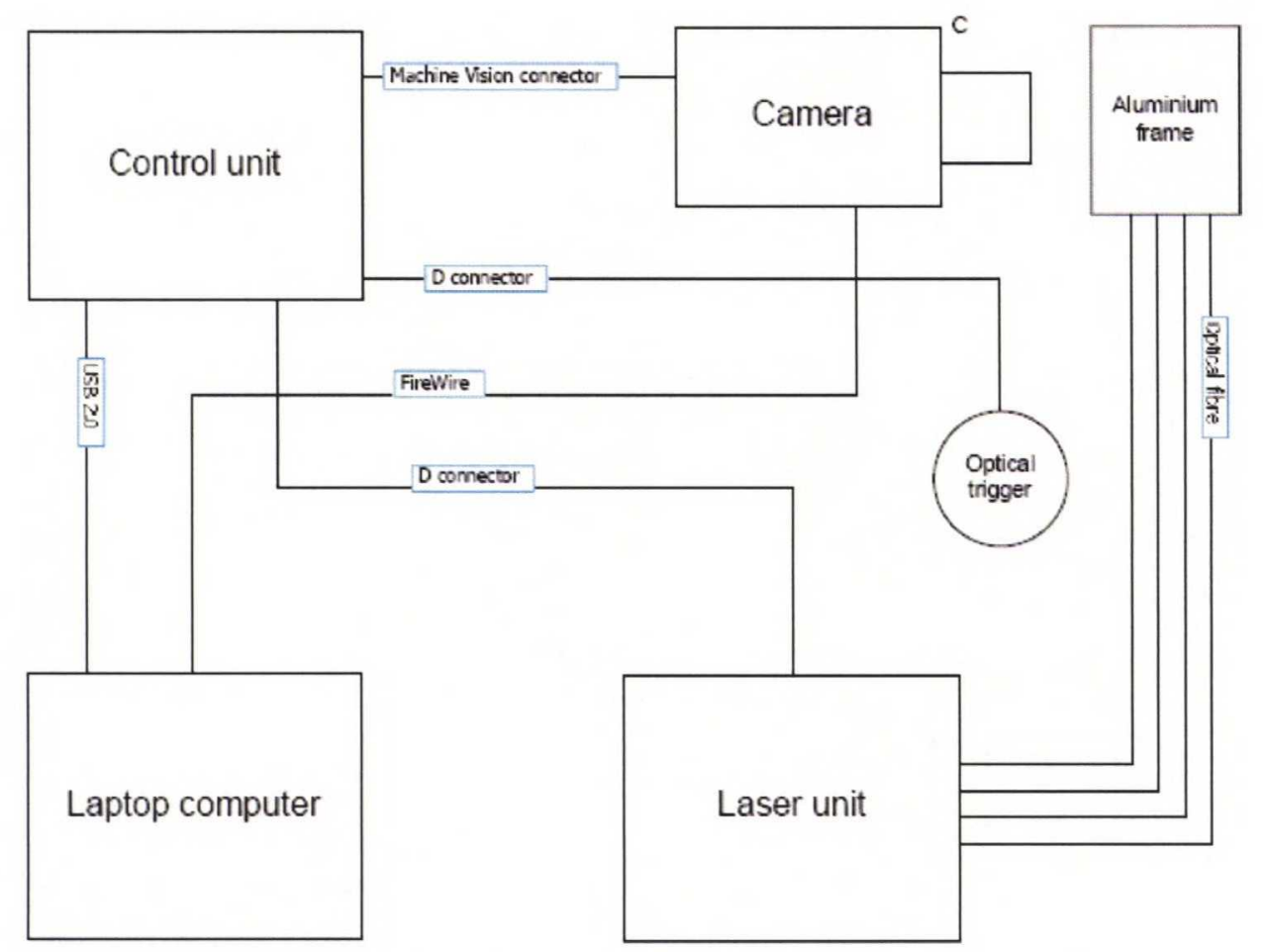

Figure 36. The imaging system components and connections.

\subsubsection{Control unit}

The control unit (Figure 37) is used by the computer software to operate the imaging equipment. It has independently programmable outputs for the laser unit and the camera. The duration of a single pulse within the output pulse pattern can be adjusted to a value between $42 \mathrm{~ns}-10 \mu$ s. The unit has a 9-pin D connector and a $\mathrm{BNC}$ connector for external synchronization purposes and a Remote Interlock 
connector which can be used to stop the operation of the imaging system for safety reasons (not used in this setup). The control unit has a manual adjustment for the laser power and a key operated master control for power.

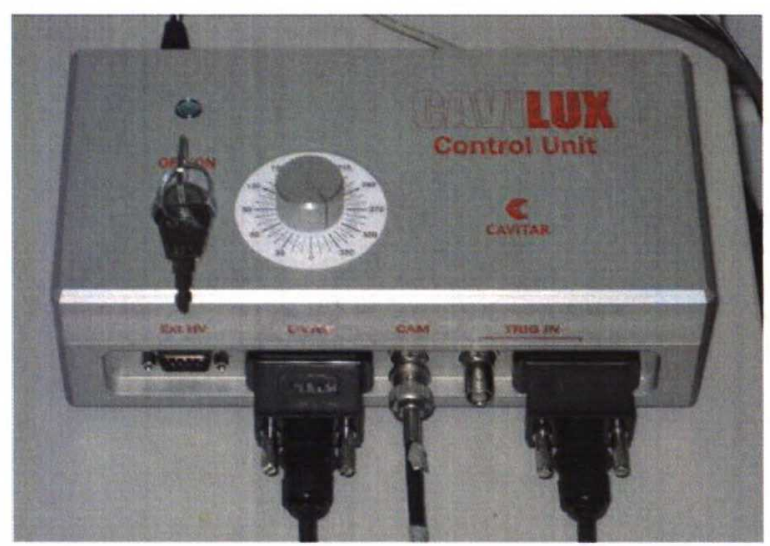

Figure 37. The imaging system control unit.

\subsubsection{Camera}

A PixeLINK ${ }^{\mathrm{TM}}$ PL-A741 machine vision camera with a telecentric $55 \mathrm{~mm}$ lens was attached to a table with a mounting arm (Figure 38). It is a 1,3 megapixel monochrome camera which is connected to the computer with a high speed FireWire interface. Because the laptop computer could not provide power to the camera via the FireWire bus, an external $12 \mathrm{~V}$ DC power supply was needed. The camera is connected to the control unit with a 6-pin Machine Vision connector. Some basic features of the camera are described in Table 3. 


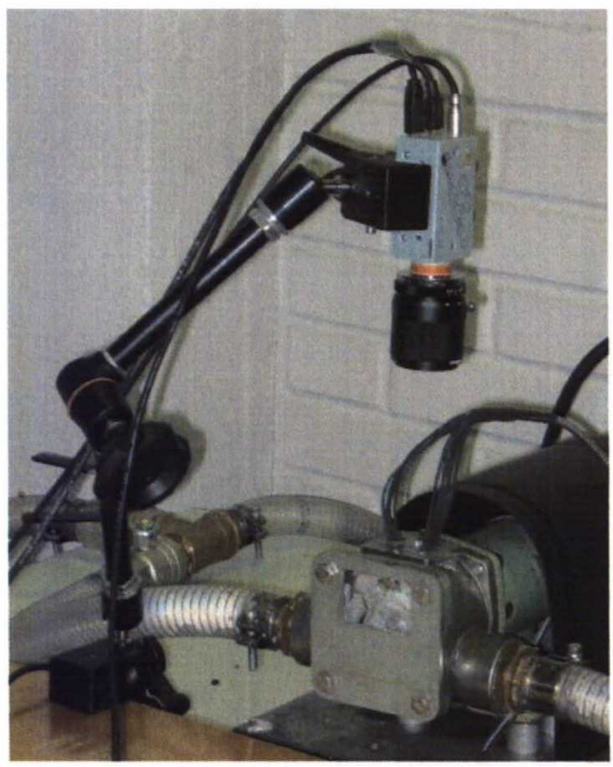

Figure 38. The installed camera and lens with mounting arm.

Table 3. Basic features of the PL-A741 machine vision camera /41/.

\begin{tabular}{|c|c|c|c|c|c|c|c|c|c|c|}
\hline Feature & 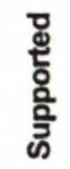 & 旁 & $\underset{\Sigma}{2}$ & 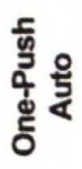 & 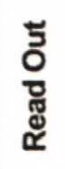 & $\begin{array}{l}\text { 告 } \\
\text { ठ }\end{array}$ & 量 & 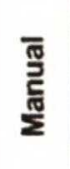 & $\begin{array}{l}\frac{9}{\mathrm{~J}} \\
\frac{\mathrm{J}}{2} \\
\frac{\mathrm{c}}{2}\end{array}$ & 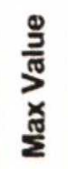 \\
\hline Brightness & Yes & $\%$ & Absolute & No & Yes & No & No & Yes & 0 & 100 \\
\hline Shutter & Yes & $\mathrm{s}$ & Absolute & No & Yes & No & No & Yes & 0.00004 & 1 \\
\hline Gain & Yes & $\mathrm{dB}$ & Relative & No & Yes & No & No & Yes & 0 & \\
\hline Temperature & Yes & ${ }^{\circ} \mathrm{C}$ & Absolute & No & Yes & No & No & No & & \\
\hline
\end{tabular}

\subsubsection{Laser unit and fibre optics}

The laser unit (Figure 39) is providing laser pulses for illuminating the area where images are captured. It can provide 500 watts of light power as a single pulse in a wavelength of $690 \mathrm{~nm}$ which makes it a class 4 laser product. This means that proper safety precautions must be taken when operating the unit. The laser unit is resistant to splash water so it could be safely installed near the pulp flow system. It is connected to the control unit with a 9-pin D connector. 


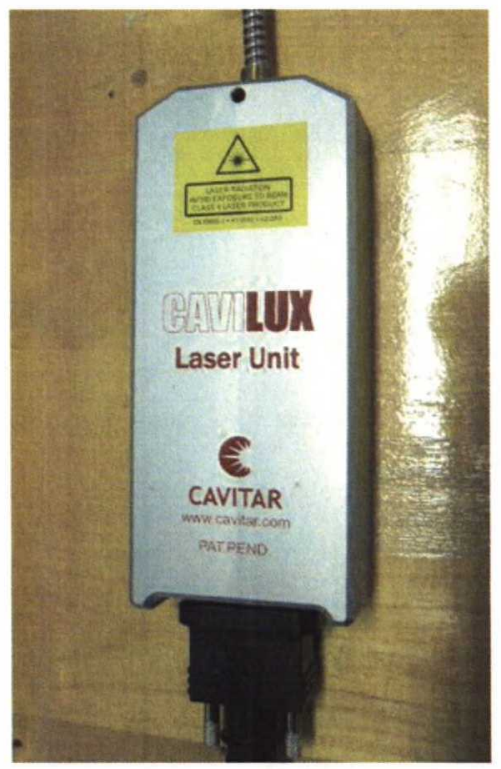

Figure 39. The imaging system laser unit.

The pulse of light is transferred from the laser unit via a fibre optic cable through an aluminum frame. A bundle of optical fibres divide the light inside the frame to provide uniform illumination through the acrylic part inside the gap between rotor and stator bars. Figure 40 shows the position of the aluminum frame and optical fibres on top of the refiner unit. The images can be taken from the opening located in the middle of the frame.

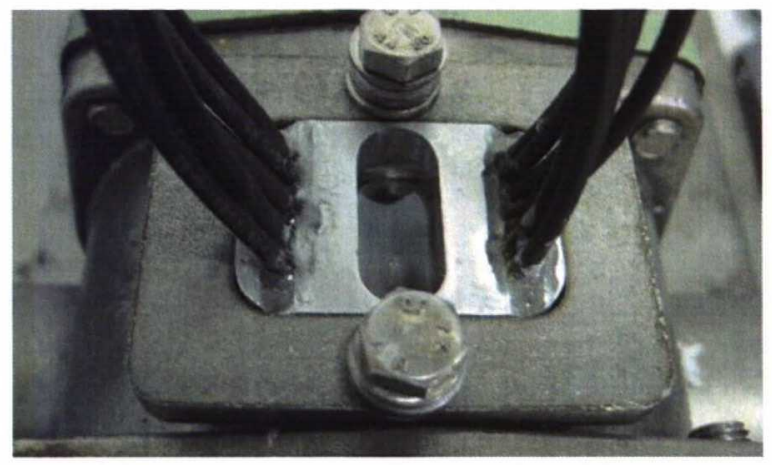

Figure 40. The aluminium frame with bundle of optical fibres installed on top of the refiner unit. 


\subsubsection{Optical trigger}

In order to synchronize the camera to capture images from the same position for each revolution of the refiner, an optical trigger was installed on the refiner unit (Figure 41). The trigger consists of a cable and a light beam sensor which sends a $5 \mathrm{~V}$ electric signal when the beam is interrupted. A metal bar was attached to the coupling between the refiner unit and its motor in a position where the stator and rotor bars were aligned. The purpose of the bar was to interrupt the light beam once per each revolution of the refiner rotor to trig the signal for the control unit. The final adjusting of the exact moment of image capture was made in the control software by creating a delay signal for the camera and laser outputs.

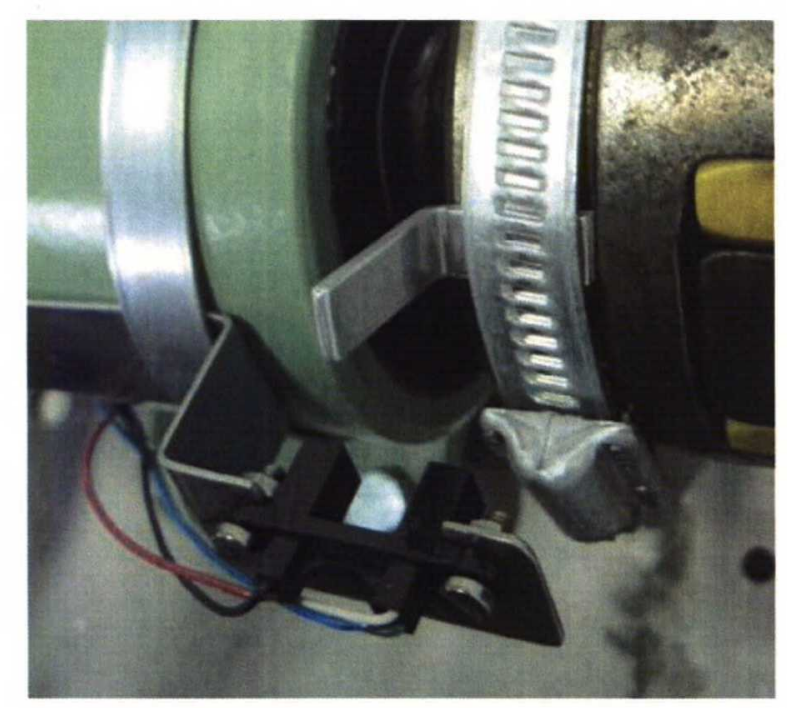

Figure 41. Metal bar crossing the light beam of the optical trigger.

\subsubsection{Computer and software}

The imaging system is controlled with a laptop computer using CAVILUX control software. The software can be operated either in normal or high speed mode which is convenient if using high speed camera. Because we are operating the PLA741 camera for capturing still images, normal mode is used. The software enables programming of different pulse patterns for the camera and laser unit to adjust synchronization with the process. 
Image capture software from Pixelink was used in recording the images on the computer. It was also possible to adjust all the camera parameters and settings such as exposure time, brightness, image size and frame rate with this software. Figure 42 shows a screen capture of the control software in the parameter set mode presenting the pulse patterns used in preliminary trials, and the image capture software settings. All the program settings are presented in appendix 5.

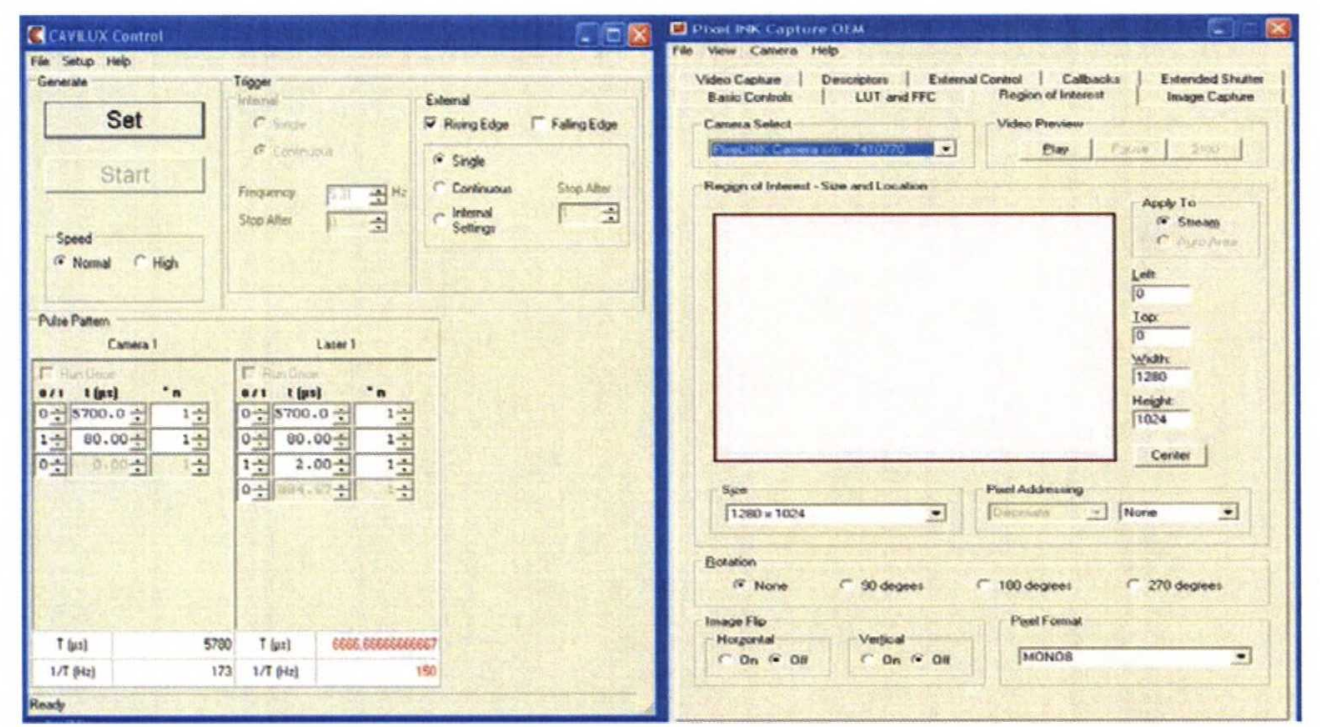

Figure 42. Screen captures from the CAVILUX control and PixeLINK image capture software.

\subsubsection{Safety equipment and accessories}

\section{Safety glasses}

Safety glasses were purchased to prevent eye injury during the operation of the laser illuminated imaging system. The model "LG7 Teal Lens" glasses (Figure 43) provide good protection for the $690 \mathrm{~nm}$ laser light while still enabling $35 \%$ of the visible light to pass through the lenses and were therefore chosen. 


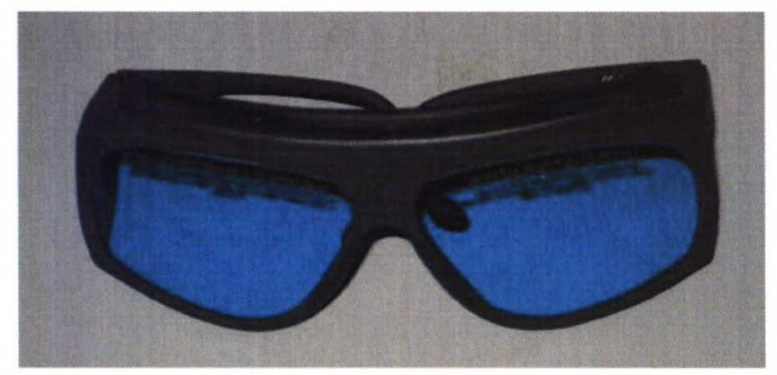

Figure 43. The LG7 Teal Lens protective glasses from Thorlabs Inc.

\section{Additional lens and illumination optics}

If there is a need to capture images from the front side window of the refiner, an additional lens is available to generate an appropriate image size. In this type of imaging system setup the laser illumination is provided from the front side by using an adjustable optical cable with the laser unit instead of the aluminum frame. In this thesis all the images were captured from above the refiner.

\subsection{Process description}

\subsubsection{Introduction}

The process of the SBR station operation can be divided to three stages described in Figure 44. Before the actual operation of the refiner, the pulp suspension has to be properly disintegrated and diluted to a desired consistency. The operation of the flow system includes the refiner, pump and globe valves. The imaging can be started when the flow system is set up. This chapter includes a more detailed description of each stage. 


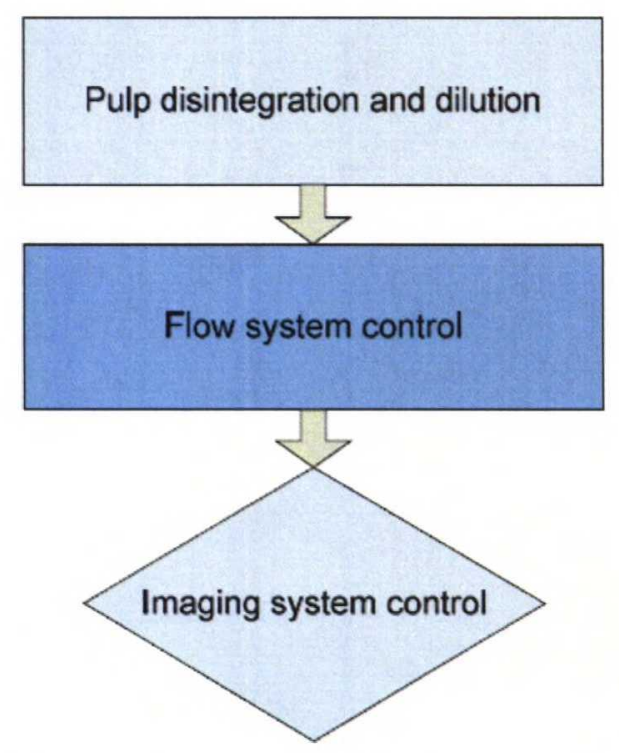

Figure 44. The process of the Single Bar Refiner station operation.

\subsubsection{Pulp disintegration and dilution}

Before starting the refiner, dry pulp sheets must be mixed with water and slushed in the pulp disintegrator. Optionally never-dried pulp can be used. The rotor inside the disintegrator creates strong shear forces which result in a flowing pulp suspension. The consistency of the suspension in the laboratory pulper should be $<5 \%$. Any higher consistency would make the draining of the suspension after the pulping difficult and the durability of the power transmission belt would also suffer. The disintegration time should be 5 minutes or more in order to generate a homogenous pulp suspension. The consistency of the pulp suspension after disintegration is:

$$
c_{p}=\frac{m_{p}}{\left(m_{p}+m_{w}\right)},
$$

where

$m_{p}$ is $\quad$ amount of dry pulp $[\mathrm{kg}]$

$m_{w} \quad$ amount of water $[\mathrm{kg}]$. 
After the disintegration pulp is drained from the globe valve to the storage tank where it is diluted with water to a desired operation consistency. The amount of dilution water required depends on the consistency after pulp disintegration, amount of the pulp suspension and the desired refining consistency:

$m_{w, d}=\frac{c_{p} \cdot\left(m_{p}+m_{w}\right)}{c}-\left(m_{p}+m_{w}\right)$,

where

$c_{p}$ is $\quad$ consistency after pulp disintegration [\%]

$c \quad$ desired refining consistency [\%].

\subsubsection{Flow system control}

The pulp flow system is controlled by the pump and two manually operated globe valves (Figure 45). The function of the valves is to control the pulp flow through the refiner and back to the storage tank. The valve to the storage tank is normally fully opened when operating the refiner in order to create high enough flow rate to enable mixing of the pulp suspension in the tank. The valve to the refiner is then adjusted to control the flow through the refiner. Both the pump and the refiner have protective switches on the wall of the SBR station. The flow system is operated by switching the power to the pump and refiner on and then adjusting the recirculation flow and flow through the refiner with the globe valves. 


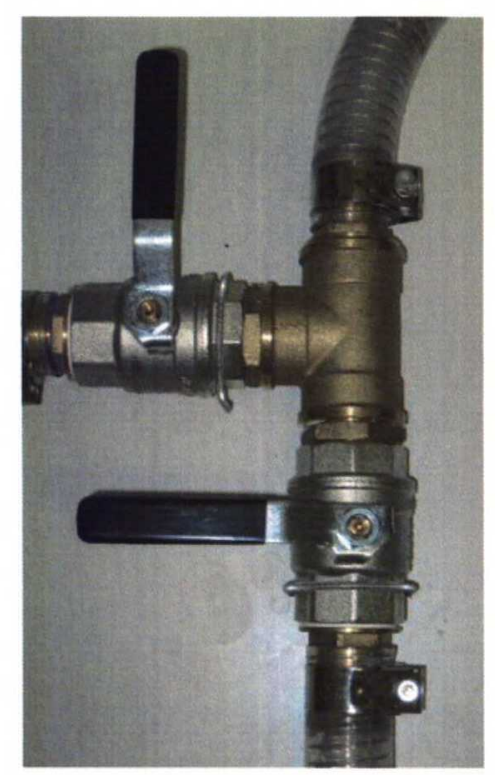

Figure 45. The globe valves used for controlling the pulp flow.

\subsubsection{Imaging system control}

The imaging system is set up as described in Figure 36. When all the cables are connected and the control unit and the computer power is on, the camera lens has to be focused on the area where stator and rotor bar slide past each others. This is done by first adjusting the camera to a distance of $\sim 15 \mathrm{~cm}$ from the targeted area and then fine tuning the focus from the lens. After the focusing is complete, imaging system is ready to use.

Synchronizing the camera to capture images at exactly the desired moment is done by first adjusting the optical trigger roughly to the correct position of the refiner bars. The exact position of the bars during image capture is then fine tuned by creating a suitable delay signal on the image system control software. If all the settings are correct and the image system is properly synchronized, image capturing is possible when the pulp flow system is operational and the refiner is rotating. The image capture is started by pressing the "capture" button on the "image capture" tab of PixeLINK image capture software shown in appendix 5. 


\section{PRELIMINARY TRIALS AND RESULTS}

\subsection{Pulp flow system and refiner testing}

The pulp flow system was tested to determine the maximum operation consistency of the SBR station. The flow system was first tested with pulp consistencies from $0,5 \%$ to $4 \%$ with the original stator bar (gap size $700 \mu \mathrm{m}$ ) using long fibred softwood pine pulp. The result from these tests was that when operating at consistencies higher than $2 \%$, the refiner unit was at risk of clogging from the pulp suspension. Also the rotor would occasionally get jammed due to the build up of pulp on the edges of the rotor bars when the flow system and refiner were stopped. This was probably caused by the fact that the refiner unit was installed higher than the storage tank which leads to the draining of pulp suspension from the refiner unit. Pulp concentration inside the refiner chamber increases which can jam the rotor when refiner is started again.

The refiner unit is driven by an electric motor equipped with a frequency converter for adjusting the rotational speed of the rotor. Because the scale of the converter adjustment was $0-100 \%$, a digital tachometer was used to measure the corresponding Revolutions per Minute values from the refiner rotor shaft. The results are presented in Table 4. Figure 46 describes the linear relationship between motor power and RPM values. These values are applicable to pulp consistencies $\leq 2 \%$.

Table 4. Measured refiner rotor RPM values.

\begin{tabular}{|l|r|r|r|r|r|r|r|r|r|r|r|}
\hline $\mathrm{P}(\%)$ & 0 & 10 & 20 & 30 & 40 & 50 & 60 & 70 & 80 & 90 & 100 \\
\hline RPM & 0 & 38 & 79 & 118 & 157 & 196 & 235 & 274 & 313 & 352 & 391 \\
\hline
\end{tabular}




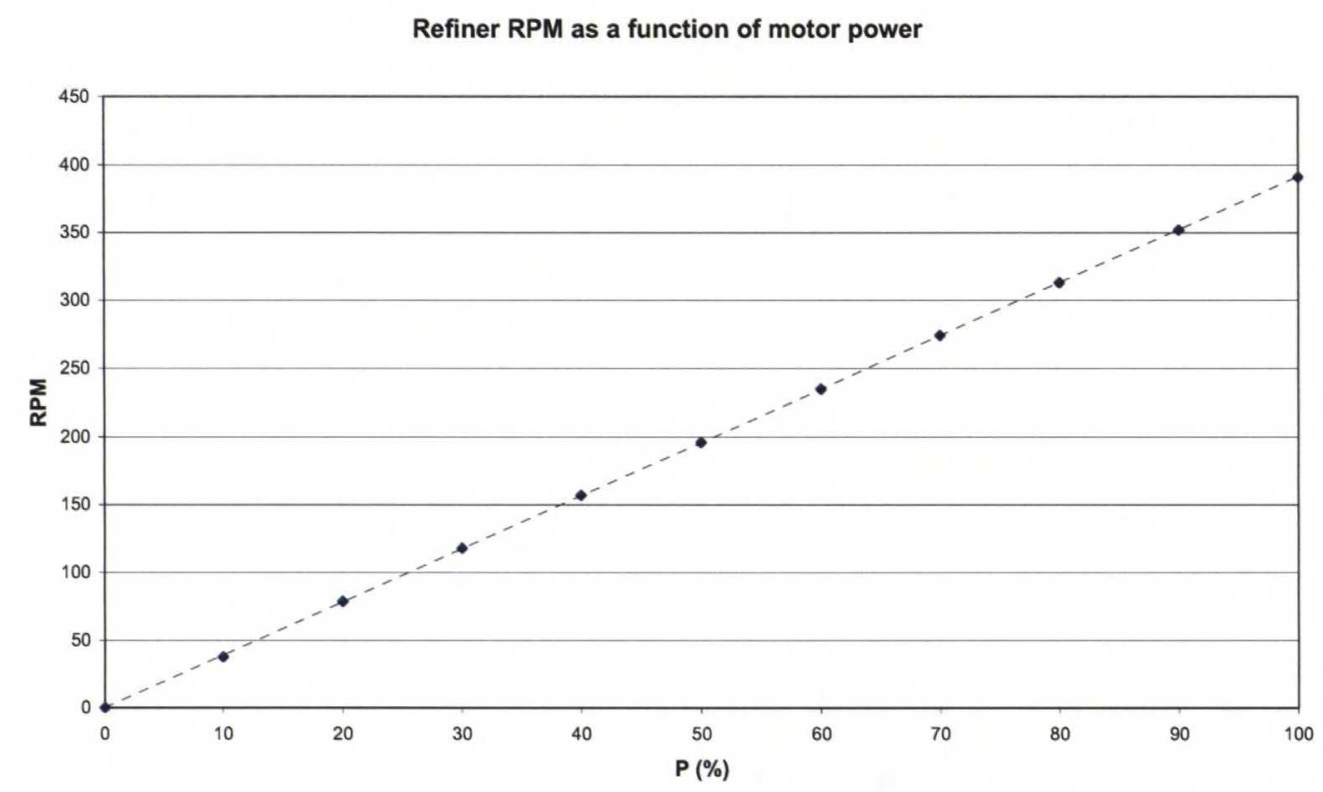

Figure 46. Single Bar Refiner RPM values as a function of the adjusted motor power.

An equation to calculate RPM value from adjusted motor power was created with Microsoft Excel(C) software from the chart presented in Figure 46:

$R P M=3,92 P+0,14$,

where

$P$ is $\quad$ adjusted motor power [\%].

The preliminary trials were concentrated mostly on testing the operation and basic functions of the SBR station. These included also testing the limits of the pulp flow system to define the maximum operating consistency of the refiner. There were not any unexpected problems during the testing of basic operation of the SBR station, but the results indicate that the flow system should not be operated with pulp suspensions that have higher consistency than $2 \%$. However if a solution to prevent the clogging of pulp suspension inside the refiner unit is discovered, it may be possible to use higher consistency pulps. It should be noted that only long fibred softwood pulp (pine) was used in the preliminary trials, so results can be different if short fibred hardwood pulp is used. 


\subsection{Measuring the amount of pulp in the refiner gap}

An idea for experimental method for measuring the exact amount of pulp between the refiner bars was preliminary tested. The first phase of the measurement was to turn the pulp flow system on but not starting the refiner. Instead, the refiner rotor was turned by hand and stopped in the position where the stator and rotor bars are aligned. After this the flow system was stopped and the refiner unit was drained from pulp, which left only the flocs of fibres trapped inside the refiner gap. This pulp was then scraped off from the surface of the rotor bar by hand and weighed after drying it for 24 hours in a temperature of $105^{\circ} \mathrm{C}$. This procedure was then used to measure 12 samples using $150 \mu \mathrm{m}$ gap size and pine pulp with a consistency of $2 \%$. The pulp mass per bar length and consistency in the gap was also calculated by using the bar dimensions given earlier. Results from these measurements are presented in Table 5.

Table 5. The results from pulp weight measurements.

\begin{tabular}{|c|c|c|c|}
\hline sample & $\mathrm{m}$ (pulp,g) & $\mathrm{m} /$ bar length $(\mathrm{kg} / \mathrm{m})$ & $\mathrm{c}$ in gap (\%) \\
\hline 1 & 0,0262 & $4,23 \mathrm{E}-04$ & 78,26 \\
\hline 2 & 0,0080 & $1,29 \mathrm{E}-04$ & 23,89 \\
\hline 3 & 0,0100 & $1,61 \mathrm{E}-04$ & 29,87 \\
\hline 4 & 0,0160 & $2,58 \mathrm{E}-04$ & 47,79 \\
\hline 5 & 0,0211 & $3,40 \mathrm{E}-04$ & 63,02 \\
\hline 6 & 0,0287 & $4,63 \mathrm{E}-04$ & 85,72 \\
\hline 7 & 0,0229 & $3,69 \mathrm{E}-04$ & 68,40 \\
\hline 8 & 0,0483 & $7,79 \mathrm{E}-04$ & 144,27 \\
\hline 9 & 0,0165 & $2,66 \mathrm{E}-04$ & 49,28 \\
\hline 10 & 0,0313 & $5,05 \mathrm{E}-04$ & 93,49 \\
\hline 11 & 0,0122 & $1,97 \mathrm{E}-04$ & 36,44 \\
\hline 12 & 0,0296 & $4,77 \mathrm{E}-04$ & 88,41 \\
\hline Average & $\mathbf{0 , 0 2 2 6}$ & $\mathbf{3 , 6 4 E}-04$ & $\mathbf{6 7 , 4 0}$ \\
\hline $95 \%$ conf. & 0,0064 & $1,03 \mathrm{E}-04$ & 19,06 \\
\hline
\end{tabular}

These results are only indicative and much larger amount of measuring points would be required in order to get any reliable data. The process of measuring a single sample is very time consuming and laborious, so measuring larger amounts would require lot of time and effort. Also the amount of pulp that was weighed was partly originated from outside the actual refining gap because some of the flocs trapped between bars would be only partly inside the gap. This makes the amount of pulp larger than it should be. But this type of "hands-on" measurement 
is perhaps the only way to know the exact amount of the pulp inside the gap so further development of this kind of technique could be considered in the future.

\subsection{Imaging system testing}

The imaging system testing included trial runs and digital image analysis of pictures that were captured from inside the refiner gap during surface-to-surface phase of the refining. The target of this trial was to study the correlation between the average pixel brightness values of analyzed images and the consistency of the refined pulp suspension. The average brightness value was expected to indicate the amount and coverage of the fibres along the bar surface because of the light refraction from the fibres. The imaging system was tested by first setting up the equipment and capturing images from inside the refiner gap during surface-tosurface phase of the refining event. The tests were conducted using pine pulp at five consistencies from $0,4 \%$ to $2,0 \%$ and using three different gap sizes of 150 $\mu \mathrm{m}, 300 \mu \mathrm{m}$ and the original $700 \mu \mathrm{m}$. 100 images per each test point were captured to increase the reliability of the test. One of the captured images is shown in Figure 47. The region highlighted with the white rectangle is the analyzed area between the stator and rotor bar surfaces where bundles of fibres and flocs are receiving refining treatment. 


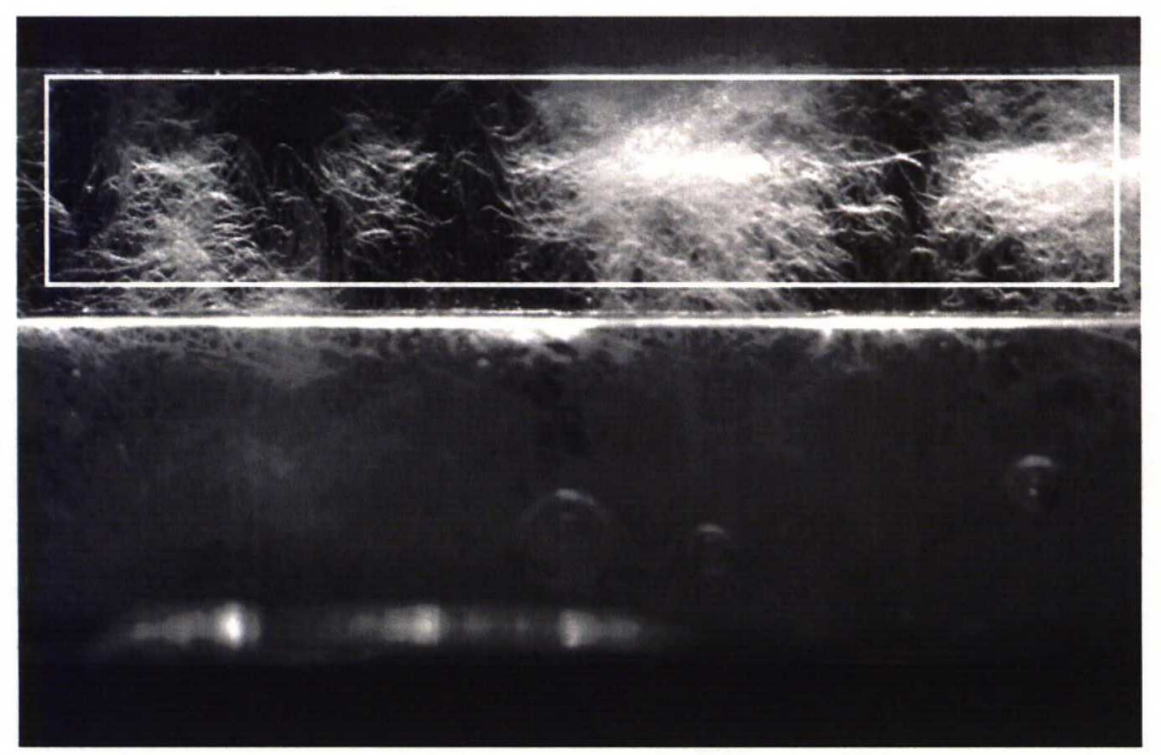

Figure 47. An image captured from inside the refiner gap. Pine pulp at 1,6 \% consistency, gap size $150 \mu \mathrm{m}$, rotation speed 196 RPM. Analyzed region is highlighted with white rectangle.

Figure 48 shows a series of example pictures taken when using different gap sizes and pulp consistencies. 


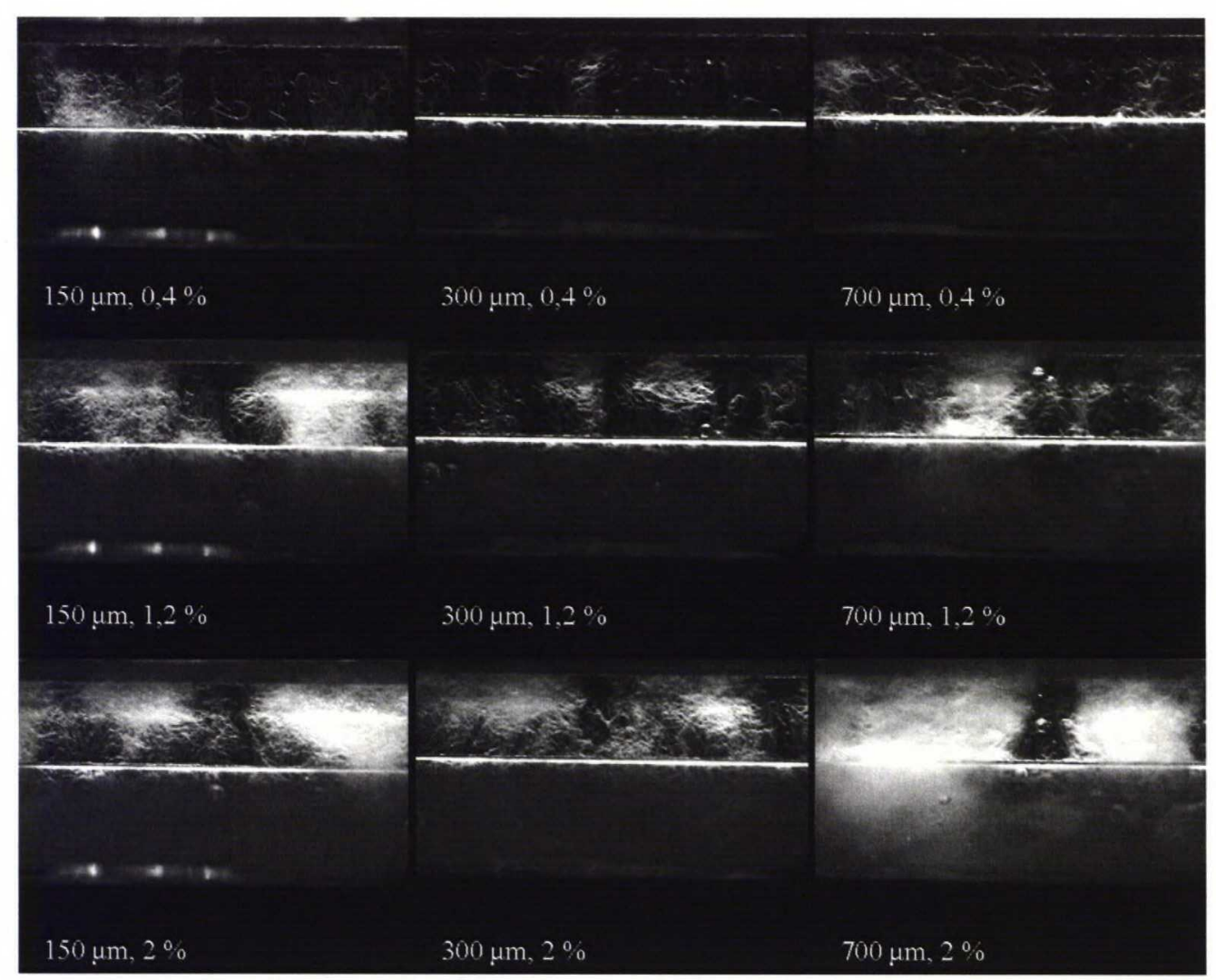

Figure 48. Pictures taken from the refining gap, variable gap size and pulp consistency, rotation speed 196 RPM.

The images that were captured are sharp enough to clearly recognize flocs, bundles of fibres and even individual fibres in the refining zone. Difference in the behavior of the fibres can be seen when the refined pulp consistency increases. Also the gap size seems to be affecting the amount of pulp and composition of the fibre flocs in the gap. It also seems that even at the most realistic conditions (150 $\mu \mathrm{m}$ gap size, $2 \%$ consistency) the bar is not fully covered with fibres.

\subsection{Image analysis}

Analyzing of the captured images was made by using Matlab(C) mathematical analyzing software. A brightness value was defined for each pixel of every image captured. Because the resolution of the images was 8 bits, every pixel would have a brightness value between $0-255\left(2^{8}=256\right)$. The average pixel brightness value of each picture in a test point was calculated and the results are presented in Figure 49 and Table 6 along with $\mathrm{R}^{2}$ values describing the correlation between 
consistency of the refined pulp and the average pixel brightness values. Appendix 6 contains the measured values for each test point.

\section{Brightness Value as a Function of Pulp Consistency and Gap Size}

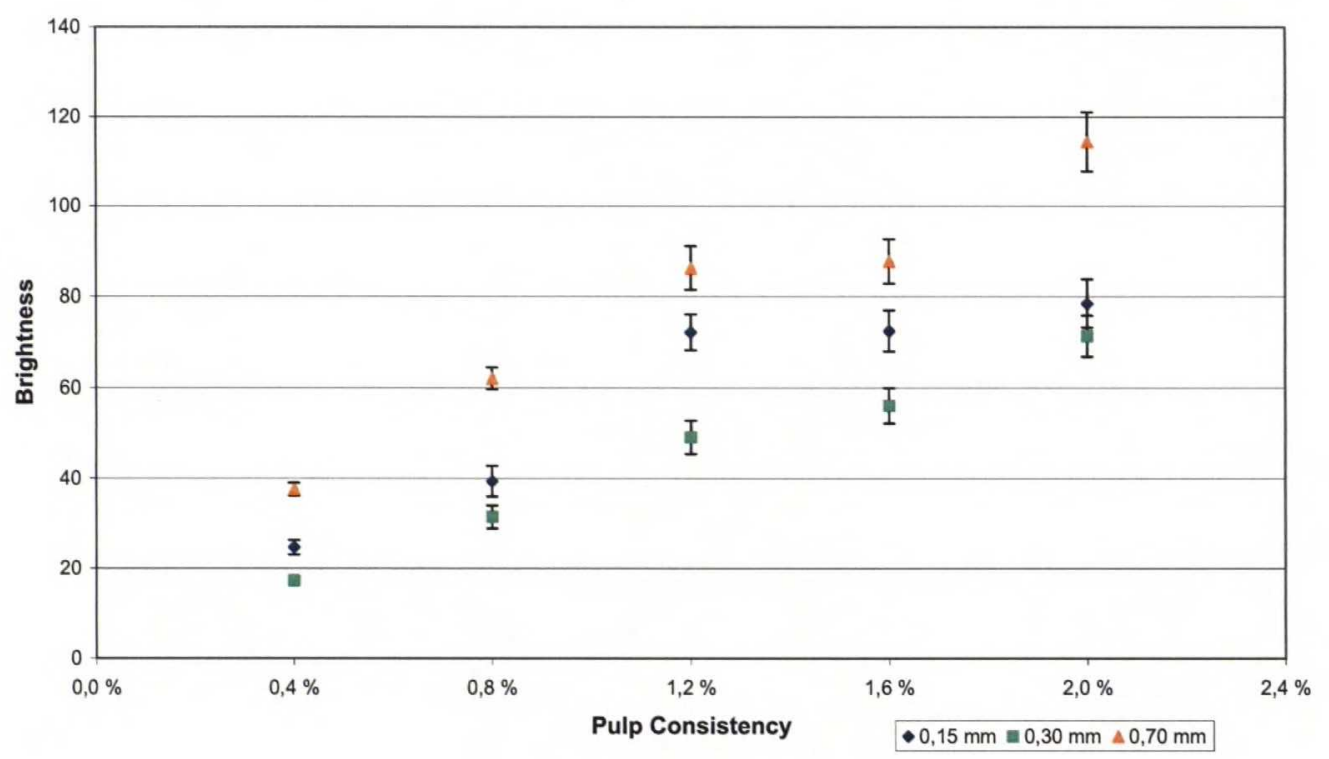

Figure 49. The average brightness values of the captured images as a function of pulp consistency and gap size. 
Table 6. The results of the average pixel brightness calculations and correlations.

\begin{tabular}{|c|c|c|c|c|}
\hline Gap size & Consistency & Brightness & $95 \%$ conf. & $\mathrm{R}^{2}$ value \\
\hline \multirow[t]{5}{*}{$0,15 \mathrm{~mm}$} & $0,4 \%$ & 24,65 & 1,61 & 0,953 \\
\hline & $0,8 \%$ & 39,37 & 3,39 & \\
\hline & $1,2 \%$ & 72,20 & 3,90 & \\
\hline & $1,6 \%$ & 72,53 & 4,48 & \\
\hline & $2,0 \%$ & 78,50 & 5,29 & \\
\hline \multirow[t]{5}{*}{$0,30 \mathrm{~mm}$} & $0,4 \%$ & 17,21 & 0,38 & 0,987 \\
\hline & $0,8 \%$ & 31,43 & 2,55 & \\
\hline & $1,2 \%$ & 49,11 & 3,71 & \\
\hline & $1,6 \%$ & 56,10 & 3,91 & \\
\hline & $2,0 \%$ & 71,37 & 4,49 & \\
\hline \multirow[t]{5}{*}{$0,70 \mathrm{~mm}$} & $0,4 \%$ & 37,59 & 1,41 & 0,866 \\
\hline & $0,8 \%$ & 62,09 & 2,38 & \\
\hline & $1,2 \%$ & 86,25 & 4,80 & \\
\hline & $1,6 \%$ & 87,74 & 4,89 & \\
\hline & $2,0 \%$ & 114,44 & 6,63 & \\
\hline
\end{tabular}

The results show that with all gap sizes, increasing the consistency of the refined pulp suspension increases the average pixel brightness value almost linearly. This means that when refined pulp consistency increases, more fibres and flocs are trapped between the stator and rotor bar surfaces. An interesting result is that average pixel brightness decreases when moving from $150 \mu \mathrm{m}$ to $300 \mu \mathrm{m}$, but is at highest value when using the original $700 \mu \mathrm{m}$ gap size. This would indicate that more pulp is simply flowing through the gap when using the original gap size compared to the more realistic smaller gap sizes where pulp has to be "captured" by the rotor edge in the gap. These results give some indication about the behavior of the consistency inside the refiner gap, but more research is needed in order to get any exact quantitative data and to link the brightness values to the consistency of the pulp inside the gap. 


\section{RECOMMENDED NEXT STEPS}

There are some proposals for future work with the Single Bar Refiner. The preliminary testing should be continued with different types of pulps (e.g. hardwood pulps) with higher consistencies to correspond with industrial scale lowconsistency refiners ( $c \geq 3 \%$ ). The SBR station could also be upgraded with measuring equipment to determine process conditions such as temperature or pulp flow rate if monitoring or controlling these variables is considered necessary in the future. A possibility to install a force sensor to be able to measure normal force acting on the fibres in the refining gap should be studied thoroughly to increase the understanding of refining forces leading to fibre deformation. The measurement of normal force in connection with knowledge of the amount of pulp in the gap would enable greatly improved analysis of forces affecting fibres.

The image analysis with its possibilities and limitations is also a potential area of future research. Only preliminary trials with pine pulps and different refining gap sizes were conducted to test the suitability of this type of image analysis for measuring the pulp consistency inside the gap during surface-to-surface phase of the refining phenomenon. The results from these trials indicate that there is a strong correlation between pulp consistency and average pixel brightness values, but to be able to determine the exact consistency of the pulp inside the gap would require some kind of calibration of the imaging system. Developing the tested measurement method for defining the amount of pulp inside the gap could be one possible solution for the calibration problem. One target of this thesis was also to en-

able calculation of the fractional bar coverage in the refiner gap. This could be possible by using image analysis, but a suitable mathematical analysis method should be developed first. 


\section{CONCLUSIONS}

The target of this thesis work was to construct a laboratory scale low-consistency refiner by modifying an existing design to enable more realistic refining conditions. The aim of the modification is to be able to study the refining forces and phenomena more closely. The designing and construction of a pulp flow system for the refiner unit was also an important part of the thesis. Also the setup and testing of a system for imaging fibres in the refining gap was realized.

The modification of the original design was made by designing a new stator bar with a groove in it. The purpose of this groove was to create more realistic conditions during refining. This design was first tested with the original stator bar by machining a groove in it similar to the one in the rotor bar, and later constructing two additional bars to reach the desired smaller gap size. The pulp flow system was designed and constructed to enable even flow conditions for the refiner unit. The installing and setup of the laser illuminated imaging system was conducted to enable image capture of the refining phenomena.

Some problems were encountered during the modification of the stator bars. The errors in measuring the original gap size resulted in wrong dimensioning of the new stator parts. For this reason some modifications had to be made afterwards to reach the targeted gap sizes. The pulp flow system was constructed without any major issues, but problems with the refiner unit clogging when operating with pulp consistencies $>2 \%$ left some room for improvement. The imaging system installation and preliminary trials were successful, resulting in some good images from the gap between the rotor and stator bars. Images showed e.g. that bar coverage is clearly not $100 \%$ at $2 \%$ refining consistency, and that there is potential in developing the image analysis method aiming to determine bar coverage and pulp consistency in the gap. Many problems were solved during this thesis but many questions are still unanswered. These include the installation of a force sensor for measurement of normal force in the refiner gap and the development of image 
analysis for further research. The target of the thesis work to construct a research tool for refining studies was achieved. 


\section{LIST OF REFERENCES}

1. Lundin, T. Tailoring Pulp Fiber Properties in Low Consistency Refining. Doctoral Thesis. Åbo Akademi University. Laboratory of Fibre and Cellulose Technology. Turku 2008. 259 p. + Appendices.

2. Hiltunen, E. On the Beating of Reinforcement Pulp. Doctoral Thesis. Helsinki University of Technology. Laboratory of Paper Technology. Espoo 2003. 65 p. + Publications.

3. El-Sharkawy, K. Different Approaches to Tailoring Chemical Pulp Fibres. Doctoral Thesis. Helsinki University of Technology. Laboratory of Paper Technology. Espoo 2008. 58 p. + Publications.

4. El-Sharkawy, K. ENGINE-report SB 1, Final. Helsinki University of Technology, Paper and Printing Technology Research and Education Group. Unpublished document. 2008. 22p. + Appendices.

5. Pearson, A. J. A Unified Theory of Refining. Joint Textbook Committee of Refining. Series No.6. Montreal 1990. 128 p.

6. Solitander, A. Kaksikymmentä luentoa paperin tuntemuksessa - Apukirja kaikille kirja- ja paperin jalostusteollisuudessa työskenteleville. Isak Julinin kirjapaino. Tampere 1912. $152 \mathrm{p}$.

7. Lumiainen, J. Refining of Chemical Pulp. Papermaking Part 1, Stock Preparation and Wet End. Ed. Hannu Paulapuro. Publ. Fapet Oy. Helsinki 2000. pp. 86-122.

8. Kerekes, R. J. Characterising Refining Action in PFI-mills. 6th Pira International Refining Conference. Toronto 2001. Paper 11.

9. Koskenhely, K. Effect of Selected Filling and Pulp Suspension Variables in Improving the Performance of Low-consistency Refining. Doctoral Thesis. Helsinki University of Technology. Laboratory of Paper and Printing Technology. Espoo 2007. 49 p. + Publications.

10. Batchelor, W. Lundin, T. Fardim, P. A Method to Estimate Fiber Trapping in Low-consistency Refining. Tappi J. 5 (2006):8. pp. 31-36.

11. Koskenhely, K. Refining of Chemical Pulp Fibres. Papermaking Part 1, Stock Preparation and Wet End, Totally Updated. Ed. Hannu Paulapuro. Publ. Finnish Paper Engineer's Association. Helsinki 2007. pp. 92-139.

12. Fahey, M. D. Mechanical Treatment of Chemical Pulps. Tappi 53 (1970):11. pp. 2050-2064.

13. Hietanen, S. Ebeling, K. A New Hypothesis for the Mechanics of Refining. Pap. Puu 72 (1990):2. pp. 172-179.

14. Page, D. The Beating of Chemical Pulps - The Action and the Effects. 9th Fundamental Research Symposium (Fundamentals of Papermaking). Cam- 
bridge, UK. Sept 17-22 1989. Mechanical Engineering Publications Ltd 1989. Vol. 1 pp. 1-38.

15. Giertz, H. W. The Influence of Beating on Individual fibers and the Causal Effects on Paper Properties. International Symposium on Fundamental Concepts of Refining. Appleton. Sept 16-18 1980. TAPPI Press 1980. pp. 87-92.

16. McIntosh, D. C. The Effect of Refining on the Structure of the Fibre Wall. Tappi 50 (1967):10. pp. 482-489.

17. Retulainen, E. Niskanen, K. Nilsen, N. Fibers and bonds. Paper Physics. Ed. Kaarlo Niskanen. Publ. Fapet Oy. Helsinki 1998. pp. 54-87.

18. Seth, R. S. Zero-span Tensile Strength of papermaking fibres. Pap. Puu 83 (2001):8. pp. 597-604.

19. Jagenberg, F. Das Holländergeschirr in Briefen an einen Papiermacher. 1887.

20. Brecht, W. A Method for Comparative Evaluation of Bar-equipped Beating Devices. Tappi 50 (1967):8. pp. 40A-44A.

21. Wultsch, F., Flucher, W. Der Escher-Wyss-Kleinrefeiner als StandardPrufgerät für Moderne Stoffaufbereitungsanlagen. Papier 12 (1958):13/14. pp. 334-342.

22. Brecht, W. Siewert, W. H. Zur Theoretisch-technischen Beurteilung des Mahlprozesses Modern Mahlmaschinen. Papier 20 (1966):1. pp. 4-13.

23. Meltzer, F. P. Technologie der Zellstoffmahlung. Doctoral Thesis. RWTH Aachen University. Aachen, Germany 1994. 148p.

24. Roux, J-C. Bloch, J-F. Nortier, P. A Kinetic Model for Pulp Refining, Including the Angular Parameters of the Equipment. Appita J. 60 (2007):1 pp. 2934.

25. Lumiainen, J. A New Approach to the Critical Factors Effecting Refining Intensity and Refining Result in Low-consistency Refining. Papermakers Conference. Atlanta, USA. April 23-25 1990. Tappi press 1990. pp. 269-278.

26. Musselman, R. Letarte, D. Simard, R. Third Stage Low Consistency Refining of TMP for Energy Savings and Quality Enhancement. 4th Pira International Refining Conference. Fiuggu 1997. Leatherhead, UK 1997. pp. 141-147.

27. Hietanen, S. Ebeling, K. Fundamental Aspects of the Refining Process. Pap. Puu 72 (1990):2. pp. 158-170.

28. Lewis, J. Danforth, D. W. Stock Preparation Analysis. Tappi J. 45 (1962):3. pp.185-188.

29. Kerekes, R. J. Characterization of Pulp Refiners by a C-factor. Nord. Pulp Pap. Res. J. 5 (1990):1. pp. 3-8.

30. Hiltunen, E. Helsinki University of Technology. Personal communications. 2.7.2009. 
31. Kerekes, R. J. Senger, J. J. Characterizing Refining Action in Low Consistency Refiners by Forces on Fibres. J. Pulp Paper Sci. 32 (2006):1. pp.1-8.

32. Kerekes, R. J. Energy and Forces in Refining. Hannu Paulapuro Symposium. Espoo, March 20, 2009. pp. 10-18.

33. Martinez, M. Kerekes R. J. Forces on Fibers in low-consistency Refining. Tappi J. 77 (1994):12. pp. 119-123.

34. Martinez, D. M. Batchelor, W. J. Kerekes, R. J. Ouellet, D. Forces on Fibres in Low-Consistency Refining: Normal Force. J. Pulp Pap. Sci. 23 (1997):1. $\mathrm{J} 10$.

35. Batchelor, W. J. Martinez, D. M. Kerekes, R. J. Ouellet, D. Forces on Fibres in Low-Consistency Refining: Shear Force. J. Pulp Pap. Sci. 23 (1997):1. J40.

36. Prairie, B. Wild, P. Byrnes, P. Olender, D. Frncis, W. Ouellet, D. Forces During Bar-Passing Events in Low-Consistency Refining: Distributions and Relationships to Specific Edge Load. J. Pulp Pap. Sci. 34 (2008):1. pp. 1-8.

37. Lumiainen, J. Refining Intensity at Low Consistency - Critical Factors. Pap. Technol. 32 (1991):11. pp. 22-26.

38. Stationwala, M. I. Atack D. Karnis, A. J. Distribution and Motion of Pulp Fibres on Refiner Bar Surface. J. Pulp Pap. Sci. 18 (1992):4. J131.

39. Demler C. L. Another Attempt at Refining Visualization. TAPPI 1994 Papermakers Conference. San Francisco, CA. April 24-27, 1994. TAPPI Press. Atlanta 1994. pp. 104-114.

40. Alahautala, T. Lassila, E. Hernberg, R. Härkönen, E. Vuorio, P. Optical Measurement of Pulp Quantity in a Rotating Disc Refiner. Meas. Sci. Technol. 15 (2004). pp. 2256-2262.

41. Anon. PL-A741 Machine Vision Camera System Guide. Pixelink. 2003. 48 p. 

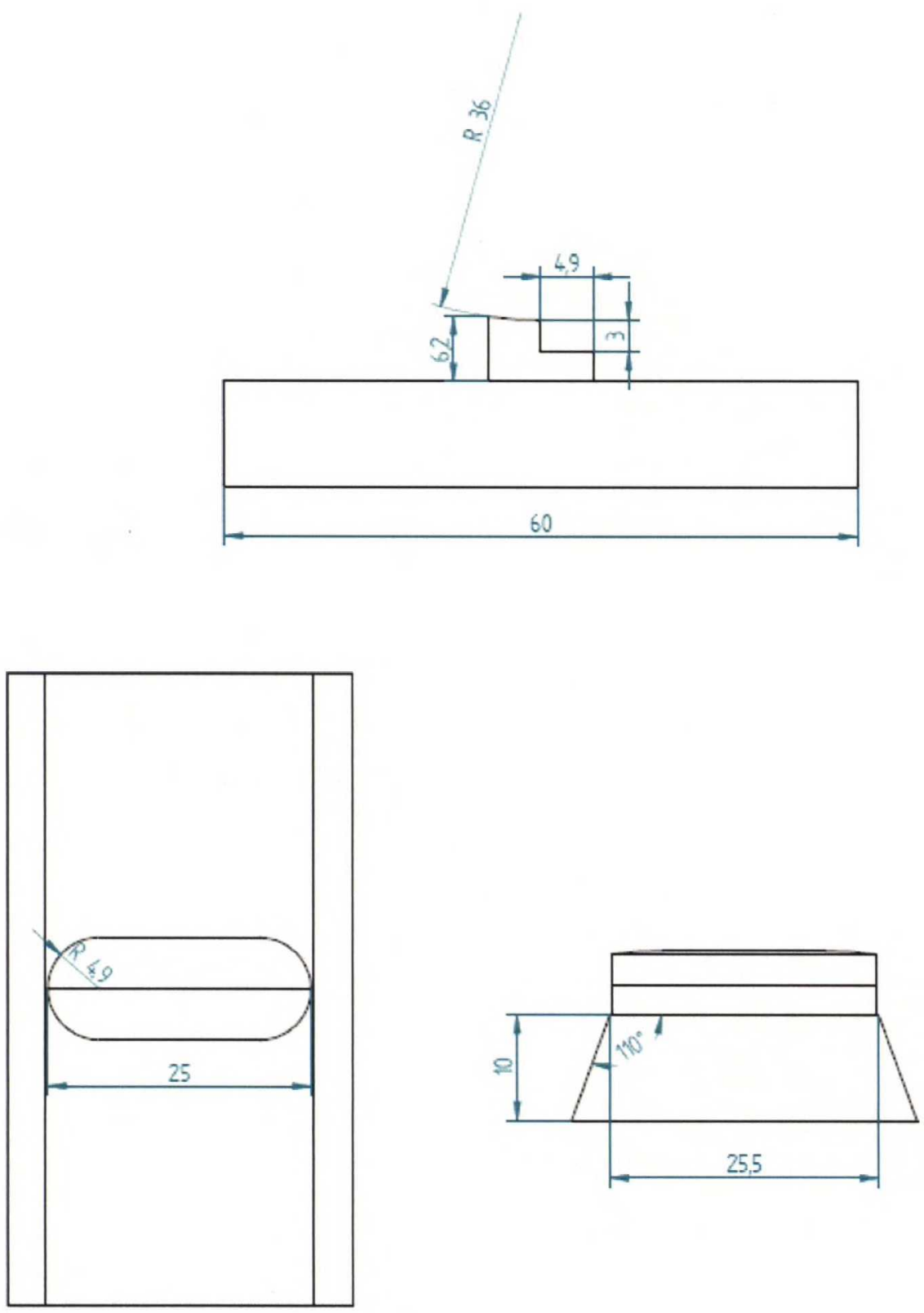

Figure 50. The dimensions of the stator bar acrylic part for $300 \mu \mathrm{m}$ gap size. 


\section{APPENDIX 2}

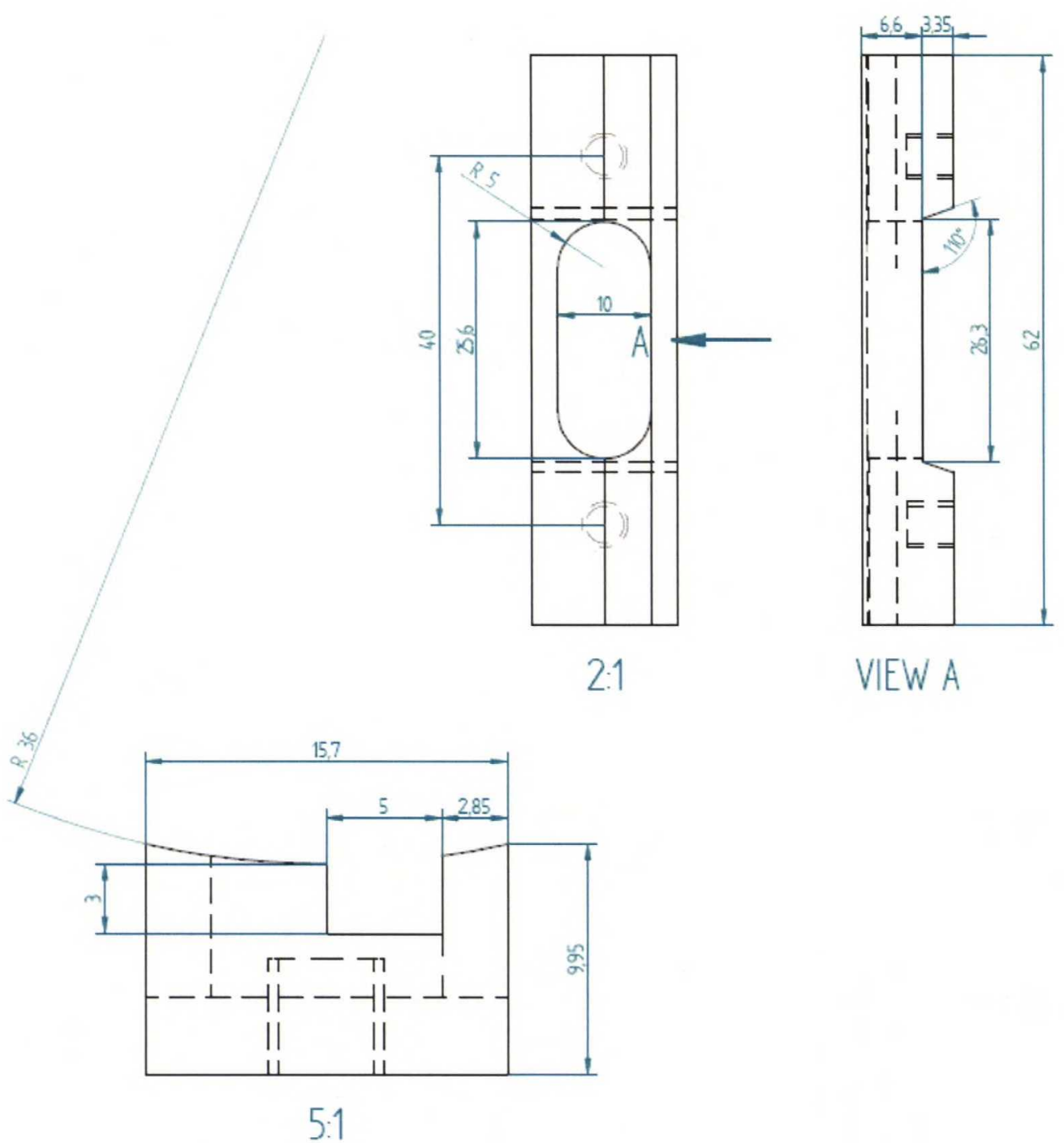

Figure 51. The dimensions of the stator bar stainless steel part for $300 \mu \mathrm{m}$ gap size. 
APPENDIX 3
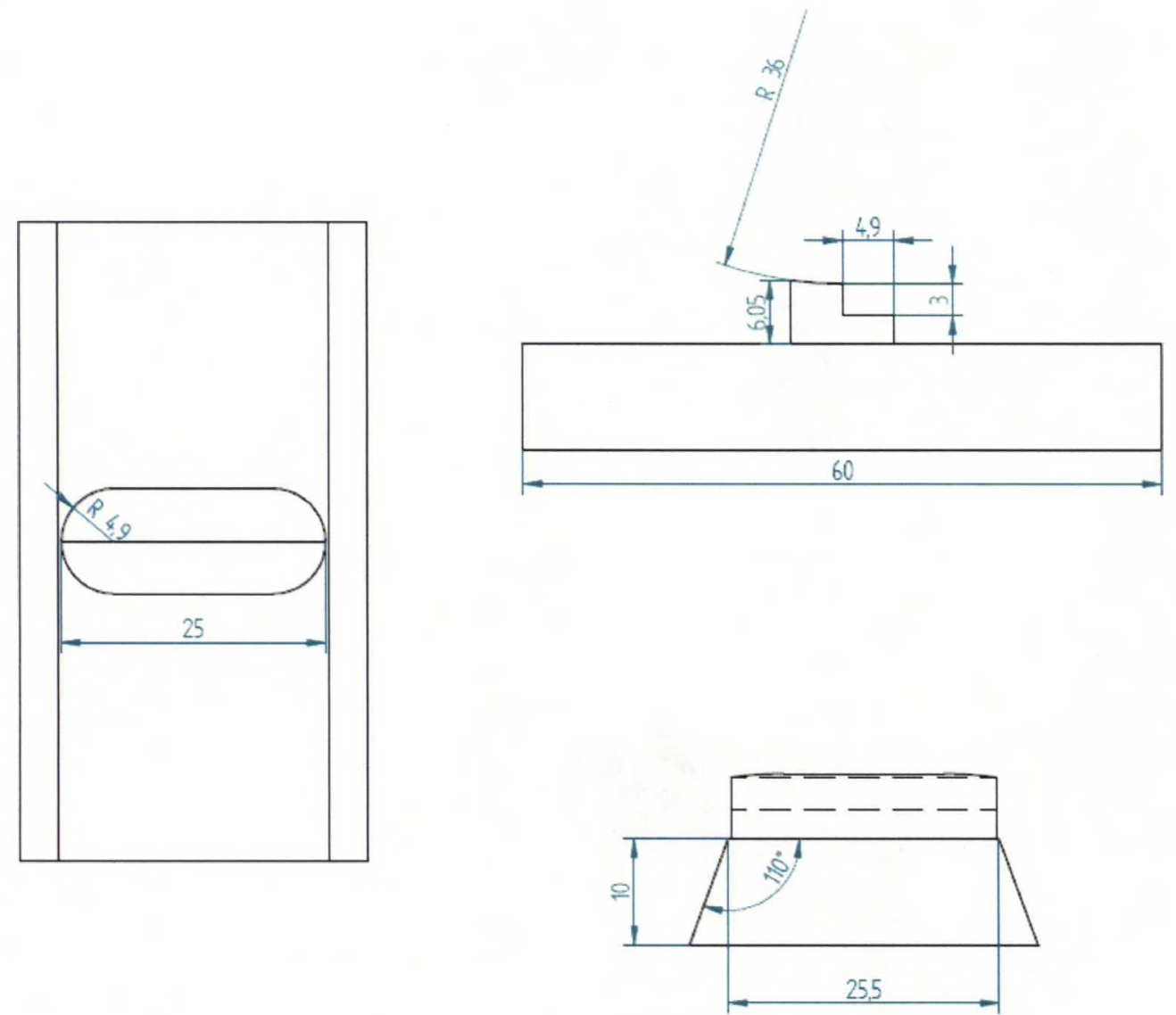

Figure 52. The dimensions of the stator bar acrylic part for $150 \mu \mathrm{m}$ gap size. 


\section{APPENDIX 4}

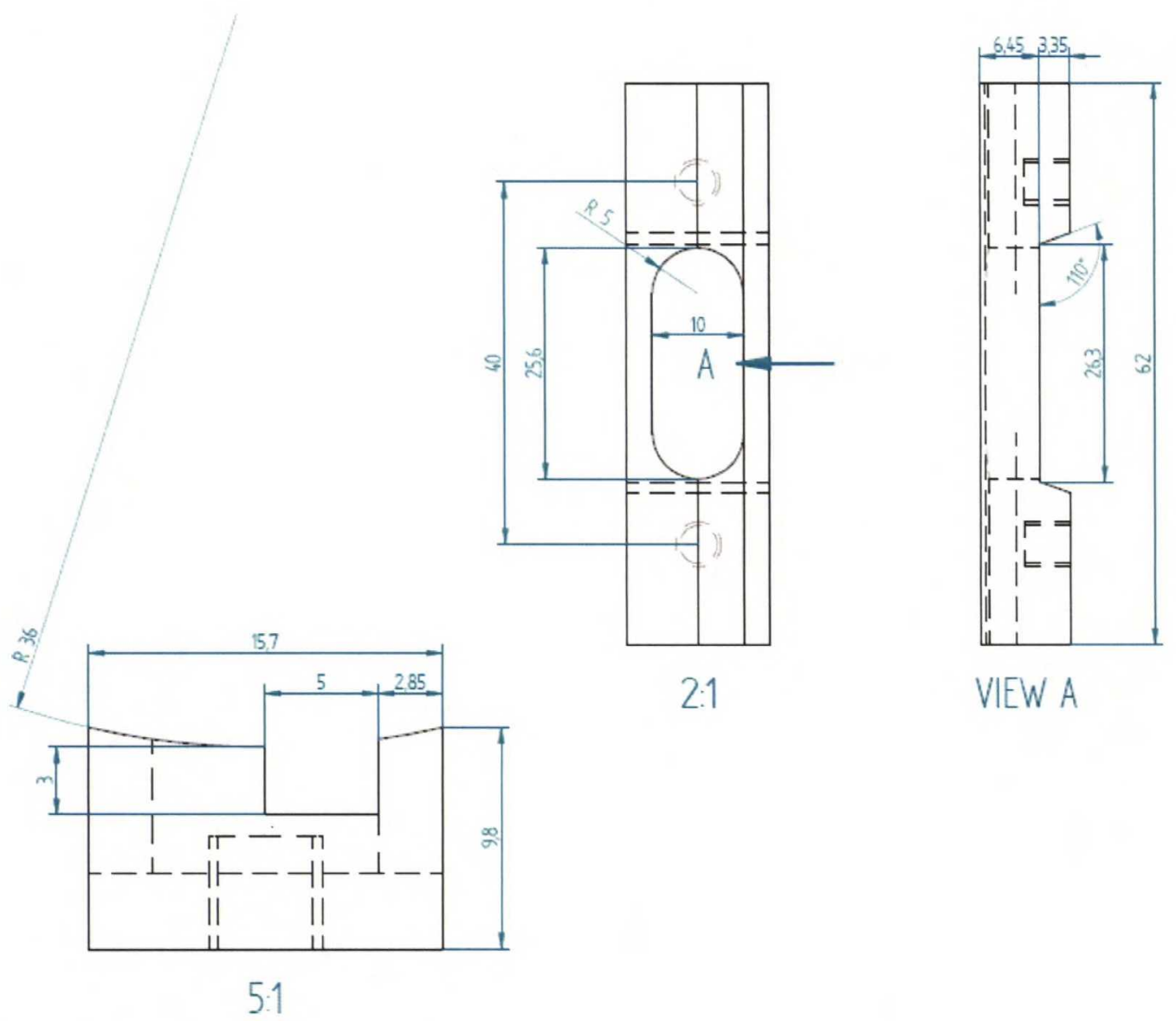

Figure 53. The dimensions of the stator bar stainless steel part for $150 \mu \mathrm{m}$ gap size. 


\section{APPENDIX 5}

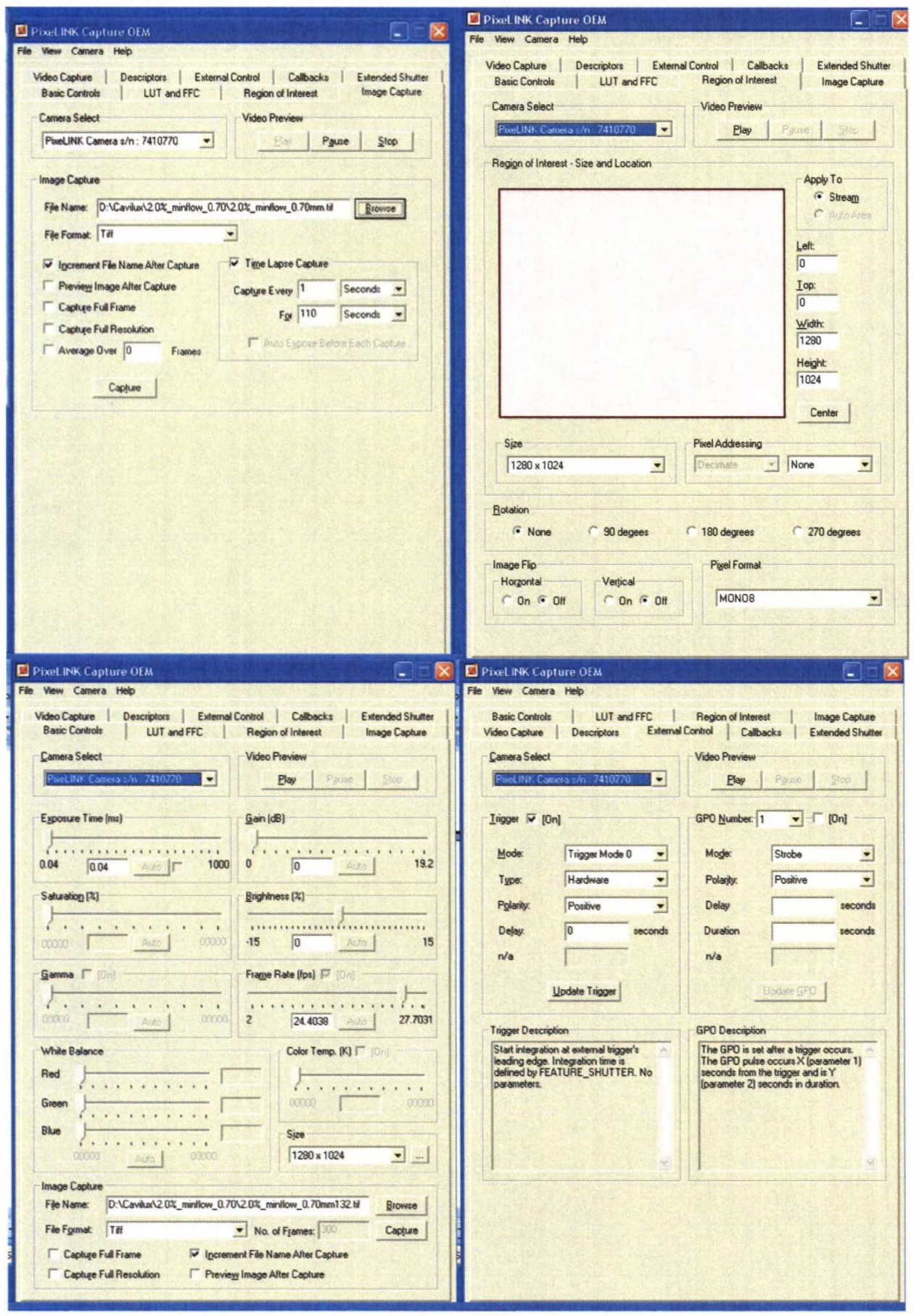

Figure 54. The tabs of the Pixelink image capture software showing the settings used in preliminary trials. 
Table 7. The average pixel brightness results from image analysis.

\begin{tabular}{|c|c|c|c|c|c|c|c|c|c|}
\hline & $0,4 \%$ & & & $0,8 \%$ & & & $1,2 \%$ & & \\
\hline & $0,15 \mathrm{~mm}$ & $0,30 \mathrm{~mm}$ & $70 \mathrm{~mm}$ & $0,15 \mathrm{~mm}$ & $0,30 \mathrm{~mm}$ & $0,70 \mathrm{~mm}$ & $0,15 \mathrm{~mm}$ & $0,30 \mathrm{~mm}$ & $0,70 \mathrm{~mm}$ \\
\hline 1 & 18,4671 & 14,6583 & 46,4924 & 52,8593 & 23,1802 & 73,2257 & 95,2917 & 46,5334 & 74,9988 \\
\hline 2 & 46,1522 & 5137 & 9,1577 & 2,8667 & 19,6299 & 55,5569 & 3,3541 & 66,8901 & 5314 \\
\hline 3 & 17,2499 & 651 & 41,0043 & 52,8458 & 21,8449 & 3,2245 & 12,291 & 512 & 2728 \\
\hline 4 & 23,9393 & 18,502 & 46,8809 & 34,6642 & 28,247 & 9,7557 & 47,6363 & 74,8213 & 84,8423 \\
\hline 5 & 16,9035 & 17,3853 & 43,2112 & 39,7378 & 41,6838 & 56,2312 & 51,156 & 101,594 & 57,1351 \\
\hline 6 & 19,8157 & 17,135 & 41,9486 & 29,9001 & 23,2913 & 78,39 & 92,4515 & 62,2255 & 75,7671 \\
\hline 7 & 37,9607 & 20,1749 & 39,7542 & 34,1154 & 61,1682 & 67,9276 & 77,007 & 68,4228 & 69,03 \\
\hline 8 & 23,7883 & 16,4256 & 57,2094 & 40,3219 & 90,4959 & 55,4863 & 69,2142 & 98,1419 & 42,1779 \\
\hline 9 & 21,4796 & 16,8659 & 48,5029 & 30,29 & 42,4811 & 45,0644 & 93,0248 & 42,349 & 117,107 \\
\hline 10 & 17,8196 & 16,6985 & 35,8507 & 19,245 & 42,1557 & 62,8862 & 80,5268 & 40,5781 & 81,8841 \\
\hline 11 & 29,3828 & 17,2615 & 27,2169 & 62,5449 & 26,3868 & 52,014 & 38,6498 & 43,8479 & 51,3717 \\
\hline 12 & 20,4209 & 17,7211 & 33,5723 & 22,3366 & 29,806 & 67,0363 & 83,7904 & 50,5393 & 71,1963 \\
\hline 13 & 20,2541 & 18,6761 & 43,5812 & 24,2859 & 24,6122 & 48,0976 & 118,222 & 39,8477 & 83,8975 \\
\hline 14 & 26,7701 & 18,1675 & 34,3111 & 28,1325 & 23,8885 & 68,9129 & 68.583 & 41,5229 & 62,4671 \\
\hline 15 & 20,7713 & 16,8282 & 37,143 & 51,6007 & 70.2545 & 65,7618 & 89,6427 & 48,6176 & 61,9187 \\
\hline 16 & 25,7082 & 17,2398 & 40,5712 & 29,8294 & 59.3497 & 56,9572 & 71,1235 & 58,7974 & 68,8707 \\
\hline 17 & 24,8199 & 16,0989 & 36,6854 & 30,5958 & 33,0575 & 71,3489 & 71,7712 & 39,3 & 94,6858 \\
\hline 18 & 21,6247 & 15,609 & 44,1376 & 29,8157 & 21,881 & 58,0724 & 57,623 & 3,6825 & 91,7353 \\
\hline 19 & 19,2822 & 15,7463 & 36,5529 & 37,1541 & 26,7187 & 79,8469 & 70,7692 & 50,4204 & 103,681 \\
\hline 20 & 42,7023 & 15, & 31,7341 & 33,099 & 17,7134 & 46,7317 & 76,0418 & 42,8565 & 84,2557 \\
\hline 21 & 23,4693 & 17,2295 & 31,727 & 22,8366 & 23,4813 & 51,8055 & 82,8449 & 29,2789 & 43,4229 \\
\hline 22 & 38,3874 & 15,1605 & 29,9536 & 25,8827 & 26,2518 & 57,6637 & 70,6457 & 31,6413 & 80,4245 \\
\hline 23 & 37,4011 & 15,0819 & 36,7857 & 27,893 & 43,4845 & 49,4618 & 49,9894 & 26,4507 & 51,0045 \\
\hline 24 & 17,5307 & 16,1332 & 33,3947 & 22,961 & 22,0575 & 60,7011 & 89,4905 & 65,4707 & 98,6513 \\
\hline 25 & 28,375 & 19,378 & 34,1964 & 35,4993 & 29,3222 & 44,5247 & 56,2635 & 61,7006 & 99,6503 \\
\hline 26 & 18,6831 & 15,7429 & 31,6744 & 50,0241 & 19,3834 & 107,842 & 52,947 & 44,8928 & 82,2916 \\
\hline 27 & 17,2659 & 15,4633 & 60,4934 & 22,7969 & 25,3771 & 66,1248 & 86,5486 & 26,7895 & 89,0157 \\
\hline 28 & 23,5324 & 17,2945 & 56,096 & 25,3645 & 29,3836 & 52,1814 & 47,0057 & 75,0685 & 103,606 \\
\hline 29 & 20.7115 & 17,0845 & 40,6612 & 29,1946 & 26,93 & 76,7276 & 33,2402 & 44,1377 & 110.762 \\
\hline 30 & 28.0096 & 08 & 40,3726 & 89,9422 & 23,8766 & 41 & 27,3496 & 49 & 332 \\
\hline 31 & 21,3804 & 35 & 33 & 49,19 & 23, & 53 & 41,3461 & 04 & 215 \\
\hline 32 & 26,0883 & 17, & 88 & 97 & & 42 & 177 & 24 & 51,6272 \\
\hline 33 & 18,7069 & 16 & 43,2 & 58 & 28 & 27 & 66,7866 & 392 & 75,3851 \\
\hline 34 & 20,0721 & 17,9866 & 34,8697 & 76,5409 & 23,0305 & 47,4215 & 64,2831 & 22,8664 & 64,4317 \\
\hline 35 & 38,0802 & 15,5 & 35,8406 & 92,5476 & 28,493 & 45,4589 & 83,7952 & 54,7363 & 79,7906 \\
\hline 36 & 34,5061 & 16,6196 & 69,8929 & 43,4565 & 45,7105 & 54,487 & 85,9502 & 29,4265 & 118,515 \\
\hline 37 & 17,2481 & 23,8073 & 29,1423 & 79,0135 & 23,3385 & 57,9159 & 54,9665 & 31,9249 & 76,4693 \\
\hline 38 & 18,5155 & 16,9387 & 43,6001 & 66,7795 & 35,6173 & 49,8463 & 94,5065 & 32,3255 & 101,009 \\
\hline 39 & 35,9434 & 16,5787 & 36,42 & 47,7885 & 69,7147 & 53,954 & 73,8566 & 43,5997 & 104,382 \\
\hline 40 & 34,5649 & 21,1635 & 39,4396 & 20,9118 & 23,7442 & 44,0609 & 55,94 & 61,4262 & 79,4048 \\
\hline 41 & 37,807 & 16,2642 & 26,8185 & 19,3724 & 56,5932 & 56,0365 & 96,3263 & 49,3093 & 82,5777 \\
\hline 42 & 16,1261 & 15,3966 & 28,8648 & 36,5229 & 30,1763 & 47,8033 & 72,1165 & 26,9739 & 76,9414 \\
\hline 43 & 17,2666 & 15,497 & 42,2802 & 26,2115 & 26,8994 & 60,4334 & 61,3428 & 40,6543 & 64,2285 \\
\hline 44 & 23.7656 & 17,3748 & 41.815 & 23.9759 & 21,2762 & 59,7502 & 83,5123 & 33,6895 & 70,2288 \\
\hline 45 & 19,9735 & 15,2018 & 34,8511 & 28,1614 & 23,1329 & 51,8552 & 91,6258 & 36,7532 & 100,191 \\
\hline 46 & 21,6717 & & 38,2 & 27,8222 & 36 & 68, & & 236 & 112,704 \\
\hline 47 & 19,2416 & 16,2 & 33, & 76,21 & 32 , & 57, & 53,0632 & 69,6718 & 89,1261 \\
\hline 48 & 17,1553 & 16,0664 & 35,3499 & 26,058 & 56,2738 & 61,2141 & 51 . & 26,6413 & 115,476 \\
\hline 49 & 16,0724 & 20,0289 & 44,08 & 42,7456 & 30,5128 & 58,0233 & 78,2378 & 68,3503 & 62,8235 \\
\hline 50 & 18,4291 & 21,1145 & 36,9313 & 30,589 & 19,4445 & 49,569 & 81,5044 & 25,9696 & 109,583 \\
\hline 51 & 34,1368 & 14,913 & 25,1045 & 46,3596 & 20,5963 & 62,393 & 102,72 & 106,023 & 96,8941 \\
\hline 52 & 38,1656 & 18,8704 & 33,9586 & 40,9019 & 33,43 & 71,1892 & 36,094 & 35,8872 & 80,8798 \\
\hline 53 & 15,6043 & 15,3567 & 30,0198 & 29,1635 & 22,9628 & 48,9802 & 77,9699 & 32,7297 & 129,923 \\
\hline 54 & 19,0315 & 17,6721 & 35,9583 & 51,9744 & 19,4876 & 86,9466 & 96,9637 & 38,6141 & 91,4054 \\
\hline
\end{tabular}




\begin{tabular}{|c|c|c|c|c|c|c|c|c|c|}
\hline 55 & 0,9857 & 3,7532 & 8,9294 & 011 & 27,9787 & 76,4237 & 68,9112 & 24,5281 & 67,6697 \\
\hline 56 & .0706 & 17,247 & & 64,9274 & 45,46 & 50,6324 & 88,7522 & 71,7384 & 70,2765 \\
\hline 57 & 19,3784 & 15,8187 & 2,7018 & 3324 & 24,4817 & 54,2862 & 37,0819 & 41,1575 & 79,9008 \\
\hline 58 & 18,7817 & 6,5161 & 35,4948 & 40,5862 & 32,313 & 66,7243 & 88,9574 & 5,8618 & 97,8404 \\
\hline 59 & 41,2599 & 8,5105 & 4,1534 & 49,962 & 26,3984 & 63,6362 & 105,397 & 53,1151 & 82,4449 \\
\hline 60 & 18,7043 & 6,5372 & 1,0723 & 19,5822 & 29,4053 & 76,6284 & 74,0159 & 8,9879 & 88,325 \\
\hline 61 & 16,8405 & 8,5178 & 30,3978 & 21,7672 & 25,8582 & 82,5445 & 90,4828 & 2,5884 & 111,789 \\
\hline 62 & 2,3503 & 8,5605 & 33,1691 & 50,1261 & 46,4565 & 74,6669 & 79,7888 & 75,6437 & 90,1422 \\
\hline 63 & 17,7995 & 0,1682 & 35,2569 & 2,2258 & 8,6714 & & 54,6156 & & 93,3382 \\
\hline 64 & 5,2699 & & 4,1598 & 1,2299 & 2802 & 3699 & & & \\
\hline 65 & 41 & 66 & 4,7753 & 038 & 8,8775 & & & & \\
\hline 66 & 29 & 99 & & & 317 & & & & \\
\hline 67 & & & & & 35 & & & & \\
\hline 68 & & & 61 & & 36,2 & & & & \\
\hline 69 & & & & & 1907 & & & & \\
\hline 70 & 3,9757 & 31 & 91 & & 34,5716 & 172 & 0263 & & \\
\hline 71 & 16,916 & & 42,1679 & 66,9374 & 20,9013 & 341 & 58,0726 & & \\
\hline 72 & 33,1646 & 15,4 & 39,646 & 21,4726 & 20,2465 & 49,6829 & 104,018 & 61,5025 & 118,2 \\
\hline 73 & 39,4834 & 12,6513 & 38,5028 & 29,6 & 15,84 & 56,9545 & 55,7115 & 55,98 & 88,956 \\
\hline 74 & 20,0648 & 16,459 & 39,5956 & 22,2911 & 26,2201 & 68,8686 & 99,7311 & 30,4379 & 56,9673 \\
\hline 75 & 20,5822 & 4,8245 & 25,7086 & 62 & 28,097 & & 54,5651 & 19,5018 & 64, \\
\hline 76 & 18,0634 & 16,3289 & 34,1 & 49,6645 & 16,2496 & & 38 & 20,9944 & \\
\hline 77 & 17,6 & 16,958 & & 15 & & & & & \\
\hline 78 & 32,5 & 6,4402 & 30 & 31,1 & 41 & 54 & 34 & 03 & 106,562 \\
\hline 79 & & & & & & & & & \\
\hline 80 & & & & & & & & & \\
\hline 81 & & & & & & & & & \\
\hline 82 & 74 & & 38, & & 30 & & & & \\
\hline 83 & & 1 & 29,2 & 30 , & 26,6302 & 52,9932 & 43,8148 & 41,1151 & 128,234 \\
\hline 84 & 28,5674 & 9922 & 34,1215 & 41, & 27,128 & 80,5012 & & 27 & \\
\hline 85 & 19,3453 & 16,925 & & & 11 & & 103 & 68,1 & 61,6447 \\
\hline 86 & 18, & 61 & 36,3978 & 27,296 & & & & & \\
\hline 87 & & & & & & & & & \\
\hline 88 & 18,7 & 38 & 43,6573 & 20 & 323 & & 75,5513 & 69,8 & 65,2469 \\
\hline 89 & 2 & & 1,6089 & & & & & & 65,0 \\
\hline 90 & 20,6738 & 18 & 36,35 & 38,0598 & 9491 & 62 & 68,7094 & 34 & 96,2 \\
\hline 91 & & & 2 & & & & & & \\
\hline 92 & 32, & & & & & & 1 & & 90 , \\
\hline 93 & & & & & & & & & \\
\hline 94 & & & & & & & & & \\
\hline 95 & & & & & & & & & \\
\hline 96 & & & & & & & & & \\
\hline 97 & & & & & & & & & \\
\hline 98 & & & & & & & & & 64,5 \\
\hline 99 & 19,5188 & 14,0789 & 37,5501 & 22,5 & 18,9964 & 84,867 & 57,9426 & 71,6586 & 91,899 \\
\hline 100 & 31,0 & 17, & & 42,2 & 24,6044 & 49,7712 & 73,5694 & 48,0308 & 106,575 \\
\hline & 24,6473 & 17,2062 & 37,5854 & 39,3723 & 31,428 & 62,0892 & 72,1993 & 49,1136 & 86,25 \\
\hline
\end{tabular}




\begin{tabular}{|c|c|c|c|c|c|}
\hline $1,6 \%$ & & & $2,0 \%$ & & \\
\hline $5 \mathrm{~mm}$ & $0,30 \mathrm{~mm}$ & $0,70 \mathrm{~mm}$ & $0,15 \mathrm{~mm}$ & $0,30 \mathrm{~mm}$ & $0,70 \mathrm{~mm}$ \\
\hline 76,2679 & 54,2314 & 102,472 & 60,6257 & 27,6717 & 77,8931 \\
\hline 68,0199 & 48,9986 & 56,3189 & 116,037 & 66,4194 & 87,5048 \\
\hline 110,58 & 47,7598 & 78,6097 & 80,4961 & 15,882 & 9314 \\
\hline 86,9484 & 45,5791 & 76,876 & 86,7548 & 62,6138 & 122,254 \\
\hline 72,5971 & 75,011 & 130,09 & 72,819 & 57,9322 & 1 \\
\hline 59,8953 & 68,6169 & 72,6291 & 67,6037 & 70,2714 & 108,228 \\
\hline 95,0469 & 53,448 & 71,6396 & 103,392 & 91,6777 & 118,744 \\
\hline 66,831 & 75,6624 & 58,3118 & 63,1692 & 93,9644 & 356 \\
\hline 101,946 & 58,818 & 127,343 & 68,3807 & 90,1779 & 813 \\
\hline 67,1392 & 69,7204 & 49,9704 & 100,628 & 55,6954 & 83,5509 \\
\hline 87,8518 & 65,4219 & 46,0089 & 99,7638 & 70,618 & 68,8197 \\
\hline 57,6761 & 60,6323 & 97,6046 & 28,9226 & 105,675 & 161,512 \\
\hline 76,7441 & 34,6701 & 100,005 & 92,9928 & 83,847 & 131,23 \\
\hline 28,3898 & 45,1393 & 121,205 & 58,609 & 90,6764 & 148 \\
\hline 100,756 & 76,5912 & 81,095 & 66,2577 & 54,4219 & 120,924 \\
\hline 95,2687 & 84,7287 & 77,8459 & 113,888 & 68,6426 & 150,555 \\
\hline 52,4645 & 29,8169 & 82,5504 & 97,7723 & 93,5386 & 159,586 \\
\hline 77,0236 & 54,2102 & 81,9152 & 30,8531 & 91, & 11 \\
\hline 75,875 & 27,796 & 75,8241 & 78,3154 & 63,3902 & 67,3798 \\
\hline 88,3038 & 61,6777 & 142,412 & 31,1697 & 97,1376 & 162,793 \\
\hline 56,8981 & 38,7693 & 60,2007 & 63,218 & 83,2983 & 117,559 \\
\hline 37,1288 & 66,2399 & 89,4768 & 66,232 & 55 , & 93 \\
\hline 79,7611 & 70,0805 & 117,84 & 118,798 & 59 & \\
\hline 39,1143 & 61,3491 & 79,1993 & 125,896 & 83 , & \\
\hline 115,213 & 39,2417 & 87,1935 & 96,4737 & 48,7205 & 80,0173 \\
\hline 80,6888 & 33,4919 & 120,902 & 23,7433 & 43,3521 & 182,15 \\
\hline 86,0728 & 55,0125 & 103,035 & 76,0936 & 28, & 92,2025 \\
\hline 67,0099 & 89 & 77, & 97,6996 & 64 & \\
\hline 99,5479 & 70,9674 & 59, & 62,0816 & 122 & \\
\hline 57,2393 & 34,9773 & 101,462 & 84,3164 & 117,739 & 10 \\
\hline 62,3022 & 75,1 & 98, & 73,7642 & 59,32 & 82 \\
\hline 112,389 & 74 , & 84 & 74 & 70 , & \\
\hline 68,2575 & 66 & 02 & 26 & 66,5 & \\
\hline 62,3524 & 15 & 575 & 07 & 64, & 91 \\
\hline 81,1248 & 21, & 66,5843 & 76,5431 & 54,7656 & \\
\hline 123,717 & 67,9849 & 68,3868 & 120,029 & 74,61 & 7 \\
\hline 71,5745 & 732 & 78,7123 & 69,6946 & 69,6055 & \\
\hline 93,6243 & 59,1721 & 41 & 33 & 87 & \\
\hline 68,4698 & 51,35 & 104 & 133,447 & 41,4822 & 371 \\
\hline 76,6662 & 102,773 & 52,5639 & 28,8663 & 63,115 & 352 \\
\hline 37,1046 & 48,9694 & 111,307 & 106,367 & 120,1 & 74,9673 \\
\hline 92,9548 & 30,2371 & 58,2788 & 113,602 & 57,4219 & 94 \\
\hline 88,2201 & 40,5338 & 59 & 73,412 & 68,6465 & 12 \\
\hline 60,6425 & 90,7264 & 116,883 & 88,3343 & 40,8249 & 160,442 \\
\hline 97,9073 & 54,3316 & 67,8512 & 87,579 & 52,8622 & 123,113 \\
\hline 67,7346 & 83,3861 & 67,0929 & 104,315 & 40,7009 & 165 \\
\hline 43,0812 & 41,2891 & 65,6922 & 102,775 & 80,6446 & 101 \\
\hline & & & 83 & 37,4392 & $\overline{116}$ \\
\hline 77,2396 & 93,3203 & 80,6 & 97,0282 & 75,7777 & 104,93 \\
\hline 99,6482 & 62,5926 & 87,9372 & 88,5158 & 130,58 & 62,7758 \\
\hline 66,2683 & 33,5075 & 54,1472 & 60,6601 & 71,9701 & 173,913 \\
\hline 54,0771 & 51,8481 & 51,4711 & 46,1243 & 81,7325 & 53,695 \\
\hline 61,4103 & 47,799 & 90,3052 & 71,8837 & 66,8016 & 117,627 \\
\hline 66,286 & 35,2092 & 89,2722 & 99,4946 & 84,4962 & 170,6 \\
\hline
\end{tabular}




\begin{tabular}{|c|c|c|c|c|c|}
\hline 5,1313 & 4,7046 & 92,8721 & 38,5715 & 933 & \\
\hline 3,4471 & 85,5761 & 72,1481 & 36,0551 & 63,0922 & 706 \\
\hline 44,3464 & 6,6345 & 75,5198 & 127,12 & 123,237 & 22,371 \\
\hline 90,4822 & 0.9482 & 56,4321 & 61,4731 & 63,3925 & 8.9092 \\
\hline 55,056 & 4,3319 & 67,0897 & 40,045 & & \\
\hline 105,535 & 33,7875 & 46,0692 & 59,4897 & 67,4827 & 35,118 \\
\hline 83,8612 & 75,5993 & 112,712 & 62,6919 & 87,1898 & 0,0727 \\
\hline 47,7996 & 33,1136 & 94,9513 & 92,6772 & 59,0854 & 7 \\
\hline & & 122,303 & 08,207 & & \\
\hline 35,8897 & 38,8096 & 91,3213 & 37,8465 & 5217 & \\
\hline 85,2863 & 51,2989 & 97,3269 & 94,4032 & 94,5396 & 115,6 \\
\hline & 64.2 & 122,086 & 912 & 36 & \\
\hline 52 & 61 & 8,4276 & 73,4 & & \\
\hline 112 & 34 & 112,051 & 55,643 & 294 & \\
\hline 60,0087 & 73 & 104,391 & 79,109 & 56,3773 & \\
\hline 65,7575 & 63, & 88,8867 & 73,6042 & 84,7503 & 92 \\
\hline 121, & 92, & 69,7579 & 87,3621 & 00 & \\
\hline 77 & & 71,586 & 57,5726 & 022 & 1 \\
\hline 10 & & 6,7226 & 70,4488 & & 5, \\
\hline 68,6 & 60 , & 100,902 & 122,996 & 84 & 84,0 \\
\hline 65,0346 & 64,7745 & 96,1242 & 149 & 97 & 146 \\
\hline 51,795 & 32 & 116,479 & 52 & 698 & \\
\hline 41 , & & 126,7 & & 57 & 4 \\
\hline 71,5451 & 40 & 167,776 & 89,5876 & & 137 \\
\hline 69,952 & 28,811 & 10,488 & & & 107 \\
\hline 133 & 53 & 116,221 & 09 & 84 & 70 \\
\hline & & & & & \\
\hline 63 & 6 & 90, & & & 63,4 \\
\hline & & 88,3273 & & 67 & \\
\hline 31 & & 92,8 & 851 & 47 & 9,8 \\
\hline & & & & & \\
\hline 43 & 7 & 94 & 62 & 55 & 155 \\
\hline & & & & & \\
\hline & & 99 & 87 & 58,0 & 5 \\
\hline & & & & & \\
\hline & & & & 17 & 10 \\
\hline & & 56, & & 47 & \\
\hline & 48 & 71,4768 & 52, & 82,9366 & 90,0 \\
\hline 93 , & 52,8 & 88,5174 & 89,2332 & 75,2476 & 121 \\
\hline & & & & & \\
\hline & 34, & 107,422 & 51,0342 & 29,7907 & 101 \\
\hline 64,7605 & 43,6952 & 82,1222 & 48,7752 & 82,3479 & 137,88 \\
\hline 83,9055 & 49,6696 & 99,0881 & 95,983 & 86,7869 & 177,59 \\
\hline & & & 93,5799 & 60,4899 & 89,544 \\
\hline 44,8704 & 46,3556 & 102,372 & 93,9571 & 78,8839 & 103,78 \\
\hline 69,8591 & 57, & 13 & 48,3169 & 50,6418 & 103 \\
\hline 72,5254 & 56,0975 & 87,7392 & 78,5042 & 71,37 & 114 \\
\hline
\end{tabular}


Aalto-yliopisto

Punjalostuk kokkeakoulu

Puunjalostustekni ikan kirjasto 